\title{
Technological learning potential of offshore wind technology and underlying cost drivers
}

Srinivasan Santhakumar ( $\nabla$ s.santhakumar@rug.nl )

University of Groningen https://orcid.org/0000-0002-6546-1153

Clara Heuberger-Austin

Shell Global Solutions International B.V. https://orcid.org/0000-0002-3798-7633

Hans Meerman

University of Groningen https://orcid.org/0000-0002-7066-721X

André Faaij

University of Groningen https://orcid.org/0000-0002-1224-5940

\section{Research Article}

Keywords: Floating wind, Offshore wind, LCOE, Cost reduction, Energy transition, North Sea, Energy policy, Learning curve, Grid connection

Posted Date: January 26th, 2022

DOI: https://doi.org/10.21203/rs.3.rs-1298062/v1

License: (1) (1) This work is licensed under a Creative Commons Attribution 4.0 International License. Read Full License 


\title{
Technological learning potential of offshore wind technology and underlying cost drivers
}

Srinivasan Santhakumar ${ }^{1,2,{ }^{*}}$, Clara Heuberger-Austin ${ }^{3}$, Hans Meerman ${ }^{1}$, André Faaij ${ }^{1,4}$

${ }^{1}$ Energy and Sustainability Research Institute Groningen, University of Groningen, Groningen, 9747 AG, The Netherlands

${ }^{2}$ Lead Contact

${ }^{3}$ Shell Global Solutions International B.V., Amsterdam, 1031 HW, The Netherlands

${ }^{4}$ Netherlands Organization for Applied Scientific Research - TNO Energy Transition, Utrecht, $3584 \mathrm{CB}$, The Netherlands

*Correspondence: s.santhakumar@rug.nl

\begin{abstract}
Detailed analysis of technological learning of energy technologies is scarce. For floating wind, this is missing altogether. In this study, we applied experience curve and bottom-up cost modeling methodologies and assessed the long-term cost reduction potential of fixed-bottom and floating offshore wind in their mature markets. The contributing factors to cost reduction are also quantified and elaborated. Further, to emphasize the role of strongly varying site characteristics of offshore wind farms and their influences, the grid connection cost is separately discussed from the total technology costs (Capital Expenditure and LCoE). Our assessment shows that, excluding grid connection costs, fixed-bottom offshore wind $\mathrm{LCoE}$ is $40 € / \mathrm{MWh}$ at $31 \mathrm{GW}$ cumulative capacity (2023-2024) and decline to $28 \pm 3 € / \mathrm{MWh}$ by $100 \mathrm{GW}$. Floating wind LCoE is $123 € / \mathrm{MWh}$ at 1 GW cumulative capacity (2027 - 2030) but decline to $33 \pm 6 € / \mathrm{MWh}$ by $100 \mathrm{GW}$. Moreover, floating wind can achieve cost parity (i.e., $40 € / \mathrm{MWh}$, excl. grid connection cost) by deploying 21 $\mathrm{GW}$, requiring 44 billion $€$ of learning investment in the form of subsidies to compensate the price gap for the technology in the energy system. Lastly, we analyzed the grid connection costs and their influencing factors, and then determined that an integrated offshore grid would be needed to efficiently connect future offshore wind farms to the onshore grid.
\end{abstract}




\section{Keywords}

Offshore wind, Cost developments, Technological learning, Floating offshore wind, LCoE, Energy policy

\section{Abbreviations}

\begin{tabular}{|l|l|}
\hline AEP & Annual Energy Production \\
\hline CAPEX & Capital Expenditure \\
\hline CCC & Climate Change Committee \\
\hline CF & Combined-Cycle Gas Turbine \\
\hline CoC & Capacity Factor \\
\hline DECOM & Cost of Capital \\
\hline DEVEX & Decommissioning Expenditures \\
\hline EMPR & Expected Market Risk Premium \\
\hline EU & European Union \\
\hline EURIBOR & The Euro Interbank Offered Rate \\
\hline FBOW & Fixed-Bottom Offshore Wind \\
\hline FLOW & Floating Offshore Wind \\
\hline GW & Giga Watt \\
\hline HVAC & High Voltage Alternating Current \\
\hline HVDC & High Voltage Direct Current \\
\hline IAM & Integrated Assessment Models \\
\hline IEA & International Energy Agency \\
\hline LCoE & Levelized Cost of Energy \\
\hline LCoT & Levelized Cost of Transmission \\
\hline LIBOR & The London Interbank Offered Rate \\
\hline LR & Learning Rate \\
\hline MWh & Mega Watt hour \\
\hline O\&M & Operation and Maintenance \\
\hline OPEX & Operational Expenditure \\
\hline
\end{tabular}




\begin{tabular}{|l|l|}
\hline PL & Project Lifetime \\
\hline RDD\&D & Research, Development, Demonstration, and Deployment \\
\hline SFEC & Single-Factor Experience Curve \\
\hline TSO & Transmission System Operator \\
\hline UK & United Kingdom \\
\hline WACC & Weighted Average Cost of Capital \\
\hline
\end{tabular}

\section{Symbols}

\begin{tabular}{|l|l|}
\hline$€$ & Euro \\
\hline $\mathrm{M} €$ & Million Euro \\
\hline$i$ & Discount rate or Cost of Capital \\
\hline$t$ & Project Lifetime \\
\hline Inv. Cost $_{X}$ & specific investment cost at cumulative installed capacity X \\
\hline Inv. $\operatorname{Cost}_{0}$ & initial specific investment cost \\
\hline$E$ & Experience Parameter \\
\hline$\delta$ & Debt share \\
\hline$\beta$ & $\begin{array}{l}\text { beta, a measure of the sensitivity of expected asset returns to the expected } \\
\text { market returns }\end{array}$ \\
\hline
\end{tabular}

\section{Highlights}

- Floating wind shows significant development potential

- 44 billion $€$ of subsidies is required for floating wind to achieve $40 € / \mathrm{MWh}$

- Grid connection cost will become a major determinant for future of offshore wind

- System level planning is vital to effectively realize offshore wind targets

\section{Introduction}

Meeting ambitious climate targets requires rapid deployment of $\mathrm{CO}_{2}$ removal measures and renewable energy technologies [1]. With the historic cost reductions observed in the EU and UK [2], offshore wind is now considered well-established and a rapidly maturing renewable energy technology. Offshore wind is also expected to play a substantial role in future energy systems, with the International Energy Agency (IEA) projecting $560 \mathrm{GW}$ of global offshore wind capacity by 
2040 in its Sustainable Development Scenario [3]. The EU alone aims to achieve $300 \mathrm{GW}$ of offshore wind capacity by 2050 [4], and the Climate Change Committee (CCC) estimates that the UK requires $75 \mathrm{GW}$ of offshore wind capacity to meet its 2050 net-zero greenhouse emission targets [5]. Achieving such optimistic deployment targets within the next 30 years calls for an accelerated change of the sector's scale, policy actions to overcome market barriers and resolve stakeholder differences [6], given the long development timescales for offshore wind farm project development ( $7-10$ years) [7].

Offshore wind technology is categorized into two variants, fixed-bottom offshore wind (FBOW) and floating offshore wind (FLOW), based on the type of support structure employed for wind turbines in transferring their loads to the seabed and how their stability is achieved [8]. FBOW ${ }^{1}$, for which foundation structures are embedded into the seabed, has already shown significant technological progress and boasts a well-developed supply chain in the EU and the UK, building on the experience from $24 \mathrm{GW}$ of installed capacity by 2020 [9]. Hereafter, the EU and UK are referred to as mature markets of offshore wind (see Appendix A). Targeted incentives (e.g., feedin-tariffs and technology-specific auctions), progress in marine spatial planning, and subsidies in the form of grid connection and site development have accelerated the deployments of FBOW in its mature markets [7], resulting in notable cost reductions in recent years (average LCoE at 2020 is $69 € / M W h$, a $54 \%$ reduction from 2010-2015 values) [10], see Fig. 1 (a). These deployments have also resulted in significant progress for offshore wind technology, in general, including convergence in foundation design and establishing mass production of components, control of cost overruns, increased technology know-how among market players, and development of technologyspecific solutions (e.g., turbines, installation vessels, Operations \&Maintenance (O\&M), and subsea cables) [10,11]. In the EU and UK, $11.6 \mathrm{GW}$ of additional capacity is expected between 2021 and 2023, and a clear pipeline of projects / announced tenders until 2030 is in place. Besides China, the primary market outside of the EU and UK, several secondary and tertiary markets, including Taiwan, the US, Korea, Vietnam, India, and Japan, have also shown increased interest in utility-scale deployments of FBOW, i.e., accelerated technology diffusion [9]. Bulder et al. [12] analyzed further cost reduction opportunities of FBOW using engineering cost modeling and experience curve approaches and stated that FBOW could reduce to 35-45€/MWh by 2030.

\footnotetext{
${ }^{1}$ Monopile, jacket, tripile and gravity-based foundation designs are categorized as Fixed foundation type.
} 

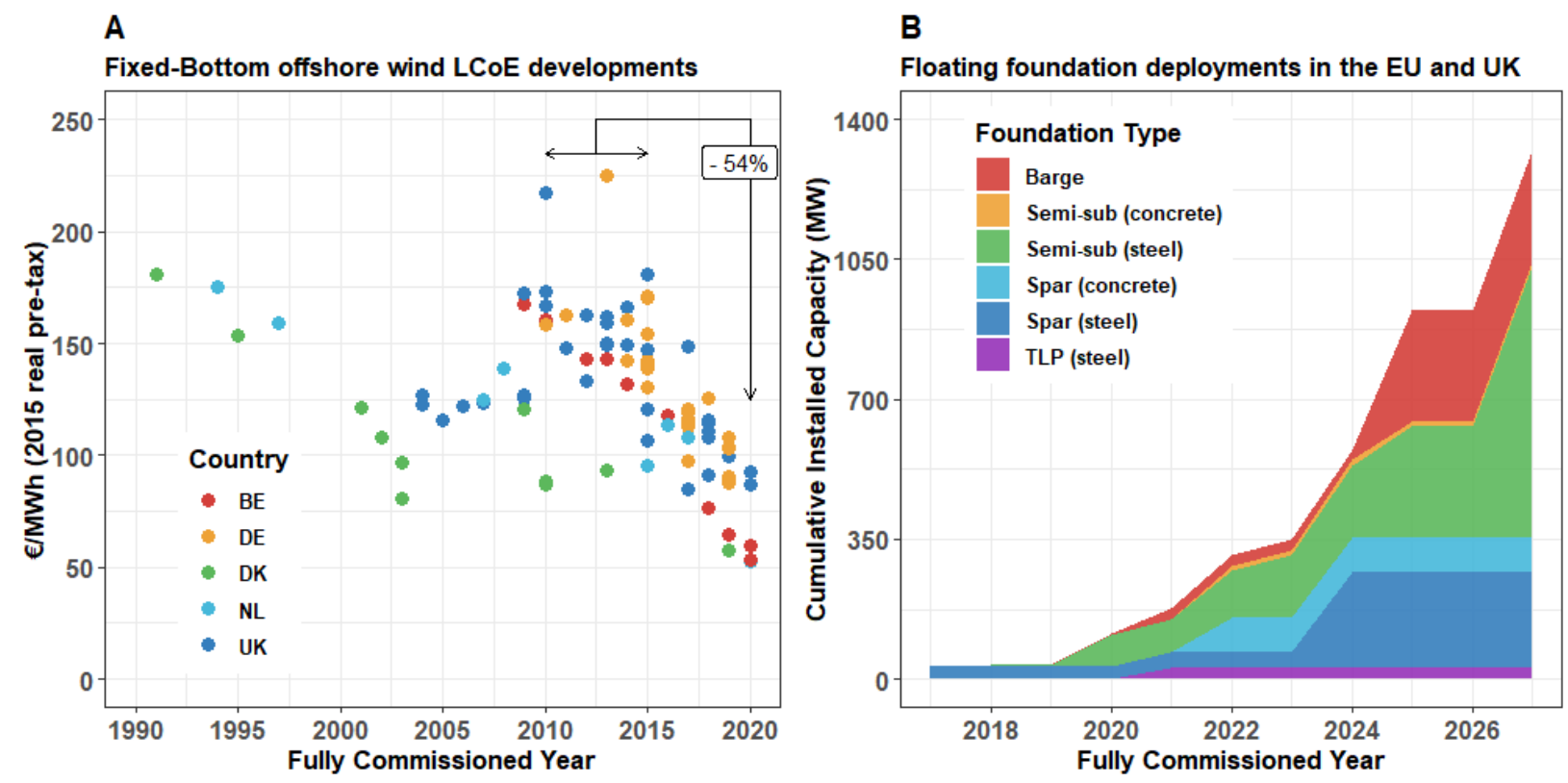

Fig. 1 Current status of offshore wind technology in its mature markets. a) LCoE (including grid connection cost) developments observed for FBOW projects [10]. b) Trend in the deployment of floating foundation technologies [13]. The figure represents single-device prototype, small-scale demonstration, and expected commercial-scale floating wind projects.

As outlined above, the FBOW is well-established and provides cost-competitive electricity in their mature markets [2]. However, to face the rising issues with nearshore spatial constraints and interests in exploiting better wind resources available in deeper waters (where fixed-bottom foundations are not suitable) [6,14], deployment of floating foundations ${ }^{2}$ is inevitable [15]. FLOW is an emerging variant of offshore wind, for which the foundation is tethered to the seabed using mooring and anchor systems. This setup allows motion for the wind turbines with certain degrees of freedom. Further, the commercial experience with FLOW is currently limited, with multiple foundation designs deployed as single-device prototypes and small-scale demonstrations [13]; see Fig. 1 (b). Each foundation design has its pros and cons (as summarized in Appendix B), and several factors, including manufacturing complexity, material needs, O\&M accessibility, and local content requirements (if any), will influence the foundation design convergence in the market. The current small-scale FLOW deployments also rely on component designs, procedures, and practices from existing Oil \& Gas and FBOW industries. The FLOW industry needs to develop dedicated

\footnotetext{
${ }^{2}$ Tension-leg platform, semi-submersible, barge and spar foundation designs are categorized as Floating foundation type.
} 
solutions and address existing technology-specific barriers to advance the technology to a commercial scale [15]. The barriers include the development of high voltage dynamic cables, cable connectors (e.g., wet-mate), floating substations, improved understanding of coupled behaviour of floating wind turbines (i.e., the interaction between floater, turbine, mooring, anchor, and dynamic cables at sea), new vessels or alternative lifting solutions for 15+ MW turbines [15-18].

Despite the emerging status of the FLOW and identified technological barriers yet to be overcome, several studies have claimed that its cost reduction potential is significant; for example, FLOW is expected to achieve 50-70€/MWh by 2030-2035 [15,19-21]. In those studies, transparency about the methodology, empirical evidence, and detailed assumptions leading to estimating the Capital Expenditure (CAPEX) and Levelized Cost of Energy (LCoE) developments were limited, consequently restricting the certainty and understanding of contributing factors' role. Studies dealing with estimating the current costs of floating wind farms based on engineering assumptions $[22,23]$ and parametric equations [24-26] exist in general. However, the long-term cost assessment of FLOW with a detailed account of contributing factors is not available, i.e., a critical limitation in literature. The case is less similar to FBOW due to its well-established status [12,22-24], but considerable uncertainty in predictions exists [13,25,26].

Furthermore, insights into two other critical issues relevant to offshore wind were lacking in the existing literature. First, achieving such drastic cost reductions for FLOW also depends on several preconditions, including convergence in technology design and solutions, supply chain development, and building a technology track record to achieve investor confidence [7,27], which were not clearly emphasized. Second, contrary to the onshore renewable energy technologies, grid connection (offshore and onshore) forms a significant component in the final energy cost of offshore wind. As wind farms are installed in challenging conditions (deeper waters and farther from the shore [10]) over time due to the nearshore spatial constraints and interest in exploiting better wind resources, the grid connection configurations, development model, and their costs are expected to become a critical element in determining the role of offshore renewables in the future energy system [28,29]. This study aims to address the key research gaps mentioned above, as detailed long-term technology cost assessments, contributing factors, and insights on necessary market preconditions are vital in designing effective energy policy actions [7,30,31], not only for FLOW but also to achieve continued progress for FBOW. Also, technology cost and performance 
forecasts are critical inputs in Integrated Assessment Models (IAM), largely influencing its outcomes, including system cost developments, technology mix, deployment scenarios, and transition pathways. Such outputs are commonly used to inform public policy designs, emphasizing the need for certainty in future technology costs $[32,33]$.

This study, therefore, provides explicit and comprehensive knowledge on long-term potential cost developments (CAPEX, LCoE) of FBOW and FLOW in their mature markets and detail contributing factors. Also, to emphasize the role of strongly varying site characteristics of offshore wind farms and their influences, the grid connection cost is separately discussed from the total technology costs (offshore wind CAPEX and LCoE); refer to Section 2.2 for more details. The analysis and results of this study are structured as follows. First, we use bottom-up engineering cost modelling to estimate and describe the CAPEX cost components of both variants of offshore wind. We then assess CAPEX developments based on increasing cumulative capacity, i.e., experience curve approach (Section 3.1). For LCoE, key assumptions reflecting the expected technological and market developments are described first, followed by constructing detailed LCoE developments and discussing the impacts of individual factors (Section 3.2). Second, grid connection cost development and its critical role in future energy system planning are discussed (Section 3.3). Lastly, we conclude with five major implications for the offshore wind industry, policymakers, and researchers (Section 4).

The technical and economic assumptions applied in this study are documented in a separate document as supplemental information (Appendices). The models developed in this study are available with open-access licenses at [34].

\section{Theory and Methods}

\subsection{Technological change process and offshore wind development}

Technological change is a complex process involving several stages of development and diverse characteristics $[35,36]$. In literature, several theoretical frameworks informing the conceptual basis of this process exists. However, the standard paradigm involves the Research, Development, Demonstration, and Deployment (RDD\&D) activities leading to cost and performance developments of energy technologies [30,37,38]. Such conceptual frameworks have also been applied to describe the development and diffusion of offshore wind technology. For example, 
Dedecca et al. described offshore wind development in three phases: innovation, market adaptation, and market stabilization, and further explored market strategies available for private players in the offshore wind market [39]. Van der Loos et al. argued that the underlying institutional construct in the European offshore wind market had led the technology to rapidly adopt a dominant design in the early stages of development. The study continued that radical experimentations, commonly observed in the early development stages of energy technologies, only emerged after 20 years of offshore wind technological diffusion [40]. Recently, Santhakumar et al. empirically analyzed the FBOW developments in the European region and stated that the overall technological progress of offshore wind has indeed followed a standard sequential development pattern commonly outlined in the literature [10,41] (as further illustrated in Appendix C). The development began with the formative phase, where the deployment of small-scale FBOW commercial units between early 2000 and 2010 enabled learning opportunities and initiated supply chain development and market creation for the technology. A rapid unit-upscaling phase ${ }^{3}$ followed next, with concurrent and increased diffusion of the technology in energy systems (growth phase) [10]. Now, next-generation design (FLOW, initially considered expensive) has emerged to benefit from FBOW developments and further progress the technology.

The approach, scope of analysis, data, and assumptions applied in this study are detailed in the following sections.

\subsection{Scope of analysis and approach followed}

Offshore wind is a complex, large-scale energy system, and the total cost of the technology is influenced by varying site characteristics and technical and economic parameters [42,43]. Several approaches have been followed in the literature to foresee its cost reduction. The experience curve approach, which assumes the technology cost to decline a certain percentage for every doubling of its output (an aggregate proxy for experience gain), has been extensively applied to predict offshore wind cost reduction (FBOW). However, the approach poses some limitations, including omitted variable bias, the inability to disaggregate the learning process and detail the underlying contributing factors and foresee radical changes in developments [30]. On the other hand, engineering assessments involve detailed component-level cost modeling, underpinning the

\footnotetext{
${ }^{3}$ The unit scale economies refer to cost reduction through upscaling of a product size or capacity, e.g., wind turbine rated capacity.
} 
techno-economic factors influencing the developments. However, only a subset of potential factors are generally considered in the analysis, and the development assumptions are based on expert knowledge or observations from analogous technologies in the market $[20,44]$. Lastly, in the expert-elicitation approach, information from subject-field experts is collated to understand the technology's potential cost and performance improvements. This approach is beneficial when historical information is limited [25]. Nevertheless, technology cost projections from model-based methods, like the experience curve approach, are observed closer to the realized developments than the elicitations [26].

In this study, to quantify the influences of the varying site and techno-economic characteristics on current and future deployments in a detailed manner, we leveraged the merits of bottom-up engineering cost modelling and experience curve methodology [30]. Bottom-up engineering cost modelling was first used to estimate and describe offshore wind variants' CAPEX breakdown, reflecting near-term commercial-scale deployment characteristics (refer to Appendix D). The assumed fully commissioned ${ }^{4}$ year is 2023-2024 for FBOW (expected to have achieved financial close in 2020-2021) and 2027-2030 for FLOW (expected to have initiated project development in 2020-2021) [9]. The long-term CAPEX developments for offshore wind variants were then derived using the experience curve approach (Wright's law) [45].

In addition to CAPEX (€), LCoE developments of offshore wind are influenced by several dynamic inputs, including discount rate $(i$, in $\%)$, project lifetime $(t$, in years), Annual Energy Production $(A E P$, in $M W h)$, Operational Expenditures $\left(O P E X\right.$, in $\left.€ M W^{-1} y r^{-1}\right)$ and Decommissioning expenditures (DECOM, in €) [42]. These parameters' expected developments were analyzed first to obtain individual assumptions, and subsequently, the long-term LCoE developments were estimated.

\subsubsection{Technology cost breakdown}

The conventional single factor experience curve (SFEC) model was applied to derive long-term CAPEX developments for offshore wind [31]. The assumed LR conflates the impact of cost drivers, including learning-by-doing, learning-by-searching, economies of scale, spillover, and cluster effects, on technology's CAPEX development [36,46]. However, the effect of site

\footnotetext{
${ }^{4}$ Fully commissioned year refer to the time when the wind farm begins its operation
} 
characteristics (water depth and distance to shore), which was shown to have a negative impact on technology cost [43], is not considered in the SFEC inherently. The site characteristics of the future deployments are also highly uncertain, as it depends on the regulatory frameworks on wind farm site development [7], developer preferences, and technology readiness [47]. In this study, the influence of varying site characteristics is considered by separating the offshore wind technology cost into two components, as shown in Fig. 2. First, the wind farm cost alone until the offshore substation (i.e., wind farm assets installed offshore) was considered. Second, the grid connection cost from offshore substation to onshore grid connection point was estimated separately, based on the wind farm's distance to shore and annual capacity utilization of the transmission asset ${ }^{5}$. These two cost components can be added to arrive at the final energy generation cost for an offshore wind farm. Such a cost breakdown provided a detailed account of the technological learning expected for offshore wind, underlying factors influencing them, and the impact of site characteristics on technology costs.

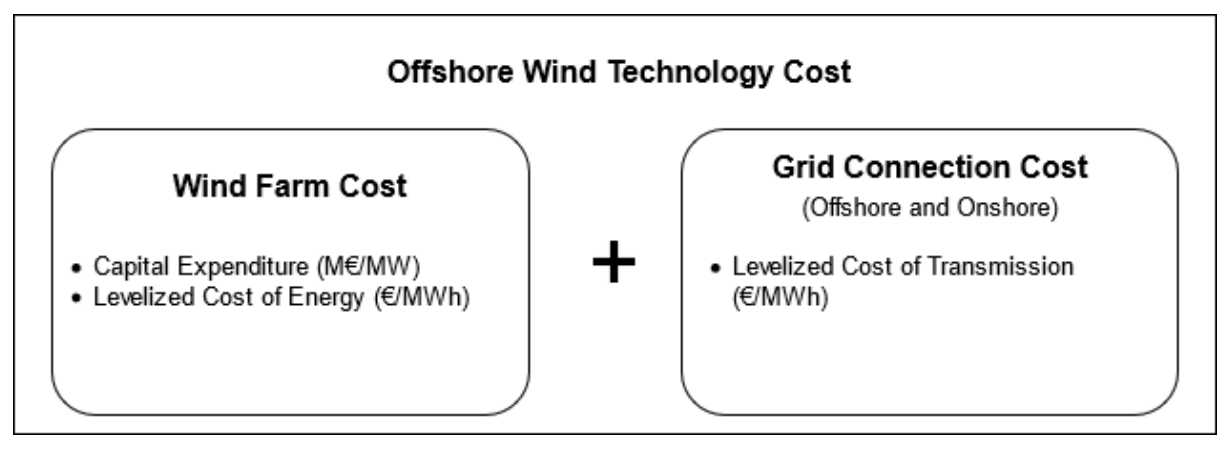

Fig. 2 Illustration of technology cost breakdown followed in this study

\subsection{Constructing CAPEX developments}

In bottom-up engineering cost modeling, the total CAPEX of offshore wind technology is decomposed into six cost categories, as shown in Equation (1).

$\operatorname{CAPEX}_{(\text {Excl. grid connection })}$

$$
\begin{aligned}
& =\text { Cost }_{\text {Devex }}+\text { Cost }_{\text {turbine }}+\text { Cost }_{\text {foundation }}+\text { Cost }_{\text {Elec. Infra }} \\
& + \text { Cost }_{\text {Installation }}+\text { Cost }_{\text {other costs }}
\end{aligned}
$$

\footnotetext{
${ }^{5}$ Annual capacity utilization refers to the extent to which the total transmission capacity has been utilized in a year, which can be represented in full load hours or capacity factor.
} 
In these equations, $\operatorname{Cost}_{\text {Devex }}, \operatorname{Cost}_{\text {turbine }}, \operatorname{Cost}_{\text {foundation }}, \operatorname{Cost}_{\text {Elec,Infra }}$, Cost $_{\text {Installation, }}$ Cost $_{\text {other costs }}$ refer to development expenditure, turbine supply cost, foundation supply cost, electrical infrastructure supply cost, and other project expenses (insurance, project management, and contingencies). The technical design and component cost assumptions applied in the bottomup engineering cost modelling are summarized in Appendix E. The long-term CAPEX developments for offshore wind were then derived by applying an LR, as shown in Equation (2).

Inv. $\operatorname{Cost}_{X}=\operatorname{Inv} \cdot \operatorname{Cost}_{0} *\left(X / X_{0}\right)^{-E}$

Inv. Cost $_{X}$, Inv. Cost $_{0}, E$ refers to specific investment cost $M € M W^{-1}$ of the offshore wind technology at cumulative installed capacity $X(G W)$, the initial specific investment cost of the offshore wind technology at $X_{0}(G W)$ unit of cumulative installed capacity, and the experience parameter. Inv. Cost $_{0}$ is the CAPEX estimated using Equation (1). The experience parameter in Equation (2) was calculated from the $\operatorname{LR}\left(L R=1-2^{-E}\right)$.

\subsubsection{LR assumptions for CAPEX developments}

Modular technologies (solar PV, LED, battery) achieve product standardization faster than complex compound technologies and yield cost reduction mainly through increased deployments (e.g., learning-by-doing), i.e., they depict high LR's for CAPEX (>10-15\%). Compound energy technologies (Nuclear power plants, CCGT systems, offshore wind), on the other hand, take extended periods to achieve technology standardization and develop know-how knowledge in the market. Their cost reduction is achieved through experimentations, design optimization, $R \& D$, and unit-scale economies; before learning-by-doing becomes prevalent, i.e., they depict low LR's for CAPEX $(<10-15 \%)[46,48]$.

For FBOW, the historic offshore wind farm project prices from the EU and the UK and cumulative installed capacity information were used to estimate the LR (LR: $6.2 \pm 6 \%$, see Appendix F). The CAPEX breakdown estimated for FBOW, reflecting deployment characteristics over the period 2023-2024, was assumed as Inv.Cost 0 ; refer to Equation (2). Thirty-one GW (approx.) of cumulative installed capacity is expected by the beginning of 2023 for FBOW [9], which was used as $X_{0}$ to project CAPEX costs further up to $100 \mathrm{GW}$ of cumulative installed capacity.

For FLOW, empirical LR could not be estimated, as there were no large-scale commercial deployments in the market by 2020. ORE Catapult (the UK's Technology Innovation and Research 
Centre for Offshore Renewable Energy) reported 9.5\% LR for FLOW based on two analyses, their understanding of supply chain dynamics, and innovation roadmaps published by Offshore Wind Innovation Hub \& European Technology Innovation Platform on Wind Energy [19,49,50]. We assumed a similar estimate but with a wide confidence interval (LR: $8 \pm 3 \%$ ) to include the potential development uncertainties; for example, FLOW builds on the existing progress of FBOW (e.g., turbine technology, vessels, O\&M practice, supply chain) which might limit its development opportunities or new radical innovations in design and fabrication processes can offer breakthrough developments for floating wind. The CAPEX breakdown estimated for FLOW, reflecting deployment characteristics over the period 2027-2030, was assumed as Inv. Cost $_{0}$ in Equation (2). One GW was assumed as the initial cumulative installed capacity $\left(X_{0}\right)$, which was also considered a learning threshold when cost overruns are controlled, performance shortfalls are corrected, foundation design convergence begins, and project costs start to decline [19,51]. This assumption is suitable as the FLOW variant is expected to build on technological progress already achieved by FBOW in the market (e.g., turbine technology, supply chain, installation, and O\&M practices). The FLOW CAPEX costs were then projected up to $100 \mathrm{GW}$ of cumulative installed capacity. The LR assumptions employed in this study are summarized in Table 1.

\begin{tabular}{|c|c|c|}
\hline $\begin{array}{c}\text { Technology } \\
\text { Variant }\end{array}$ & LR & Analysis Notes/Comments \\
\hline $\begin{array}{c}\text { FBOW } \\
\text { (refer to } \\
\text { Appendix F) }\end{array}$ & $6.2 \pm 6 \%$ & $\begin{array}{l}\text { - Empirical cost information of FBOW wind farms installed } \\
\text { between 1990-2020 was used in estimating LR } \\
\text { - SFEC model was used as the site characteristics of future } \\
\text { wind farms are highly uncertain } \\
\text { - Learning threshold assumption of } 2.5 \mathrm{GW} \text { cumulative } \\
\text { installed capacity was assumed to neglect the influence of } \\
\text { early cost overruns } \\
\text { 95\% confidence interval based on standard error is } \\
\text { calculated to illustrate LR uncertainty }\end{array}$ \\
\hline FLOW & $8 \pm 3 \%$ & $\begin{array}{l}\text { - No large-scale commercial deployments in the market by } \\
2020 \text { to estimate empirical LR }\end{array}$ \\
\hline
\end{tabular}


- LR assumptions were based on estimates used in the past literature and LR's commonly observed for similar largescale compound energy technologies

Table 1 Summary of the LR assumptions employed for offshore wind CAPEX projections

\subsection{Constructing LCoE developments}

$\mathrm{LCoE}$ is the $€ / \mathrm{MWh}$ amount the offshore wind project developer must earn for each MWh electricity generated to cover the total costs incurred over the project lifetime. It is also a critical metric that significantly impacts investment and policy actions and compares different technologies' competitiveness in the market; however, it neglects system-level values $[3,52]$. The LCoE was estimated as shown in Equation (3).

$L C O E=\frac{C A P E X+\left(\sum_{n=1}^{t} \frac{O P E X}{(1+i)^{t}}\right)+\frac{D E C O M}{(1+i)^{t+1}}}{\sum_{n=1}^{t} \frac{A E P}{(1+i)^{t}}}$

To separate the financial expenditures from the $\mathrm{LCoE}$, we first estimated a baseline $\mathrm{LCoE}$ at a $0 \%$ discount rate, as illustrated in Equation (4). This step resulted in the actual contribution of the CAPEX, OPEX, and DECOM in the LCoE. Subsequently, we estimated the LCoE again at the discount rates derived in this study, using Equation (3). The difference between the LCoE at a discount rate $(i)$ and the baseline $\operatorname{LCoE}(i=0 \%)$ was assigned as financing expenditures for the offshore wind technology.

$$
L C o E_{i=0}=\frac{C A P E X+\left(\sum_{n=1}^{t} O P E X\right)+D E C O M}{\sum_{n=1}^{t} A E P}
$$

\subsubsection{Discount rate or Cost of Capital (CoC)}

Renewable energy technologies are considered capital-intensive, for which a significant portion of their lifecycle costs is incurred upfront. At the early development stage, the limited technology track record for emerging renewable energy technologies poses higher risks for investors in the market (i.e., higher return expectations), which also forms a limiting effect on technology deployments. Nevertheless, as the technology becomes more mature and reliable with experience, the risks perceived by the investors decrease, which results in lower expected returns (provided that market conditions are favourable) [53]. In this study, project finance capital structure is 
assumed for discount rate estimation of offshore wind, as this structure theoretically ties the cost of capital to the project risks. In project finance, the investment is made off the balance sheet of project owners, and the project is also turned into a separate business entity called a Special Purpose Vehicle (SPV). The Weighted Average Cost of Capital (WACC) formula was used to estimate the cost of capital of the project, where both debt $(\delta, \%)$ and equity $(1-\delta, \%)$ are proportionally weighted, as shown in Equation (5). No tax considerations were assumed. The cost of capital is usually stated in nominal terms. Therefore, the inflation expectations (implied) were used to deflate the $W A C C_{\text {nominal pre-tax }}$ into $W A C C_{\text {real pre-tax }}$, as shown in Equation (6).

$$
\begin{aligned}
& W A C C_{\text {nominal pre-tax }}=\delta * \text { cost of debt }+(1-\delta) * \text { cost of equity } \\
& W A C C_{\text {real pre-tax }}=\frac{\left(1+W A C C_{\text {nominal pre-tax }}\right)}{(1+\text { inflation })}-1
\end{aligned}
$$

The resulting $W A C C_{\text {real pre-tax }}$ was used as a discount rate $(i)$ for $\mathrm{LCoE}$ estimation.

\subsubsection{Cost of debt and equity}

The cost of debt and equity were estimated from available market proxies. The cost of debt was estimated by adding a premium to the reference interest rate, as shown in Equation (7).

Cost of debt $=$ reference interest rate + debt premium

Reference interest rates were generally approximated as LIBOR (for the UK)/EURIBOR (for EU) rate plus swap premium [54]. The debt premium refers to the margin expected by the lending institutions, reflecting the risks of the offshore wind project.

The cost of equity was estimated using the Capital Asset Pricing Model (CAPM), as illustrated in Equation (8).

Cost of equity $=$ risk - free rate $+\beta * E M R P+\alpha$

$\beta, E M R P, \alpha$ in Equation (8) refers to beta (a measure of the sensitivity of expected asset returns to the expected market returns), the expected market risk premium (average return investors expect over the risk-free rate for equity investments), and alpha (asset-specific premium reflecting the risks of the investment, e.g., offshore wind project). While the reference/risk-free rates and EMRP depend on exogenous developments in the market, the debt premiums and $\alpha$ depend on the learning 
dynamics related to the technology's deployment and financing in the market [53]. Here, we estimated long-term LCoE developments based on increasing cumulative installed capacity and not time-period. Therefore, exogenous parameters were not changed, and the endogenous variables were varied based on technology's cumulative experience gain. The approach and detailed assumptions applied for the cost of debt and equity estimation are discussed in Appendix G.

\subsubsection{Annual Energy Production (AEP)}

The Annual Energy Production (AEP) of the wind farm is a function of the Capacity Factor (CF), as illustrated in Equation (9). Capacity factor refers to "the ratio of the amount of electricity produced by the wind farm to its total potential, based on nameplate capacity, over a period of time (usually one year, to account for seasonal variability in output)" [55]. Besides technological developments (e.g., larger rotors, increased hub height, increased rated power capacity of wind turbines, and wind farm availability), the site characteristics also influence the wind farm's capacity factor, i.e., better wind resources result in a higher capacity factor.

$A E P_{M W h}=$ capacity factor $_{n e t} *$ wind farm capacity in $M W * 8760$

As mentioned in Section 2.1.2, the site characteristics of the future deployments are highly uncertain. Therefore, the capacity factors for two wind turbine models (one representing current installations and one representing future installations) at six different imaginary sites in the North Sea region (site characteristics ranging from nearshore to far offshore) were estimated to derive capacity factor assumptions. The approach and assumptions applied in the capacity factor estimation are summarized in Appendix $\mathrm{H}$.

\subsubsection{Project lifetime}

For FBOW, a project lifetime of 30 years is assumed due to its existing experience and improved understanding of its operation and performance [56]. For FLOW, a project lifetime of 20 years is assumed for the first GW, 25 years from 1-10 GW, and 30 years after 10+ GW cumulative capacity. The assumption for FLOW is derived from the practices seen in FBOW developments [11]. Project life beyond 30 years was not assumed in this study because the technology is still considered maturing. The first projects to be decommissioned will likely favour repowering to adopt improved technologies available in the market rather than an extension of project lifetime [57]. 


\subsubsection{OPEX}

OPEX refers to expenditures incurred for operating and maintaining the wind farm assets, including predictive and corrective maintenance costs (onshore and offshore), insurance, and management costs.

$O P E X=O \& M_{\text {onshore\& offshore }}+$ insurance $_{O \& M}$

In specific markets, wind farm owners also incur transmission charges and seabed rent as operating expenses. Furthermore, from the wind farm owner's perspective, the opportunity cost of turbine downtime (forgone revenue) as a direct result of the inspection, maintenance, and repair tasks are also included as operating expenses [58]. However, those expenditures and foregone revenues are excluded from the calculations in this study, and the wind farm's LCoE estimates will increase upon including them. The OPEX assumptions made in this study are detailed in Appendix I.

\subsubsection{Decommissioning (DECOM) Expenditure}

Decommissioning offshore wind farms mean removing wind farm assets, reinstation of the site, and clearance verified upon lease termination. To ensure the decommissioning of these OWF's and avoid public cost burden, regulators in most markets require developers to set aside funds for future use upfront or provide security that the developer will make funds available in the future [59]. The assumption is that the wind farm's total installation cost $\left(8 \% \text { of } \mathrm{FBOW}^{\prime} \mathrm{S} C A P E X, 3 \% \text { of } \mathrm{FOW}^{\prime} \mathrm{S} C A P E X\right)^{6}$ is equal to DECOM expenditure, and the developer will incur this cost after the end of the project lifetime. This assumption neglects the learning that will be gained in the marine engineering practices, vessel improvements over time, and residual value that might be attached to the assets (which could be sold or used in the event of repowering) at the end of the project lifetime. Nevertheless, this omission's impact will be negligible on the LCoE, as the DECOM expenditure is discounted after the end of the project lifetime, as shown in Equation (3).

\subsection{Grid connection cost}

As mentioned in Section 2.1.2, the grid connection cost for a wind farm from an offshore substation to an onshore grid connection point is estimated separately. Two offshore grid development models are being followed in FBOW's mature markets; the developer build (decentralized) and

\footnotetext{
${ }^{6}$ This assumption is result of cost estimation made for the windfarm illustrated in Appendix D.
} 
Transmission System Operator (TSO) build (centralized) development model. They mainly differ on how the risks of developing and operating transmission assets are borne between the Government (or entity mandated by the Government) and the project developer [28]. The developer build model allows project developers to optimize the transmission assets to achieve low overall wind farm costs. However, the TSO build model benefits the strategic coordination of offshore grid connection to ease onshore grid constraints and may also deliver net lower societal costs for the system [7]. The TSO build model also reduces the construction risks for wind farm developers; however, it increases the risks of revenue loss in the event of a delay in providing grid connection. In this study, the TSO build development model is assumed to estimate the grid connection cost as a Levelized Cost of Transmission (LCoT). Here, the LCoT is defined as the $€ / M W h$ amount the TSO must charge the wind farm owner to cover the cost of developing and operating an offshore grid connection system to the shore.

Different grid connection topologies exist, namely, radial, hub, and hybrid systems [28]. A radial connection directly connects the wind farm to the onshore grid connection point (point-to-point connection, a prevalent grid connection concept for offshore wind farms). A hub connection clusters more than one wind farm in an offshore hub (facilitating asset sharing) and transfers the electricity generated to an onshore grid connection point. The hybrid connection allows the transmission asset to be used as a grid connection for the wind farms and as an interconnector where electricity can be traded in both directions. In this study, the LCoT for three radial HVAC connection capacities (350, 700, and $1050 \mathrm{MW}$ ) are estimated. Beyond $\sim 1000 \mathrm{MW}$ and with longer transmission distances, the HVDC system is expected to be competitive [60]. Moreover, the LCoT was also estimated as a matrix with annual capacity utilization (a function of capacity factor) and distance to shore as variables to illustrate the influence of site characteristics on technology costs. Annual capacity utilization refers to the extent to which the total transmission capacity has been utilized in a year, which can be represented in full load hours or capacity factor ${ }^{7}$.

The capital expenditure of the grid connection was first calculated by totalling the investments for both offshore (semi-submersible HVAC offshore substation, export cable) and onshore (onshore substation, underground cable) equipment, Equation (11). By assuming project lifetime ( $t=$

\footnotetext{
${ }^{7}$ Here, the capacity factor refers to the ratio of energy delivered to the onshore grid (after the transmission losses) to the total energy capable of transmitting in a year.
} 
30 years), discount rate $(4 \%)^{8}$, and OPEX [29] (1\% of CAPEX), the LCoT was estimated [29], using Equation (12). No learning assumptions were considered here, as HVAC is regarded as mature technology [61].

$C A P E X_{\text {grid connection }}=C A P E X_{\text {offshore grid }}+C A P E X_{\text {onshore grid }}$

$L C o T=\frac{C A P E X_{\text {grid connection }}+\left(\sum_{t=1}^{n} \frac{O P E X_{\text {grid connect }}}{(1+i)^{t}}\right)}{\sum_{t=1}^{n} \frac{A E P_{\text {wind farm }}}{(1+i)^{t}}}$

The summary of the technical characteristics assumed is provided in Appendix $\mathrm{J}$, and the detailed assumptions can be seen in the cost estimation model made available with the article (see Data Availability section).

\subsection{Reference LCoE and breakeven capacity}

A reference $L C o E$ is commonly chosen in similar studies to benchmark the development of technology in the context. More commonly, the conventional fossil fuel technology cost is chosen [62]. Here, the reference $L C o E$ of $40 € / \mathrm{MWh}$, reflecting the wholesale electricity price developments in European electricity markets between 2017 and 2020 [63], is used to benchmark offshore wind development. This assumption is made because wholesale electricity price reflects the cost of generating and delivering electricity in the system and can be used as an appropriate metric to determine the price gap that needs to be compensated for emerging technologies (as subsidies/incentives, e.g., Feed-in-Tariffs). Further, the cumulative installed capacity required to achieve the reference LCoE is referred to as breakeven capacity in this study [45].

\subsection{Learning Investment}

Learning investments for a technology refer to the additional costs, as investments, necessary to make the technology cost-competitive in the market [45]. These additional costs are generally provided through several market mechanisms, including direct and indirect transfer to producers

\footnotetext{
${ }^{8}$ TSO's have better access to cheaper capital due to their regulated revenue model. In some cases, they can even recover the incurred losses by passing charges to their consumers.
} 
or consumers to compensate the price gap, preferential tax treatments, $R \& D$, direct investments in energy infrastructure, trade restrictions, and regulations in the market [64]. In this study, we only estimated the cumulative additional costs required to close the price gap between the LCoE of the technology and a reference LCoE, as learning investments, as shown in Equation (13). Therefore, it should be highlighted that total learning investment will increase upon including the excluded incentives. Reference LCoE assumption is $40 € / \mathrm{MWh}$; see Section 2.6.

Learning Investment $=$

$$
\begin{aligned}
& =\sum_{n=1}^{\text {breakeven capacity }}\left(L C o E_{n}-\text { ref. LCoE }\right) * A E P_{n, M W h} \\
& * \text { Project lifetime }_{n}
\end{aligned}
$$

\section{Results and Discussion}

\subsection{CAPEX outlook of offshore wind and contributing factors}

As discussed in Section 2.3, the CAPEX breakdown estimated using the bottom-up engineering cost-modeling is first used to describe major cost drivers. Then, experience curve approach was applied to derive future CAPEX developments.

Before projecting offshore wind variants' CAPEX, it is essential to understand their differences and cost drivers. Fig. 3 (a) shows the component level CAPEX breakdown for FBOW and FLOW. It is to be reminded here that FLOW is considered emerging, and FBOW is considered wellestablished in the market. Nevertheless, a comparison of CAPEX at the current development state of each variant is warranted as FLOW builds on technological progress already achieved by FBOW, excluding the foundation component and associated modifications (refer to Appendix E for more details). The five major differences observed are as follows: 1) The high proportion of fixed costs involved in the project development currently results in higher specific Development Expenditure (DEVEX) for FLOW (assumed project scale in Fig. 3 (a): 1020 MW for FBOW and $300 \mathrm{MW}$ for FLOW). 2) The higher turbine supply cost assumption for FLOW reflects the modifications required for FLOW turbines (tower and control software to compensate floater motions) and reduced scale of turbine orders (assumed no of turbines in Fig. 3 (a): 85 for FBOW, 25 for FLOW). 3) The foundation cost of FLOW is roughly seven times higher than that of FBOW, with the semi-sub floater supply cost being the major cost contributor. In FBOW, the site's water 
depth directly influences the foundation design and material needs, as the embedded foundation structure is raised from below the seabed to roughly $15-20 \mathrm{~m}$ above the water level. However, for a FLOW foundation, the water depth primarily influences the mooring and anchor costs (which form less than one-third of the total foundation cost), as the foundation structure is tethered to the seabed. Refer to Fig. 3 (b) for a comparison of foundation cost breakdown. 4) FLOW installation does not require expensive heavy-lift vessels (typical for FBOW), as primary lifting and assembly operations for the wind turbine structure can be made onshore (or deep nearshore waters, specifically for spar foundations [65]) and towed to the wind farm site using less expensive anchor handling vessels and tug boats. 5) FLOW has higher construction insurance and contingency costs due to the limited track record, resulting in increased "Other CAPEX" costs.
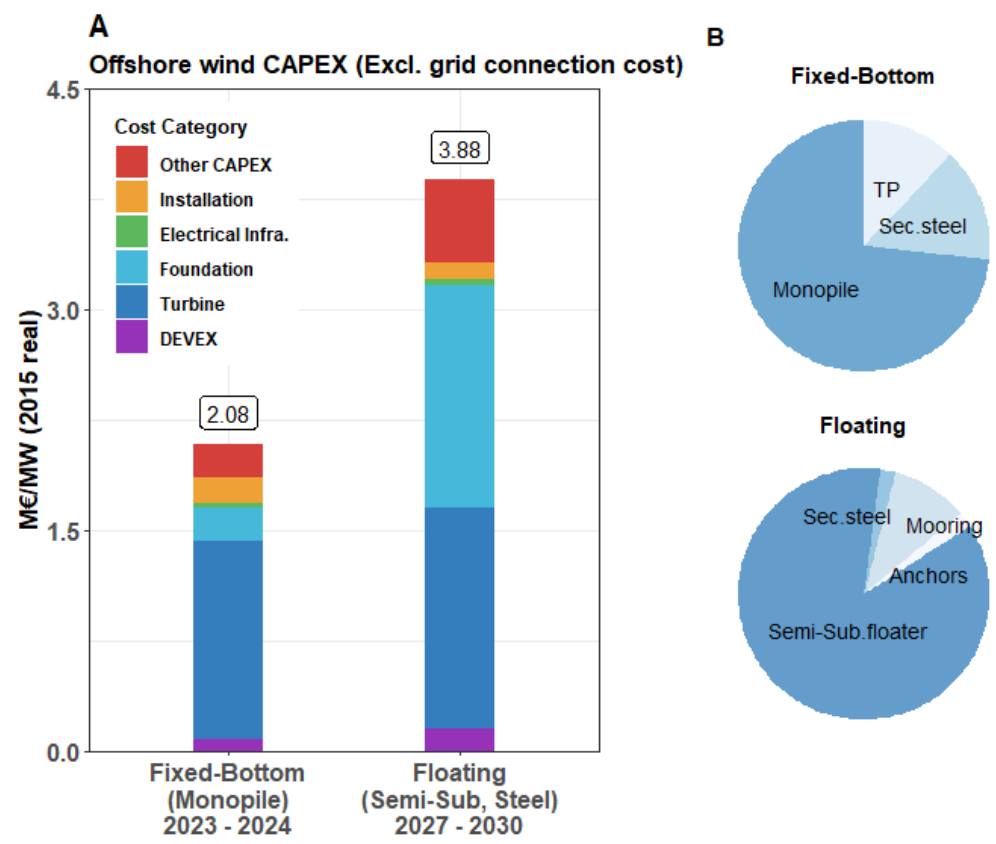

Fig. 3 Offshore wind technology CAPEX breakdown. a) CAPEX breakdown for FBOW and FLOW estimated using bottom-up engineering cost modelling (see Appendix D for wind farm characteristics). b) Comparison of cost breakdown for foundation systems

Compared to FBOW [10], potential cost drivers behind long-term CAPEX developments of FLOW have not been assessed in the literature previously. Therefore, technical and economical 
design variables of FLOW were varied to determine factors with the highest impacts ${ }^{9}$, see Fig. 4. The changes in DEVEX and the day rates of installation vessels/equipment have a minor impact, as these cost components form a smaller portion of the total CAPEX. Nevertheless, the influence of weather conditions (e.g., delays) can increase wind farm's installation cost. Sharing an anchor system between multiple wind turbines or increasing the number of mooring lines to ensure an acceptable risk profile for the turbine's station-keeping (mooring configuration can vary across foundation designs [17]) also has a minor impact. Water depth variation has a minor but counterintuitive effect on CAPEX because the mooring line's vertical suspended length is shorter in shallow waters (roughly 60-100m deep). Therefore, heavier steel chains are needed to develop the necessary restoring forces for station-keeping. However, in deeper waters where longer mooring lengths are necessary, lighter steel chains are sufficient to develop necessary restoring forces for station-keeping, thus reducing the material costs $[18,66]$.

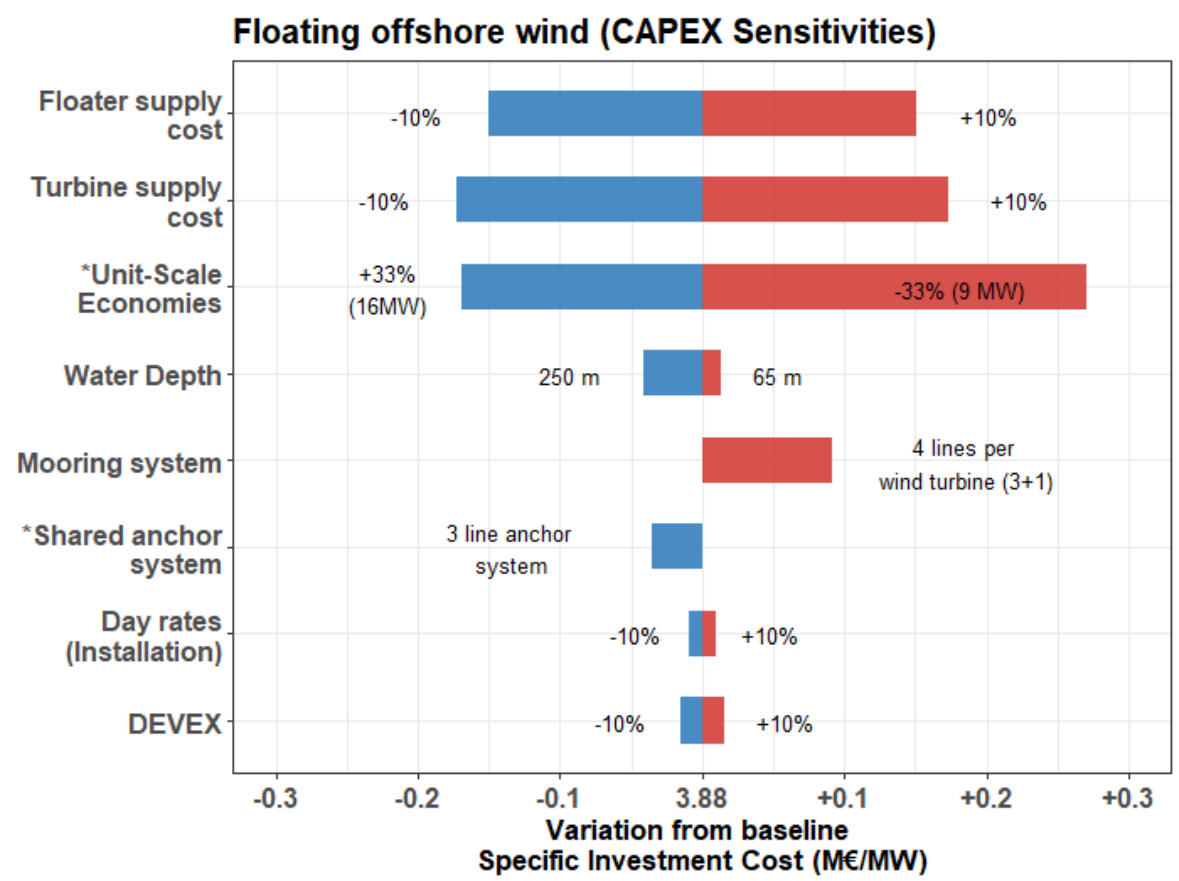

Fig. 4 Tornado chart describing the CAPEX sensitivities of several technical and economical design variables of FLOW. *Unit-scale economies: Turbine supply cost variations are excluded here. *Shared anchor system: Driven pile anchor is assumed for shared anchor system

\footnotetext{
${ }^{9}$ It is to be reminded here that the factors mentioned here are subset of techno-economic variables that majorly impacts wind farms costs, and the combination of these factors will influence the cost developments of FLOW.
} 
configuration (instead of drag embedded anchor) because of the requirement to withstand cyclic loads from mooring systems in different directions $[67,68]$.

Moreover, three other factors, unit-scale economies, turbine, and floater supply cost, have been observed to have the highest impacts on CAPEX, i.e., major cost drivers. The installation of turbines with higher rated power reduces the number of turbine positions in the wind farm (thereby, reduced installation operations, mooring and anchoring systems) and specific material consumption in the Balance of Plant (e.g., foundation mass and cables), which decreases the specific CAPEX of the wind farm (unit-scale economies effect) [10,69]. However, the unit-scale economies effect will diminish when the cost of developing and installing turbines with higher rated power exceeds the benefits it brings to the final cost of energy. Studies have already noted that turbine upscaling is outpacing the supporting technologies (cranes, vessels with increased height, reach, and lifting requirements) required to install them [11,19], indicating potential bottlenecks for future deployments. The higher impacts observed for turbine and floater supply costs show that notable cost reduction can be achieved by converging the technological design faster and initiating mass production of the technology components (i.e., learning-by-doing). Equally, diverged focus on foundation designs and market concentration in the supply chain can hamper potential cost reduction for FLOW.

As a final step, CAPEX development for FBOW and FLOW was projected until $100 \mathrm{GW}$ of cumulative capacity from its assumed initial deployment level (current status) using experience curve approach. The Learning Rate (LR) applied to FBOW was based on historic project prices and cumulative capacity. For FLOW, empirical LR could not be estimated, as there were no largescale commercial deployments in the market. Therefore, LR was assumed based on the theoretical understanding outlined for large-scale energy technologies' developments and estimates applied in past studies (see Section 2.3.1). The LRs depicting technology developments are also subject to uncertainty due to several factors. These factors include the limitations of the underlying data, market shifts, commodity price changes, cost overruns, and potential step-change developments through Research \& Development (R\&D) [31]. These uncertainties were considered by estimating 95\% standard error-based confidence interval (FBOW) or by including a potential range (FLOW) for LR. The initial specific CAPEX applied in the experience curve projection is from the bottom- 
up engineering cost modeling discussed above. Fig. 5 illustrates potential CAPEX developments, which reduces to 1.87 M€/MW for FBOW and 2.23 M€/MW for FLOW by $100 \mathrm{GW}$.
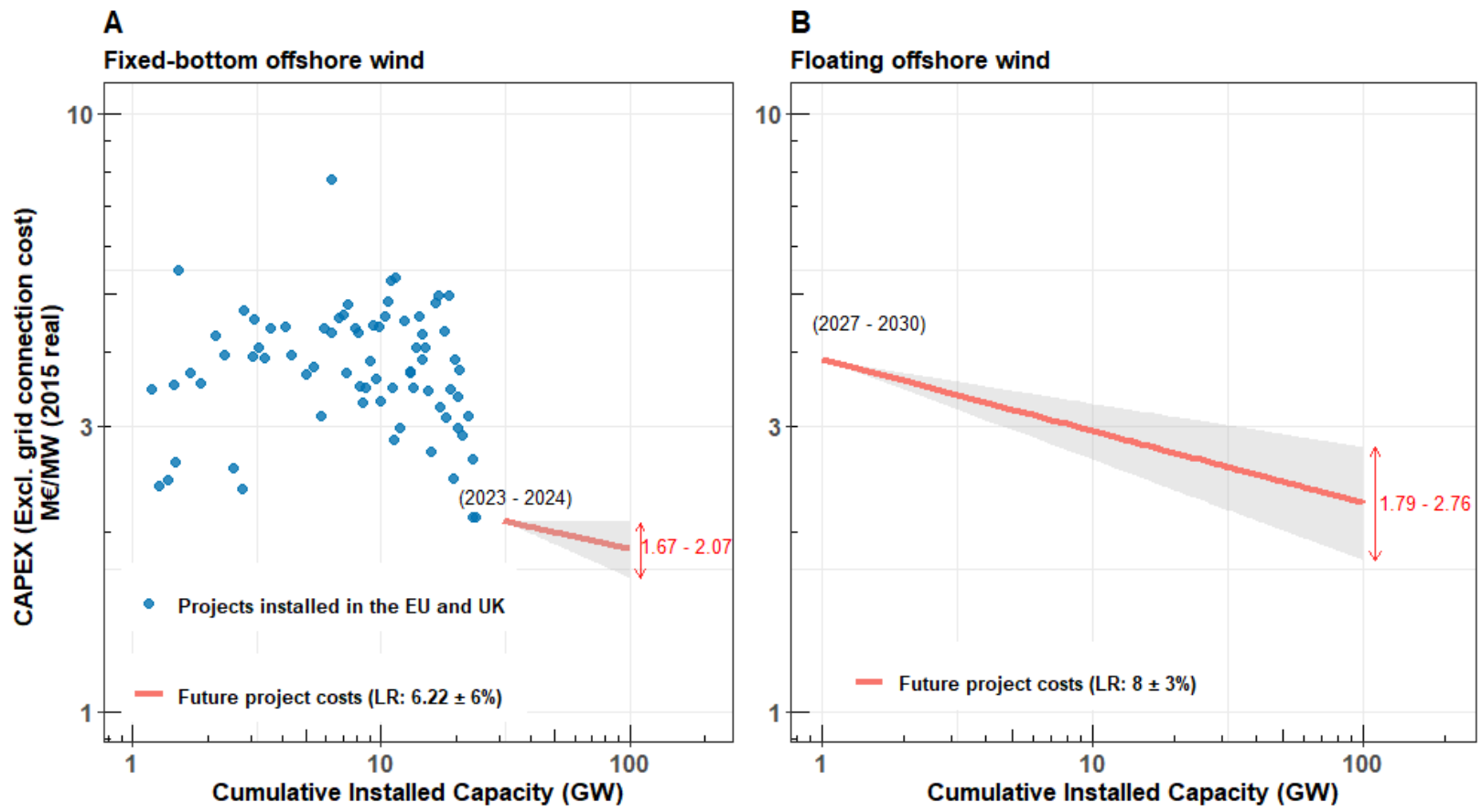

Fig. 5 CAPEX outlook of offshore wind. a) FBOW CAPEX developments projected from 31 to 100 GW cumulative capacity. b) FLOW CAPEX developments projected from 1 to $100 \mathrm{GW}$ cumulative capacity. 


\subsection{LCoE outlook of offshore wind and the drivers of technological learning}
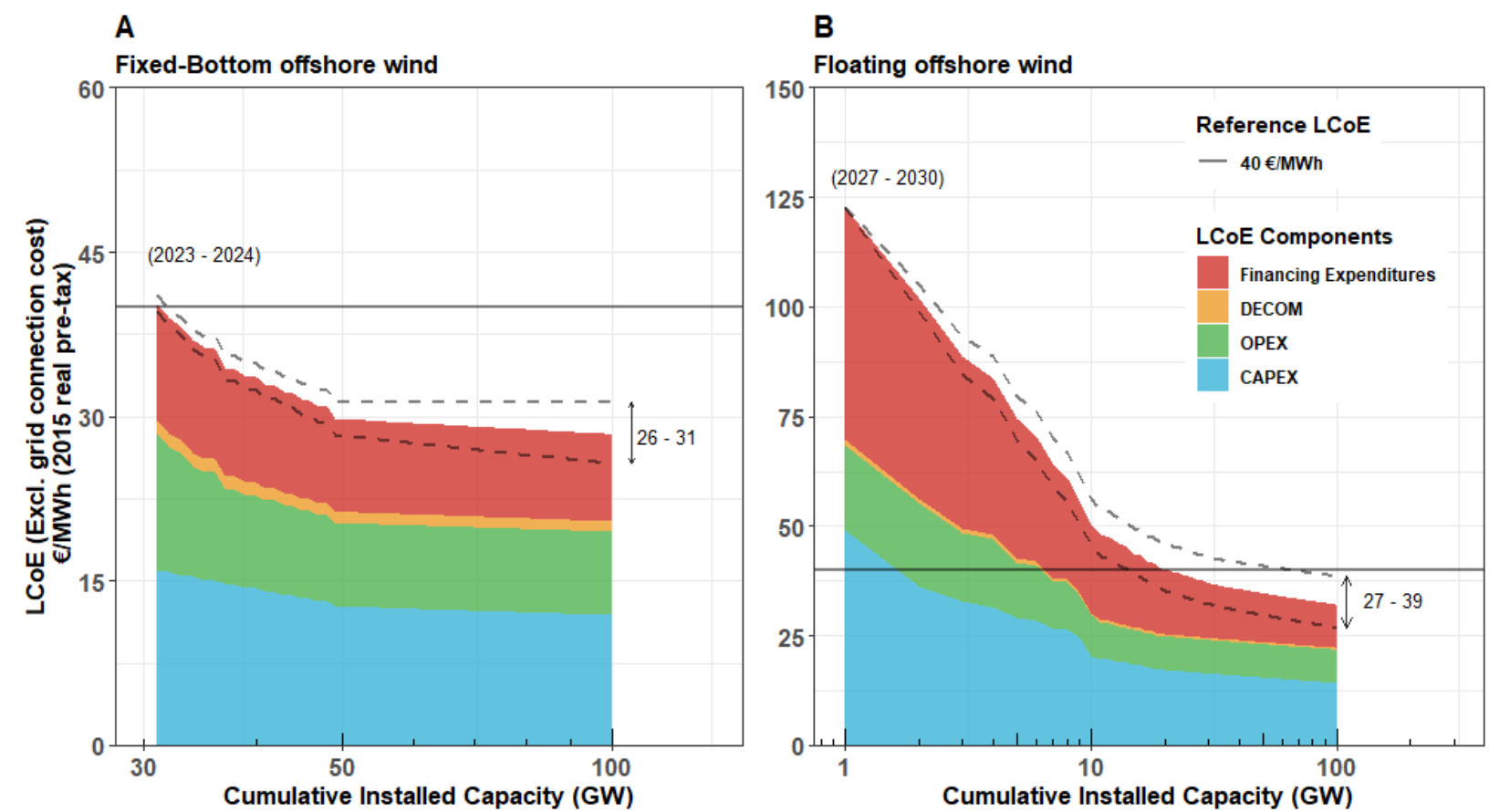

Fig. $6 \mathrm{LCoE}$ outlook for offshore wind. a) FBOW LCoE developments projected from 31 to 100 GW of cumulative capacity. b) FLOW LCoE developments projected from 1 to $100 \mathrm{GW}$ of cumulative capacity. The dotted lines in the figure indicate the uncertainty range of the $\mathrm{LCoE}$ development trajectory (upon considering CAPEX LR interval estimates, 95\% confidence interval).

The LCoE of offshore wind technology was estimated as described in Section 2.4. Fig. 6 shows the detailed component-level LCoE developments expected for FBOW and FLOW. LCoE reduces to $28.4 € / \mathrm{MWh}$ for FBOW (30\%) and $32.0 € / \mathrm{MWh}$ (74\%) for FLOW by $100 \mathrm{GW}$ from its assumed initial deployment level. The reference $\mathrm{LCoE}$ of $40 € / \mathrm{MWh}$, reflecting the wholesale electricity price developments in European electricity markets between 2017 and 2020 [63], is used to benchmark offshore wind development; refer to Section 2.6. FBOW breakeven at $31 \mathrm{GW}$ of cumulative capacity and is expected to be reached between 2023-2024. FLOW could achieve breakeven by deploying roughly $21 \mathrm{GW}$ of cumulative capacity, requiring 44 billion $€$ of learning investment (see Section 2.7). When the LR uncertainties of FLOW are considered, the breakeven capacity ranges between 14 and $64 \mathrm{GW}$, requiring 34-70 billion $€$ of learning investment. 

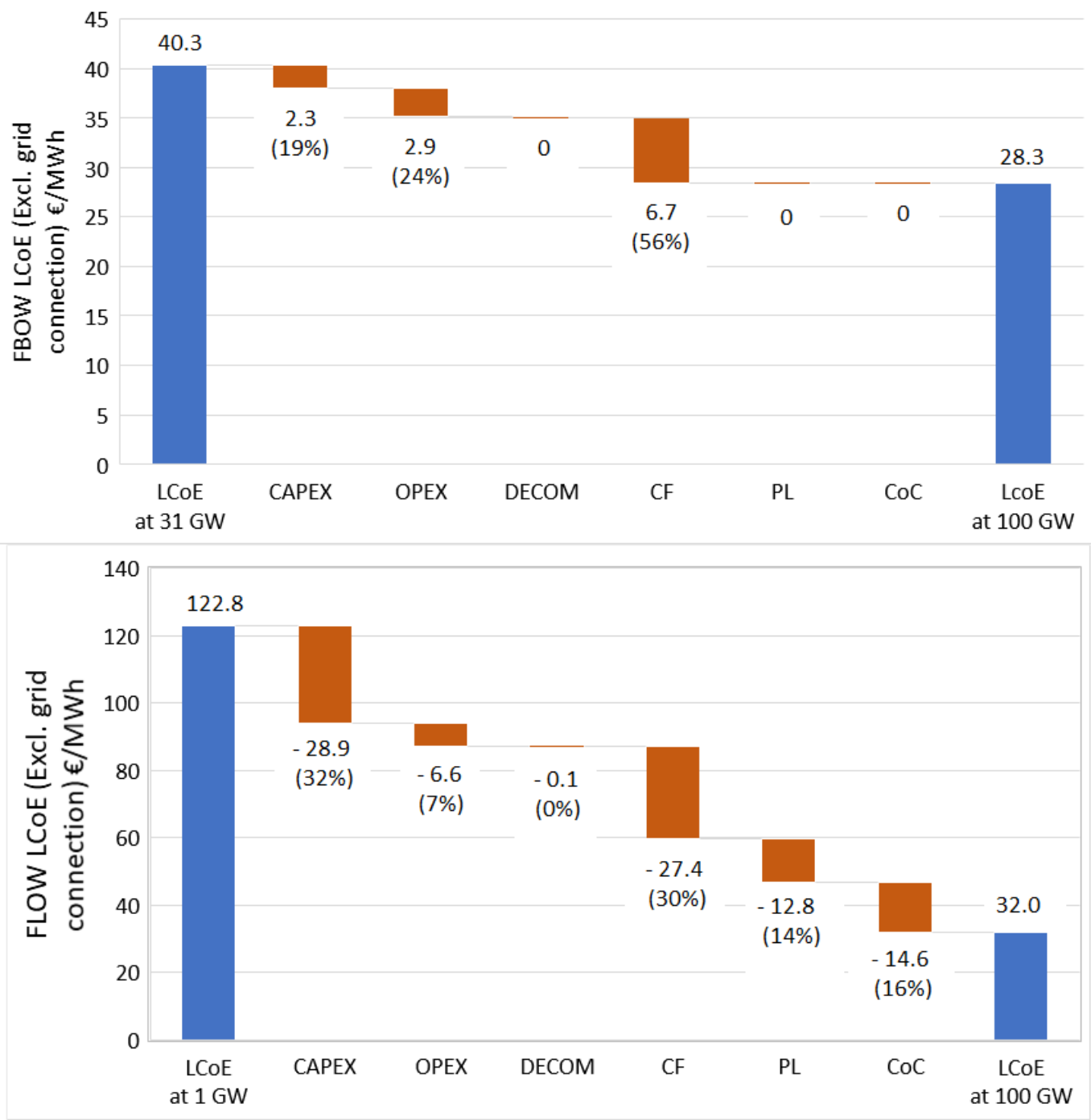

Fig. 7 Impact of individual factors contributing to the $\mathrm{LCoE}$ reduction. The figure presents the base case cost reduction (i.e., excluding uncertainty range) considered for FBOW and FLOW in Fig. 6

Furthermore, the impacts of identified factors behind potential $\mathrm{LCoE}$ reduction of offshore wind variants are estimated (Fig. 7) and detailed below. 1) Technology Costs (CAPEX, OPEX, and DECOM): The reduction in technology costs contribute to $5.2 € / \mathrm{MWh}$ reduction (43\%) for FBOW and $35.6 € / \mathrm{MWh}$ reduction (39\%) for FLOW in the overall LCoE development towards $100 \mathrm{GW}$ from its initial assumed cumulative capacity. Besides learning through deployments (learning-bydoing), the rapid unit-upscaling of offshore wind turbines that occurred after 2010 has reduced the specific CAPEX, OPEX [70], (expected) decommissioning expenditures, and also increased the 
Annual Energy Production (AEP) for FBOW [10]. The further upscaling of turbines ${ }^{10}(15+\mathrm{MW})$ is expected to advance the technology costs for FBOW and FLOW (Fig. 4). However, learningby-doing is expected to play a more prominent role in further years as the unit-scale economies effects are diminishing ([10] and see Fig. 4) and potential bottlenecks in terms of installation are arising $^{11}$. Also, for FLOW, the technological barriers mentioned earlier need to be addressed first to benefit from continuous cost decline. O\&M strategy varies depending on distance to shore, scale of the project, FBOW or FLOW, resulting in OPEX differences between wind farm projects [70,71]. Nevertheless, developments in unit-upscaling, project size, vessel improvements, improved marine practices and learning has decreased the OPEX over time (in $€$ per MW per year) [72,73]. 2) AEP (a function of CF): Future turbine platforms with larger rotors result in reduced specific power rating for the wind turbines ${ }^{12}$; see Fig. 8 (a). Reduced specific power rating, increased hub heights of turbines, and deploying projects far-offshore with better wind resources will further improve the wind farm's capacity factor $^{13}$ (see Appendix H). The turbine availability for FLOW will be lower in its early commercial deployments due to its excitations at higher wind speeds and wave conditions [74]. However, with experience, improved operation controls will be implemented to diminish these effects for future deployments and existing projects. In overall LCoE development, the capacity factor improvements contribute to $6.7 € / \mathrm{MWh}$ reduction (56\%) for FBOW and 27.4 $€$ /MWh reduction (30\%) for FLOW. As FLOW is expected to be deployed in far-offshore regions with better wind resources, where FBOW is unsuitable, the increased capacity factor resulting from turbines with higher rated power plays a more vital role in offsetting FLOW's higher CAPEX (Fig. 7). 3) Project lifetime: Extending the wind farm projects' economic lifetime increases the long-term profitability for the developers [75]. For FBOW, a project lifetime of 30 years is assumed due to its existing experience and improved understanding of its operation and

\footnotetext{
${ }^{10}$ The average turbine rated power between 2016 and 2020 was roughly 9.5 MW [10]. GE Renewable Energy introduced $12 \mathrm{MW}$ turbine platforms in 2020, with planned deployments in 2023-2025 [93]. Siemens Gamesa announced 14 MW turbine platform in 2020, with commercial use expected by 2024 [94]. Vestas announced 15 MW offshore platform and serial production is expected for 2024 [95].

${ }^{11}$ The learning-by-doing effect is expected to specifically crucial for FLOW as multiple foundation designs exist currently in the prototype stage and a design convergence is essential to initiate mass production of components and standardize necessary technological modifications (e.g., turbine control systems, O\&M strategy, installation techniques).

${ }^{12}$ Specific power rating of wind turbine: Specific power rating of wind turbine relates its capacity to the swept area of its rotor in terms of Watt per square meter. Refer to [96] for more details.

${ }^{13}$ Technological improvements do improve the energy capture and increases the capacity factor. Nevertheless, the better wind resources resulting from the site-characteristics is observed to be a major driver for higher capacity factors (as shown in Appendix H).
} 
performance. Hence, there is no further contribution from the project lifetime factor. For FLOW, a project lifetime of 20 years was assumed for the first GW, 25 years from 1-10 GW, and 30 years after 10+ GW cumulative capacity (see Section 2.4.4). This increased project economic lifetime resulting from operational experience gain will result in a $12.8 € / \mathrm{MWh}$ reduction $(14 \%)$ in the overall LCoE development of FLOW. 4) Cost of Capital ( $\mathrm{CoC}$ ): For capital-intensive technologies such as offshore wind, the discount rate (cost of capital) plays a major role in LCoE [76]. The pricing of FBOW is already competitive in its mature markets due to its experience, market competition, availability of low interest rates, and prevailing regulatory settings [77,78]. Hence, there is no $\mathrm{LCoE}$ reduction expected from this factor. It is to be reminded here that exogenous market conditions like general interest rates, which are considered to be not changing in this study, can alter the influence of $\mathrm{CoC}$ for FBOW (refer to Appendix G). For FLOW, on the other hand, a higher cost of capital is expected for early commercial deployments because of its limited track record, see Fig. 8 (b). However, with experience from the deployments and availability of favourable market conditions (e.g., subsidies and long-term market visibility), the financing expenditures are expected to decline to similar levels observed for FBOW, as shown in Fig. 6. In overall $\mathrm{LCoE}$ development, the $\mathrm{CoC}$ factor contribute to $14.6 € / \mathrm{MWh}$ reduction (16\%) for FLOW.
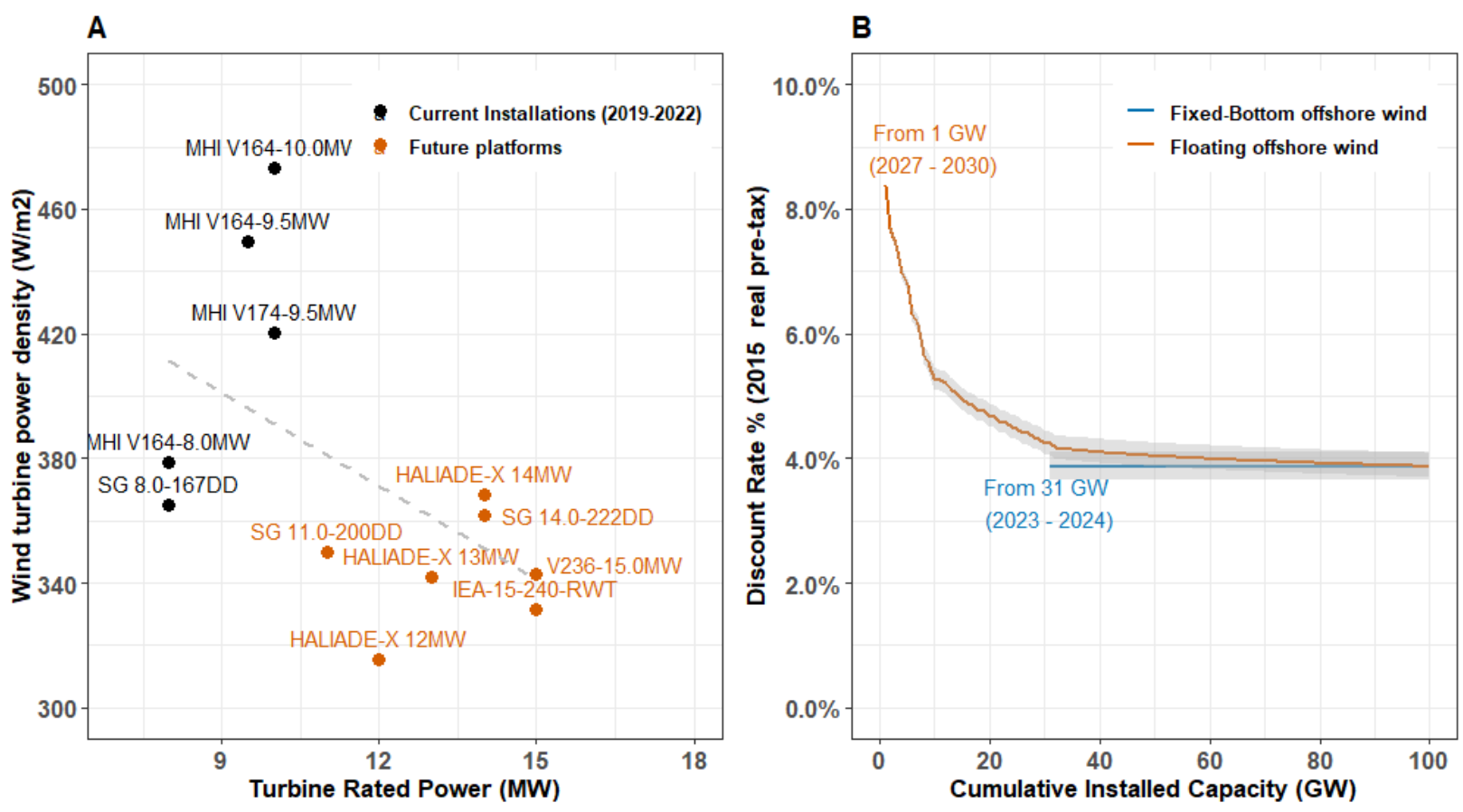

Fig. 8 Drivers of technological learning of offshore wind. a) Power density developments for offshore wind turbines. The dotted line indicates the trend in the reduction of wind turbine power 
density. b) Expected discount rate developments for FBOW and FLOW, based on increasing cumulative capacity (not time). The shaded region in the figure indicates the uncertainty range of the discount rate developments; see Experimental Procedures and Table S6 for further details.

Lastly, to map the LCoE developments through time, deployment projections from the literature and market diffusion process modelled with S-curve are applied, see Appendix K for more details on deployment projections. For FBOW, $96 \pm 9 \mathrm{GW}$ of cumulative capacity could be deployed by 2030 in the EU and UK, with LCoE reaching $28 \pm 3 € / M W h$; see Fig. 9 (a). For FLOW, considerable uncertainties exist on future deployments. 26-130 GW of cumulative capacity is foreseen by 2050 in the EU and UK, with LCoE reaching 27-44 €/MWh; see Fig. 9 (b).
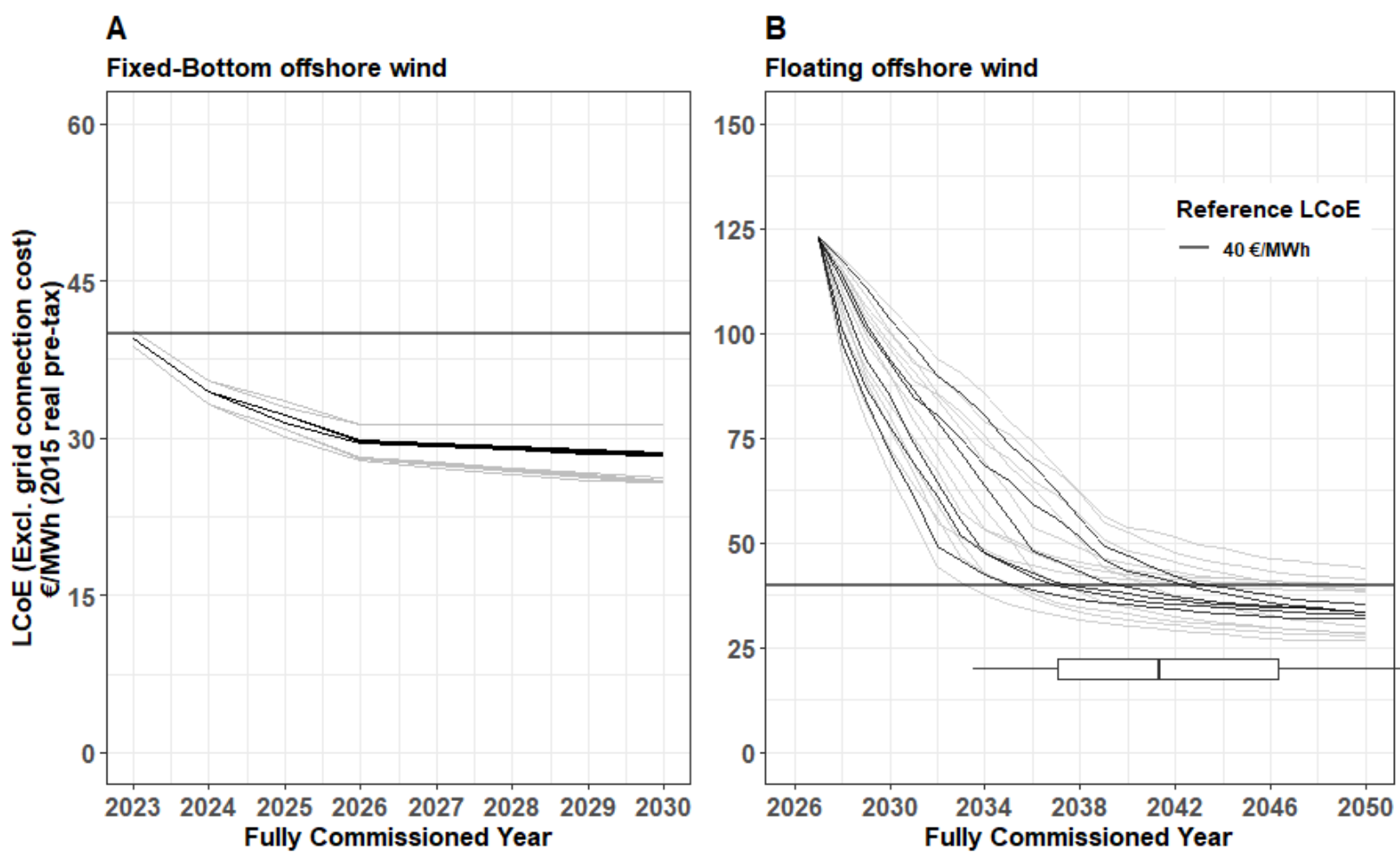

Fig. 9 Mapping LCoE developments for offshore wind technology over time. A) Fixed-Bottom offshore wind LCoE developments projected from 2023 to 2030. B) Floating offshore wind LCoE developments are projected from 2026 to 2050 . Breakeven periods, where floating wind achieves $40 € / \mathrm{MWh}$, observed from the deployment scenario's are summarized using a box plot. 


\subsection{Grid connection cost for offshore wind}

The grid connection costs were estimated separately as Levelized Cost of Transmission (LCoT) to illustrate the influence of site characteristics on offshore wind technology costs (see Experimental Procedures). Fig. 10(a) shows the LCoT for 700 MW High Voltage Alternating Current (HVAC) radial connection as a function of capacity factor and distance to shore. Fig. 10(b) then outlines the increasing LCoT for HVAC radial connections with a distance to shore up to $100 \mathrm{~km}$ and the impact of scale effects. Beyond $100 \mathrm{~km}$, and with increased project capacities (>1 GW), the HVAC systems require additional components like reactive power compensators to reduce the power losses in the export cables $[79,80]$, thereby increasing LCoT for longer distances steeper than the trend shown in Fig. 10(b). High Voltage Direct Current (HVDC) technology is expected to become competitive in such cases, as it is efficient in long-distance bulk power transfers (expensive converter station, but lighter cables, lower losses, and no reactive energy) [81]. Ruijgrok et al. estimated LCoT for radial connections and described the competitiveness of HVDC for long distances. However, the upscaling effects were not considered in their analysis. The study showed the LCoT for HVDC radial connection with a $325 \mathrm{kV}$ DC cable (at $30 \mathrm{~m}$ water depth, assuming fixed-bottom foundation) for distance to shore between 100 and $300 \mathrm{~km}$ in the range of 13-19 $€ / \mathrm{MWh}$, compared to 11-24 €/MWh in the case of HVAC with a $220 \mathrm{kV}$ AC cable [82].
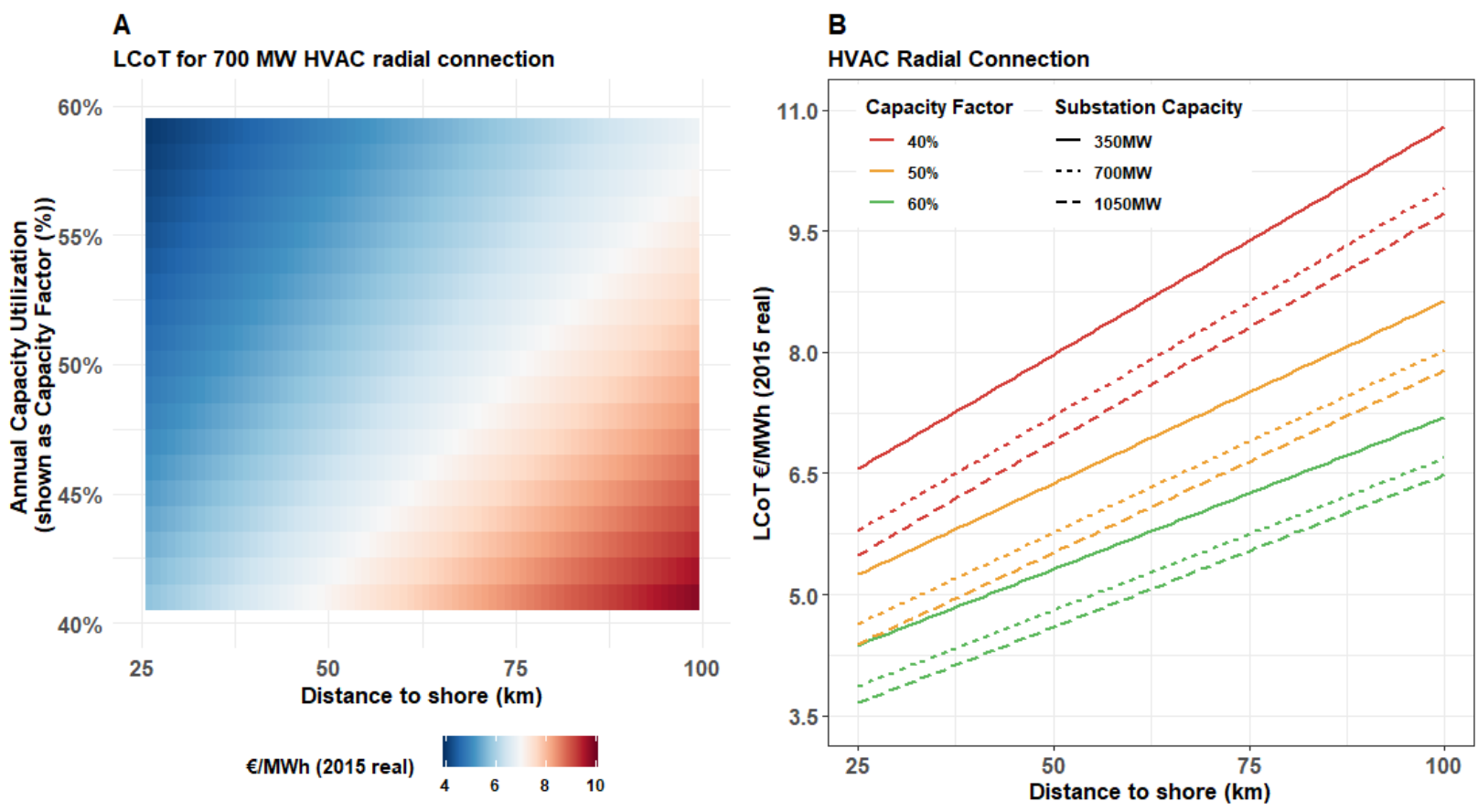
Fig. 10 Grid connection cost for offshore wind. a) LCoT cost matrix estimated for 700 MW HVAC radial connection, as a function of distance to shore and capacity factor. b) Outlining the impacts of distance to shore and upscaled transmission capacity on LCoT.

Besides increasing LCoT with distance to shore, increased deployment targets and rapid installation rates of offshore wind add complexity to integrating them efficiently onto the onshore grid. The complexities include rising spatial constraints for offshore energy infrastructures (subsea cable routes [83]) and the need for long-duration flexibility to manage a high share of renewables [84]. Studies have shown that an integrated offshore grid, with transmission assets serving as grid connection for wind farms and as interconnector, provides more cost advantages through economies of scale, reduces overall environmental impacts, and increases energy security compared to separate radial connections [82,85]. e-Highway2050, a project funded by the European Commission (EC) to analyze the expansion of the pan-European electricity grid, forecasted $336 \mathrm{GW}$ of net transfer capacity (cross-border interconnectors) by 2050 in its $100 \%$ Renewable Energy System scenario. This estimate is roughly a four-fold increase from the capacity in $2020(90 \mathrm{GW})$, and the EC has already pointed out the stalling of interconnector expansion due to existing regulatory barriers. In the event of continued delays, $\mathrm{CO}_{2}$ emissions, variable electricity generation costs, and renewable energy curtailment are expected to increase in the energy system[86]. Moreover, Power-to-Gas and Gas-to-Power conversion routes (e.g., hydrogen) that can re-use existing onshore and offshore gas infrastructures and provide longduration time-shifting flexibility are regarded as promising solutions to reduce offshore wind power curtailments and increase the utilization of transmission systems [85,87]. These challenges and proposed solutions indicate that the integration routes for future large-scale wind farms will be more complex and integrated, especially if the ambitious deployment targets set for offshore wind are to be achieved efficiently. The development of such an integrated grid infrastructure would require coordinated long-term system-level planning, which is currently absent[88].

\section{Conclusions}

Based on the long-term cost assessment presented in this article, five major implications for the offshore wind industry, policymakers, and researchers are discussed below.

First, FBOW is well-established in its mature markets and reaches $40 € / \mathrm{MWh}$ (excl. grid connection cost) by $31 \mathrm{GW}$ of cumulative capacity (2023-2024). FLOW, on the other hand, is an 
emerging variant but shows significant development potential. FLOW could achieve the same progress (40€/MWh, excl. grid connection cost) by deploying roughly $21 \mathrm{GW}$ of cumulative capacity $^{14}$, requiring $€ 44$ billion of learning investment. When the LR uncertainties of FLOW are considered, the breakeven capacity in reaching $40 € / \mathrm{MWh}$ (excl. grid connection cost) ranges from 14-64 GW, requiring 34-70 billion $€$ of learning investment. For comparison, in 2017 alone, the EU-27 countries and the UK provided $€ 65$ billion of subsidies for renewable power generation, including tax expenditures and direct and indirect transfers to compensate price-gap (1 US $\$=0.83$ $€$ ) [64]. This result suggests that providing the learning investments for FLOW in the form of subsidies (e.g., Contracts for Difference, Feed-in-Tariff) through strategic allocation among several countries (preferably in a global context) could fasten the technological progress of FLOW; thereby benefitting economies in achieving their emission reduction targets faster. Moreover, for effective policy actions, more transparency in cost developments of early projects is necessary to identify whether the cost increases (if any) are due to technological barriers or market effects.

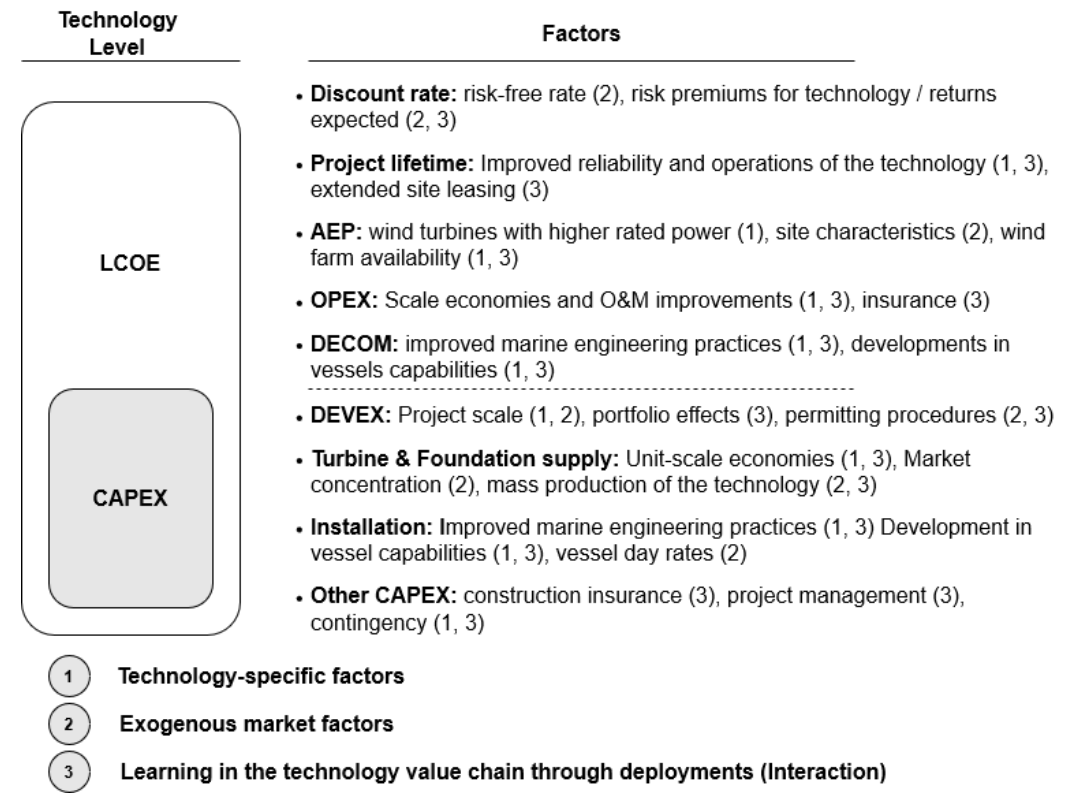

Fig. 11 Summary of factors influencing offshore wind technology developments

\footnotetext{
14 The cost reductions estimated in this study are also compared with forecasts available in the literature. Refer to Appendix L. It is observed that FBOW cost developments in the literature are underestimated. For FLOW, on the other hand, the initial costs illustrating the near-term developments towards 2030 are observed to have been optimistic. In long-term, the FLOW costs estimated in this study are in line with values from literature.
} 
Second, our assessment shows that several factors influence offshore wind technology's cost developments. These factors are categorized into three levels to highlight the multi-dimensional policy effort required to continue the growth of FBOW and successfully commercialize FLOW; see Fig. 11. 1) Technology-specific factors need to be advanced through dedicated R\&D, such as for lighter turbine blades and towers, testing facilities, and O\&M automation. As capacity factor improvements are expected to play a significant role in both FBOW and FLOW developments (see Fig. 7), R\&D efforts towards unit-upscaling, wind farm availability improvements are crucial. 2) Exogenous factors need to be influenced through policy measures that can create a favourable marketplace for the technology deployments, e.g., innovative funding mechanisms that de-risk emerging innovations and increases deployments [89], streamlining permitting procedures [7]. 3) Learning in the technology value chain is also crucial to avoid bottlenecks in realizing the ambitious deployment targets set by the governments. This effect can be influenced by encouraging the development of joint projects (e.g., OEM taking a minority share in projects [7]), passing on the know-how knowledge, and clear communication of technology roadmaps to inform the supply chain about market expectations.

Third, as offshore wind technology costs is expected to decline through learning, grid connection will become a significant cost component. We determined that a complex integrated offshore grid would be needed to overcome the increasing spatial constraints and effectively integrate largescale offshore wind farms onto the onshore grid. The development of such a network demands coordinated long-term system-level planning. However, several barriers, including cross-border regulatory differences, uncertainty in stakeholder responsibilities, and the absence of a multi-actor governance structure, hinder the realization of such a network [88]. For example, the average duration of an electricity transmission PCI (Projects of Common Interest, e.g., interconnectors) in the EU from planning approval until commissioning is about 10 years [90]. Nevertheless, those barriers can be overcome if stakeholders make a timely and concerted effort, as seen in Kriegers Flak - Combined Grid Solution project, a grid network in the Baltic Sea connecting Denmark and Germany via two offshore wind farms [91]. Several grid solutions similar to Kriegers Flak are needed to effectively realize the ambitious deployment targets, demanding policymakers to focus on long-term system-level planning. 
Fourth, emerging technologies spatially diffuse into new markets as they mature with experience and observe cost reductions in their core markets. Several new countries have already shown increased interest in utility-scale deployments of FBOW. This effect is also expected for FLOW. Our results and insights on offshore wind cost developments have global implications. Nevertheless, future studies extrapolating developments in a new market should be cautious about the technology- and market-level differences. For example, the availability of technology (turbines and installation vessels) and local learning (sourcing of electrical components, manufacturing capabilities, and installation practices) can introduce differences in technology's CAPEX. Similarly, market differences, including competition, commodity prices, interest rates, site characteristics, and regulatory settings, can affect the final energy cost in a particular country [7,92]. Realizing these differences and their impacts will benefit the policymakers in designing targeted policy actions to overcome the barriers and effectively stimulate offshore wind's technological progress.

Lastly, by leveraging the merits of bottom-up engineering cost modelling, we overcame the limitations of the experience curve approach in describing the cost drivers and impacts of site characteristics on offshore wind technology costs. However, long-term cost assessment accuracy depends on the LR uncertainties and assumptions applied in bottom-up cost modelling, affected by factors including data limitations, commodity price variations, market shifts[31]. Future studies should incorporate any further growth of offshore wind deployments and price developments in their mature and new markets, floor cost estimation (minimum technology cost estimated using material and production costs alone [31]) in their analysis to account for these changes, and update the cost assessment. It is also suggested that studies apply the cost outlook provided here and perform system-level modelling with increased spatial granularity to assess potential integration

pathways, bottlenecks, and infrastructure and investment needs for offshore wind deployments in future energy systems.

\section{Data Availability}

The dataset and codes generated during this study are available in the Zenodo digital repository. DOI: 10.5281/zenodo.4706023 (https://doi.org/10.5281/zenodo.4706023). 


\section{Supplementary Information}

The appendices mentioned throughout the manuscript are compiled in a separate document as supplementary information, which can be found as an attachment.

\section{Acknowledgments}

This study is part of a research project named ENergy SYStems in TRAnsition (https://ensystra.eu/). ENSYSTRA received funding from the European Union's Horizon 2020 research and innovation program under the Marie Skłodowska-Curie grant agreement No: 765515. This publication reflects only the authors' views, and the Commission cannot be held responsible for any use that may be made of the information contained herein.

As part of the ESR training program, the corresponding author performed a three-month secondment at Shell Global Solutions International B.V, the Netherlands. The author would also like to thank members of Shell Global Solutions International B.V., The Netherlands, for fruitful discussions and the valuable inputs provided during the study. The author would also like to thank the Analysis and Insights Team of ORE Catapult, the UK, who actively contributed to this study, particularly Miriam Noonan and Gavin Smart. The authors would also like to thank the reviewers for their fruitful suggestions, which improved the manuscript.

\section{Author Contributions}

Conceptualization, S.S., C.H., H.M, and A.F.; Methodology, S.S., C.H., H.M., A.F.; Software, S.S.; Formal Analysis, S.S.; Investigation, S.S.; Visualization, S.S.; Writing - Original Draft, S.S.; Writing - Review \& Editing, S.S., C.H., H.M., A.F.; Funding Acquisition, A.F.; Supervision, C.H., H.M., A.F.; Project Administration, H.M., A.F.

\section{Competing Interests}

The authors declare no competing interests. 


\section{References}

[1] Masson-Delmotte V, Zhai P, Pörtner HO, Roberts D, Skea J, Shukla PR, et al. IPCC, 2018 : Summary for Policymakers. In: Global warming of $1.5^{\circ} \mathrm{C}$. An IPCC Special Report on the impacts of global warming of $1.5^{\circ} \mathrm{C}$ above pre-industrial levels and related global greenhouse gas emission pathways, in the context of strengthening the global. World Meteorological Organization, Geneva, Switzerland: 2018.

[2] Jansen M, Staffell I, Kitzing L, Quoilin S, Wiggelinkhuizen E, Bulder B, et al. Offshore wind competitiveness in mature markets without subsidy. Nat Energy 2020;5:614-22. https://doi.org/10.1038/s41560-020-0661-2.

[3] IEA. Offshore Wind Outlook 2019 - World Energy Outlook Special Report. 2019.

[4] European Commission. An EU Strategy to harness the potential of offshore renewable energy for a climate neutral future. Brussels: 2020.

[5] Committe on Climate Change. Net Zero: The UK's contribution to stopping global warming. 2019.

[6] Gusatu LF, Yamu C, Zuidema C, Faaij A. A spatial analysis of the potentials for offshore wind farm locations in the North Sea region: Challenges and opportunities. ISPRS Int J Geo-Information 2020;9:96. https://doi.org/10.3390/ijgi9020096.

[7] IEA-RETD. Comparative Analysis of International Offshore Wind Energy Development REWIND Offshore. 2017.

[8] Wu X, Hu Y, Li Y, Yang J, Duan L, Wang T, et al. Foundations of offshore wind turbines: A review. Renew Sustain Energy Rev 2019;104:379-93. https://doi.org/10.1016/j.rser.2019.01.012.

[9] GWEC. Global Offshore Wind: Annual Market Report 2020. 2020.

[10] Santhakumar S, Smart G, Noonan M, Meerman H, Faaij A. Technological progress observed for fixed-bottom offshore wind in the European markets (Under Review). Technol Forecast Soc Change 2021.

[11] Murphy O. Evidence Log - ORE Catapult Offshore wind. 2017.

[12] Bulder B, Swamy SK, Warnaar PM., van den Brink IDM, de la Vieter ML. Pathways to potential cost reductions for offshore wind energy. 2021.

[13] Musial W, Beiter P, Spitsen P, Nunemaker J, Gevorgian V, Cooperman A, et al. 2019 Offshore Wind Technology Data Update. 2020.

[14] Santhakumar S, Florentina LG, Godoy J de, Gordon RM, Kilmartin A, Faaij A. Opportunities for an efficient future North Sea energy system - the case of the Netherlands. 2021. https://doi.org/10.5281/zenodo.4601586.

[15] Spearman DK, Strivens S, Matha D, Cosack N, Macleay A, Regelink J, et al. Floating Wind Joint Industry Project - Phase 2 summary report. 2020.

[16] Ikhennicheu M, Lynch M, Doole S, Borisade F, Wendt F, Schwarzkopf M-A, et al. 
Corewind D3.1 - Review of the state of the art of dynamic cable system design. 2020.

[17] Ikhennicheu M, Lynch M, Doole S, Borisade F, Matha D, Dominguez JL, et al. Corewind D2.1 - Review of the state of the art of mooring and anchoring designs, technical challenges and identification of relevant DLCs. 2020.

[18] Carbon Trust. Floating Wind Joint Industry Project Phase I Summary Report - Floating Wind JIP. 2018.

[19] ORE Catapult. Floating offshore wind: Cost reduction pathways to subsidy free. 2021.

[20] Freeman K. Floating Offshore. 2017.

[21] DNV GL. Floating Wind: the Power To Commercialize. 2020.

[22] Ioannou A, Angus A, Brennan F. A lifecycle techno-economic model of offshore wind energy for different entry and exit instances. Appl Energy 2018;221:406-24. https://doi.org/10.1016/j.apenergy.2018.03.143.

[23] Judge F, McAuliffe FD, Sperstad IB, Chester R, Flannery B, Lynch K, et al. A lifecycle financial analysis model for offshore wind farms. Renew Sustain Energy Rev 2019;103:370-83. https://doi.org/10.1016/j.rser.2018.12.045.

[24] Valpy B, Freeman K, Roberts A. Future renewable energy costs: offshore wind (Update 2016). 2014.

[25] Wiser R, Rand J, Seel J, Beiter P, Baker E, Lantz E, et al. Expert elicitation survey predicts $37 \%$ to $49 \%$ declines in wind energy costs by 2050. Nat Energy 2021;6:555-65. https://doi.org/10.1038/s41560-021-00810-z.

[26] Meng J, Way R, Verdolini E, Diaz Anadon L. Comparing expert elicitation and modelbased probabilistic technology cost forecasts for the energy transition. Proc Natl Acad Sci 2021;118:e1917165118. https://doi.org/10.1073/pnas.1917165118.

[27] IEA. Technology Innovation to Accelerate Energy Transitions. 2019. https://doi.org/10.1787/ed67526d-en.

[28] Flin D. Connecting Offshore Wind Farms - A Comparison of Offshore Electricity Grid Development Models in Northwest Europe. 2019.

[29] DIW Econ GmbH. Market design for an efficient transmission of offshore wind energy - A study commissioned by Ørsted Offshore Wind. Berlin: 2019.

[30] Santhakumar S, Meerman H, Faaij A. Improving the analytical framework for quantifying technological progress in energy technologies. Renew Sustain Energy Rev 2021;145:111084. https://doi.org/10.1016/j.rser.2021.111084.

[31] Junginger M, Louwen A. Technological Learning in the Transition to a Low-Carbon Energy System. Elsevier; 2020. https://doi.org/10.1016/C2018-0-04547-8.

[32] Bosetti V, Marangoni G, Borgonovo E, Diaz Anadon L, Barron R, McJeon HC, et al. Sensitivity to energy technology costs: A multi-model comparison analysis. Energy Policy 2015;80:244-63. https://doi.org/10.1016/j.enpol.2014.12.012. 
[33] Dowlatabadi H. Sensitivity of climate change mitigation estimates to assumptions about technical change. Energy Econ 1998;20:473-93. https://doi.org/10.1016/s01409883(98)00009-7.

[34] Santhakumar S. Technological learning potential of offshore wind technology and underlying cost drivers (Data, Calculation Models). Zenodo 2021. https://doi.org/10.5281/zenodo.4706023.

[35] Grübler A, Nakićenović N, Victor DG. Dynamics of energy technologies and global change. Energy Policy 1999;27:247-80. https://doi.org/10.1016/S0301-4215(98)00067-6.

[36] Junginger M, Lako P, Lensink S, Weiss M. Technological learning in the energy sector Lessons for Policy, Industry and Science. Netherlands Program Sci Assess Policy Anal Clim Chang 2010:1-190.

[37] Junginger M, Lako P, Lensink S, Van Sark W, Weiss M. Technological learning in the energy sector Scientific Assessment and Policy Analysis for Climate Change (WAB), project technological learning in the energy sector (TLITES). Wetenschappelijke Assessment en Beleidsanalyse (WAB) Klimaatverandering 2008.

[38] Gallagher KS, Grübler A, Kuhl L, Nemet G, Wilson C. The Energy Technology Innovation System. Annu Rev Environ Resour 2012;37:137-62. https://doi.org/10.1146/annurevenviron-060311-133915.

[39] Dedecca JG, Hakvoort RA, Ortt JR. Market strategies for offshore wind in Europe: A development and diffusion perspective. Renew Sustain Energy Rev 2016;66:286-96. https://doi.org/10.1016/j.rser.2016.08.007.

[40] van der Loos HZA, Negro SO, Hekkert MP. International markets and technological innovation systems: The case of offshore wind. Environ Innov Soc Transitions 2020;34:121-38. https://doi.org/10.1016/j.eist.2019.12.006.

[41] Wilson C. Up-scaling, formative phases, and learning in the historical diffusion of energy technologies. Energy Policy 2012;50:81-94. https://doi.org/10.1016/j.enpol.2012.04.077.

[42] Smart G, Smith A, Warner E, Sperstad IB, Prinsen B, Lacal-Arantegui R. IEA Wind Task 26: Offshore Wind Farm Baseline Documentation. 2016. https://doi.org/10.2172/1259255.

[43] Voormolen JA, Junginger HM, van Sark WGJHM. Unravelling historical cost developments of offshore wind energy in Europe. Energy Policy 2016;88:435-44. https://doi.org/10.1016/j.enpol.2015.10.047.

[44] Beiter P, Musial W, Smith A, Kilcher L, Damiani R, Maness M, et al. A Spatial-Economic Cost- Reduction Pathway Analysis for U.S. Offshore Wind Energy Development from 2015-2030. Natl. Renew. Energy Lab., 2016, p. 214.

[45] IEA/OECD. Experience Curves for Energy Technology Policy. International Energy Agency; 2000. https://doi.org/10.1787/9789264182165-en.

[46] Samadi S. The experience curve theory and its application in the field of electricity generation technologies - A literature review. Renew Sustain Energy Rev 2018;82:234664. https://doi.org/10.1016/j.rser.2017.08.077. 
[47] Tardieu P, Vandenberghe A. ETIPWind Roapmap. 2019.

[48] Malhotra A, Schmidt TS. Accelerating Low-Carbon Innovation. Joule 2020;4:2259-67. https://doi.org/10.1016/j.joule.2020.09.004.

[49] European Technology \& Innovation Platform on Wind Energy. ETIP Wind Roadmap 2019. https://etipwind.eu/roadmap/.

[50] ORE Catapult. Offshore Wind Innovation Hub 2021. https://offshorewindinnovationhub.com/.

[51] Rubin ES, Yeh S, Antes M, Berkenpas M, Davison J. Use of experience curves to estimate the future cost of power plants with CO2capture. Int J Greenh Gas Control 2007;1:188-97. https://doi.org/10.1016/S1750-5836(07)00016-3.

[52] IEA. Projected Costs of Generating Electricity. Paris: 2020.

[53] Egli F, Steffen B, Schmidt TS. A dynamic analysis of financing conditions for renewable energy technologies. Nat Energy 2018;3:1084-92. https://doi.org/10.1038/s41560-0180277-y.

[54] PwC. Offshore wind cost reduction pathways study - Finance work stream. 2012.

[55] DNV GL. Potential to improve Load Factor of offshore wind farms in the UK to 2035. 2019.

[56] Noonan M. Delivering 40GW - Accelerating the UK's Transition to Net Zero. ORE Catapult 2020. https://ore.catapult.org.uk/blog/delivering-40gw-accelerating-the-ukstransition-to-net-zero/ (accessed February 9, 2021).

[57] Bergvall D. Cost Comparison of Repowering Alternatives for Offshore Wind Farms. Uppsala University, 2019.

[58] Offshore Wind Innovation Hub. Operations \& Maintenance: Cost Drivers (Industry Insights Series). 2019.

[59] Department of Business Energy and Industrial Strategy. Cost Estimation and Liabilities in Decommissioning Offshore Wind Installations Public Report. 2018.

[60] Koivisto MJ, Gea-Bermúdez J. NSON-DK energy system scenarios - Edition 2. 2018.

[61] Cole S, Martinot P, Rapoport S, Papaefthymiou G, Gori V. Study of the Benefits of a Meshed Offshore Grid in Northern Seas Region. 2014.

[62] IRENA. Renewable Power Generation Costs in 2019. 2019.

[63] Market Observatory for Energy of the European Commission. Quarterly Report on European Electricity Markets (Volume 13 - third quarter of 2020). vol. 13. 2021.

[64] Taylor M. Energy subsidies: Evolution in the global energy transformation to 2050. 2020.

[65] Crome T. Hywind Demo - Technip Experience with Offshore Wind. 2010.

[66] Brommundt M, Krause L, Merz K, Muskulus M. Mooring system optimization for floating wind turbines using frequency domain analysis. Energy Procedia 2012;24:289-96. 
https://doi.org/10.1016/j.egypro.2012.06.111.

[67] Fontana C. A Multiline Anchor Concept for Floating Offshore Wind Turbines. University of Massachusetts Amherst, 2019.

[68] Cribbs A, Kärrsten G, Laud M, Fiand F, Broadbent S. Overview of anchoring solutions and smart installation methods for offshore floating wind. n.d.

[69] Shields M, Beiter P, Nunemaker J, Cooperman A, Duffy P. Impacts of turbine and plant upsizing on the levelized cost of energy for offshore wind. Appl Energy 2021;298:117189. https://doi.org/10.1016/j.apenergy.2021.117189.

[70] Ørsted A/S. Ørsted Capital Markets Day 2018 (Presentation). 2018.

[71] Offshore Wind Innovation Hub. Floating wind: Cost modelling of major repair strategies. 2020.

[72] IREA. Renewable Power Generation Costs in 2020. 2020.

[73] Lacal-Arántegui R, Yusta JM, Domínguez-Navarro JA. Offshore wind installation: Analysing the evidence behind improvements in installation time. Renew Sustain Energy Rev 2018;92:133-45. https://doi.org/10.1016/j.rser.2018.04.044.

[74] Barter GE, Robertson A, Musial W. A systems engineering vision for floating offshore wind cost optimization. Renew Energy Focus 2020;34:1-16. https://doi.org/10.1016/j.ref.2020.03.002.

[75] AFRY af Pöyry. The business case and supporting interventions for Dutch offshore wind 2020.

[76] Hundleby G. Never mind the technology - feel the WACC What is WACC and why is it important for LCOE? How are projects achieving low WACC ? 2017.

[77] Green Giraffe. Recent trends in offshore wind finance. 2019.

[78] Credit Suisse. Global Offshore Wind - Propelling up the value chain. 2018.

[79] Ørsted. Hornsea Project One - Presentation for Ofgem OFTO TR6 Launch Event. 2018.

[80] Curvers APW., Pierik JT. ORECCA Project, Task 3: Grid Integration Aspects (WP3: Technology). 2011.

[81] Xiang X, Merlin MMC, Green TC. Cost analysis and comparison of HVAC, LFAC and HVDC for offshore wind power connection. IET Conf Publ 2016;2016:1-6.

[82] Ruijgrok ECM, van Druten EJ, Bulder BH. Cost Evaluation of North Sea Offshore Wind Post 2030. 2019.

[83] NorthSEE. The role of MSP and MSP issues for grid development / spatial implications. NorthSEE n.d. https://northsearegion.eu/northsee/e-energy/the-role-of-msp-for-griddevelopment-spatial-implications/ (accessed April 1, 2021).

[84] Weichenhain U, Elsen S, Zorn T, Kern S. Hybrid projects : How to reduce costs and space of offshore developments North Seas Offshore Energy Clusters study. 2019. 
[85] North Sea Wind Power Hub Consortium. Integration routes North Sea offshore wind 2050 - A quantitative insight into possible grid integration routes, including sector coupling, to facilitate large scale offshore wind roll-out. 2020.

[86] Ritter D, Meyer R, Koch M, Haller M, Bauknecht D, Heinemann C. Effects of a delayed expansion of interconnector capacities in a high RES-E European electricity system. Energies 2019;12. https://doi.org/10.3390/en12163098.

[87] Blanco H, Nijs W, Ruf J, Faaij A. Potential for hydrogen and Power-to-Liquid in a lowcarbon EU energy system using cost optimization. Appl Energy 2018;232:617-39. https://doi.org/10.1016/j.apenergy.2018.09.216.

[88] Gorenstein Dedecca J, Lumbreras S, Ramos A, Hakvoort RA, Herder PM. Expansion planning of the North Sea offshore grid: Simulation of integrated governance constraints. Energy Econ 2018;72:376-92. https://doi.org/10.1016/j.eneco.2018.04.037.

[89] Schmidt TS, Steffen B, Egli F, Pahle M, Tietjen O, Edenhofer O. Adverse effects of rising interest rates on sustainable energy transitions. Nat Sustain 2019;2:879-85. https://doi.org/10.1038/s41893-019-0375-2.

[90] ACER. Consolidated Report on the progress of electricity and gas Projects of Common Interest (2020). 2020.

[91] Energinet. Kriegers Flak - Combined Grid Solution 2021. https://en.energinet.dk/Infrastructure-Projects/Projektliste/KriegersFlakCGS (accessed April 5, 2021).

[92] Steffen B. Estimating the cost of capital for renewable energy projects. Energy Econ 2020;88:104783. https://doi.org/10.1016/j.eneco.2020.104783.

[93] GE Renewable Energy. GE Haliade-X 12 MW offshore wind turbine platform 2020. https://www.ge.com/renewableenergy/wind-energy/offshore-wind/haliade-X-offshoreturbine (accessed March 10, 2020).

[94] SGRE. SG 14-222 DD 2020. https://www.siemensgamesa.com/en-int/products-andservices/offshore/wind-turbine-sg-14-222-dd (accessed August 21, 2020).

[95] Vestas. Vestas V236-15.0 MW 2021. https:/www.vestas.com/en/products/offshoreplatforms/v236_15_mw\#!technical-specifications (accessed July 18, 2021).

[96] Bolinger M, Lantz E, Wiser R, Hoen B, Rand J, Hammond R. Opportunities for and challenges to further reductions in the "specific power" rating of wind turbines installed in the United States. Wind Eng 2021;45:351-68. https://doi.org/10.1177/0309524X19901012. 


\section{Supplementary Material}

\section{Technological learning potential of offshore wind technology and underlying cost drivers}

Srinivasan Santhakumar ${ }^{1,2, *}$, Clara Heuberger-Austin ${ }^{3}$, Hans Meerman ${ }^{1}$, André Faaij ${ }^{1,4}$

${ }^{1}$ Energy and Sustainability Research Institute Groningen, University of Groningen, Groningen, 9747 AG, The Netherlands

${ }^{2}$ Lead Contact

${ }^{3}$ Shell Global Solutions International B.V., Amsterdam, 1031 HW, The Netherlands

${ }^{4}$ Netherlands Organization for Applied Scientific Research - TNO Energy Transition, Utrecht, 3584 CB, The Netherlands

*Correspondence: s.santhakumar@rug.nl 


\section{Appendix A: Offshore wind technology mature markets}

By the end of 2020, 67\% of global fixed-bottom offshore wind capacity ( $\sim 36 \mathrm{GW})$ were installed in the EU and UK (mainly in the North Sea basin [1]), with the rest of the global share in China (30\%) and other countries (3\%). In China, the largest market outside of the EU and UK, the turbine supply, learning in installation (geographic differences), and sourcing of balance of plant (local learning) is different, compared to the EU and UK market[2]. Turbine supply for wind farms in China are made through regional Original Equipment Manufacturers (OEMs), and the development is more focused on learning-by-doing (unit-upscaling is limited compared to EU and UK market)[2]. Besides, emerging markets like Taiwan and the US are expected to benefit from the technological progress and expertise developed in the European region [3-5]. Hence, the learning prospects for fixed-bottom offshore wind (FBOW, water depth: 0-60 m) and floating wind (FLOW, water depth $>\sim 60 \mathrm{~m}$ ) in the EU and UK are considered in this study. The EU and UK markets are also referred to as mature markets of offshore wind in this study.

The deployment of FBOW is expected to grow strongly in the North Sea, Baltic Sea, and several other EU coastal regions. For FLOW, deeper water areas, including the northern region of the North Sea basin, Mediterranean sea, the Celtic sea, are of primary interest (e.g., Scotland, Norway, Spain, Portugal, France, Greece) [6]. The figure below shows the North Sea basin water depth profile, categorized to indicate the potential deployment regions for offshore wind variants. The northern region is more suited for FLOW, and the southern region with shallow waters is suited for FLOW deployments. 


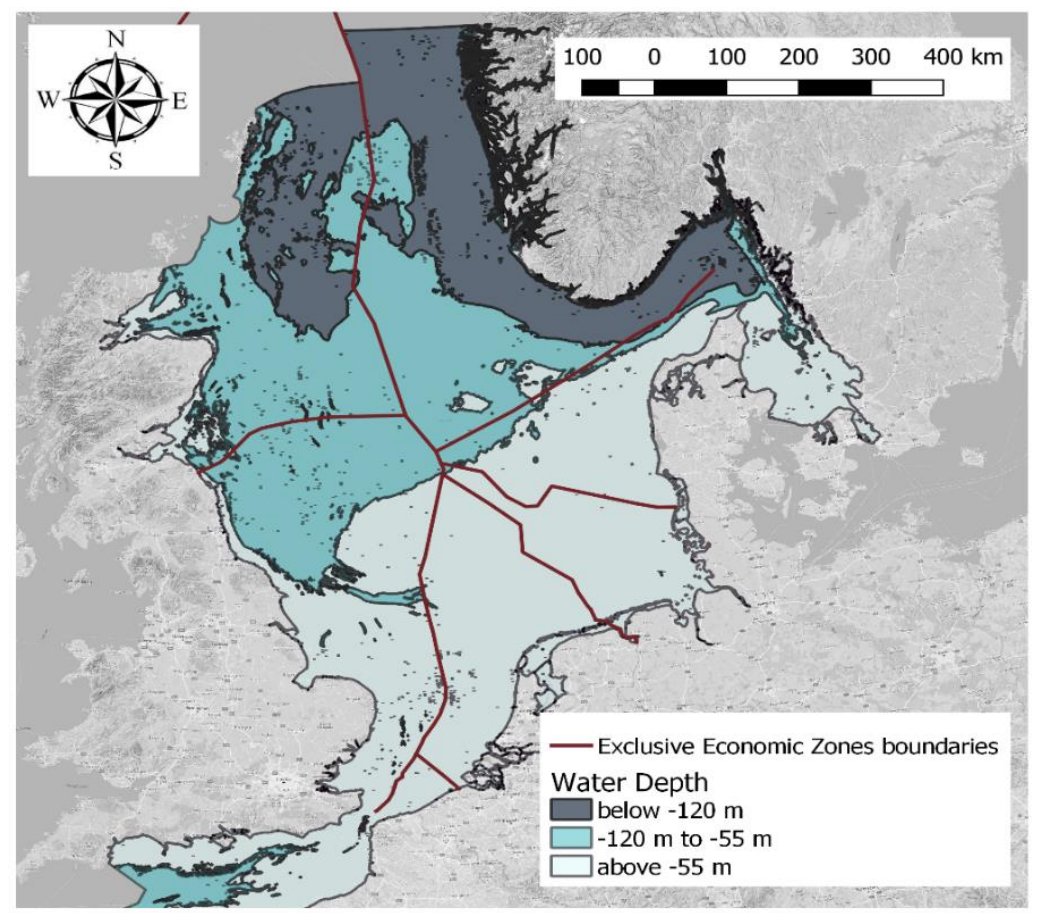

Bathymetry data for North Sea basin (water depth categorized in three levels to indicate potential deployment regions for FBOW and FLOW) [7] 


\section{Appendix B: Comparing pros and cons of different floater foundation technologies[2,8-10]}

Material needs (e.g., primary steel) and manufacturing complexity of the foundations are scored based on the summary. Indications for the score: 1 - lightweight structure/easy for serial manufacturing, 4 - heavy structure/complex for serial manufacturing). Moreover, the Potential convergence of the foundation design is not ranked/scored because it is influenced by several location-specific or exogenous factors, including manufacturing capabilities and local content (if any), besides the foundation designs' technical advantages.

\begin{tabular}{|c|c|c|}
\hline Floating Foundation va & Pros & Cons \\
\hline $\begin{array}{l}\text { Tension leg platform (TLP) } \\
\text { TLP is a semi-submerged large buoyant } \\
\text { structure that is restrained to the seabed } \\
\text { by a tension-leg mooring system. } \\
\text { Material needs (Score): } 1 \\
\text { Manufacturing Complexity (Score): } 3\end{array}$ & $\begin{array}{l}\text { - Shallow draft and tension stability (low } \\
\text { motions) allow for a smaller and lighter } \\
\text { structure } \\
\text { - Very good water depth flexibility, as they can } \\
\text { be installed in relatively shallow to very deep } \\
\text { waters } \\
\text { - TLP designs can be assembled onshore or in } \\
\text { a dry dock }\end{array}$ & $\begin{array}{l}\text { - Complex installation procedure (require } \\
\text { specialized vessels to ensure the stability of the } \\
\text { structure during transit and installation) } \\
\text { - The design allows for increased stresses on the } \\
\text { tendon and anchor system (large vertical loading } \\
\text { increases the operational risks of the system, e.g., } \\
\text { mooring failure) } \\
\text { - Depending on the seabed specifications, anchors } \\
\text { choices vary among gravity-based, suction, or } \\
\text { pile-driven }\end{array}$ \\
\hline $\begin{array}{l}\text { Semi-submersible } \\
\text { Large waterplane (buoyancy) stabilized } \\
\text { structure with a relatively shallow draft. }\end{array}$ & 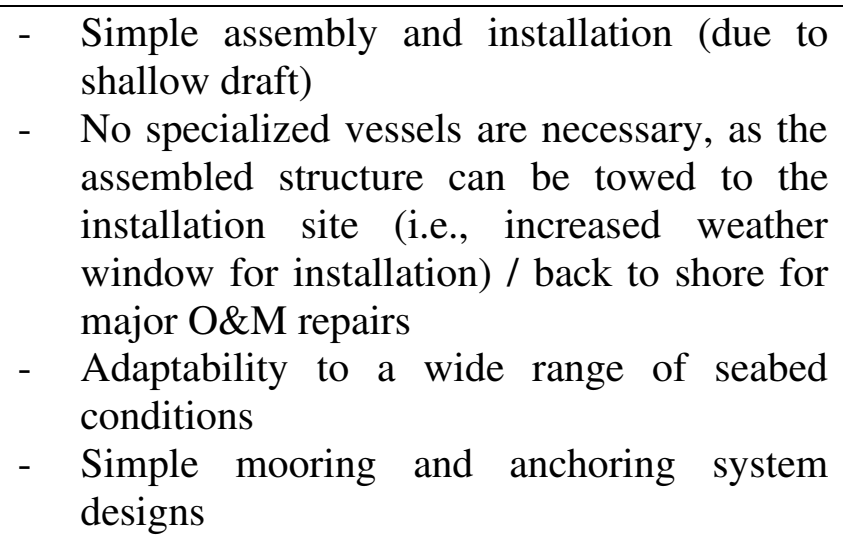 & 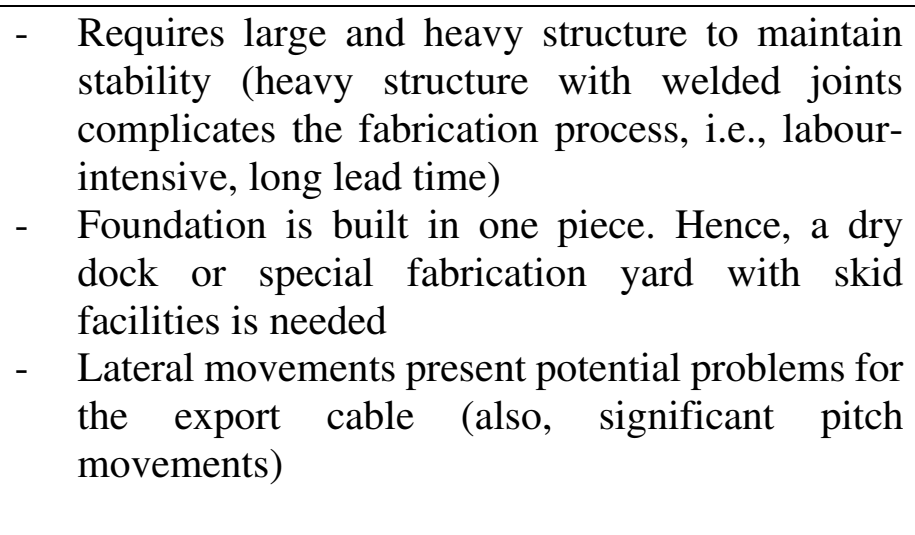 \\
\hline
\end{tabular}




\begin{tabular}{|c|c|c|}
\hline $\begin{array}{l}\text { Barge } \\
\text { (Similar to semi-submersible, with the } \\
\text { shallowest draft of both) } \\
\text { Material needs (Score): } 3 \\
\text { Manufacturing Complexity (Score): } 1\end{array}$ & $\begin{array}{l}\text { - Shallow operating draft (Installation, O\&M } \\
\text { advantages similar to the semi-submersible } \\
\text { type) } \\
\text { - } \begin{array}{l}\text { Simple construction and potential for serial } \\
\text { manufacturing } \\
\text { - }\end{array} \\
\text { Adaptability to a wide range of seabed } \\
\text { conditions }\end{array}$ & 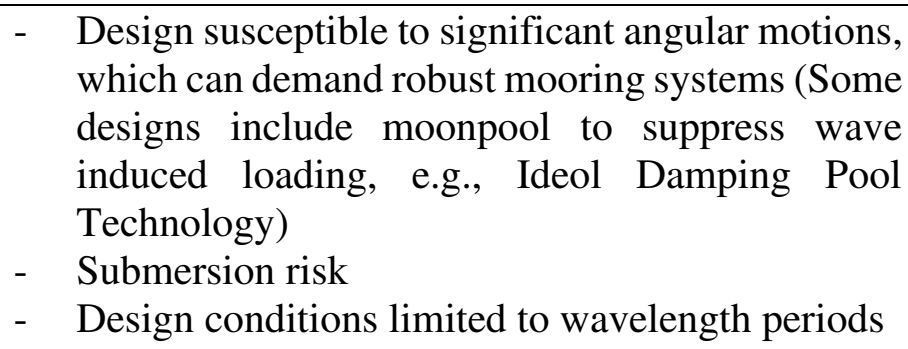 \\
\hline $\begin{array}{l}\text { Spar } \\
\text { Spar is a cylindrical ballast-stabilized } \\
\text { structure (buoyancy) with a small } \\
\text { waterplane area and a large vertical } \\
\text { distance between its centre of gravity } \\
\text { and centre of buoyancy, which } \\
\text { counteracts the inclining moment and } \\
\text { stabilizes the platform. } \\
\text { Material needs (Score): } 4 \\
\text { Manufacturing Complexity (Score): } 2\end{array}$ & $\begin{array}{l}\text { - Provides better structural stability and } \\
\text { insensitive to seabed conditions } \\
\text { - The manufacturing process is } \\
\text { straightforward, as it is a long, slender } \\
\text { welded structure without complex parts } \\
\text { - Potential for serial manufacturing, which can } \\
\text { yield manufacturing-scale economies }\end{array}$ & 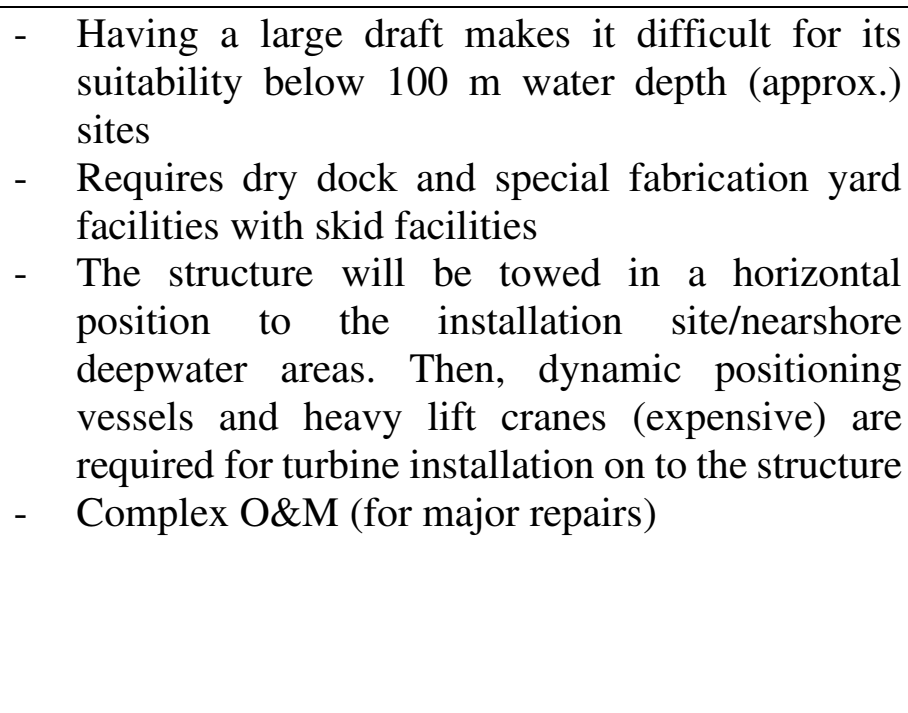 \\
\hline
\end{tabular}




\section{Appendix C: The technological progress of offshore wind}

a) Generic illustration of energy technology innovation process. The figure also indicates the main stages, characteristics, and drivers across each development stage [11-13] b) Unit- (turbine rated power) and industry-upscaling (market growth) observed for FBOW in its mature markets [14]. After 2010, rapid unit-upscaling was observed for offshore wind turbines. Turbine manufacturers also made recent announcements for 15+MW offshore wind turbines[15] (expected deployments after 2025). Such developments are expected to bring wind farm cost down and increase annual energy production. Nevertheless, studies have also noted that turbine upscaling is outpacing the development of installation technologies (vessels, cranes) required to install them. Therefore, potential sites (market demand), added advantages to the balance of plant and technical barriers will determine the saturation limit of turbine upscaling. 
a)

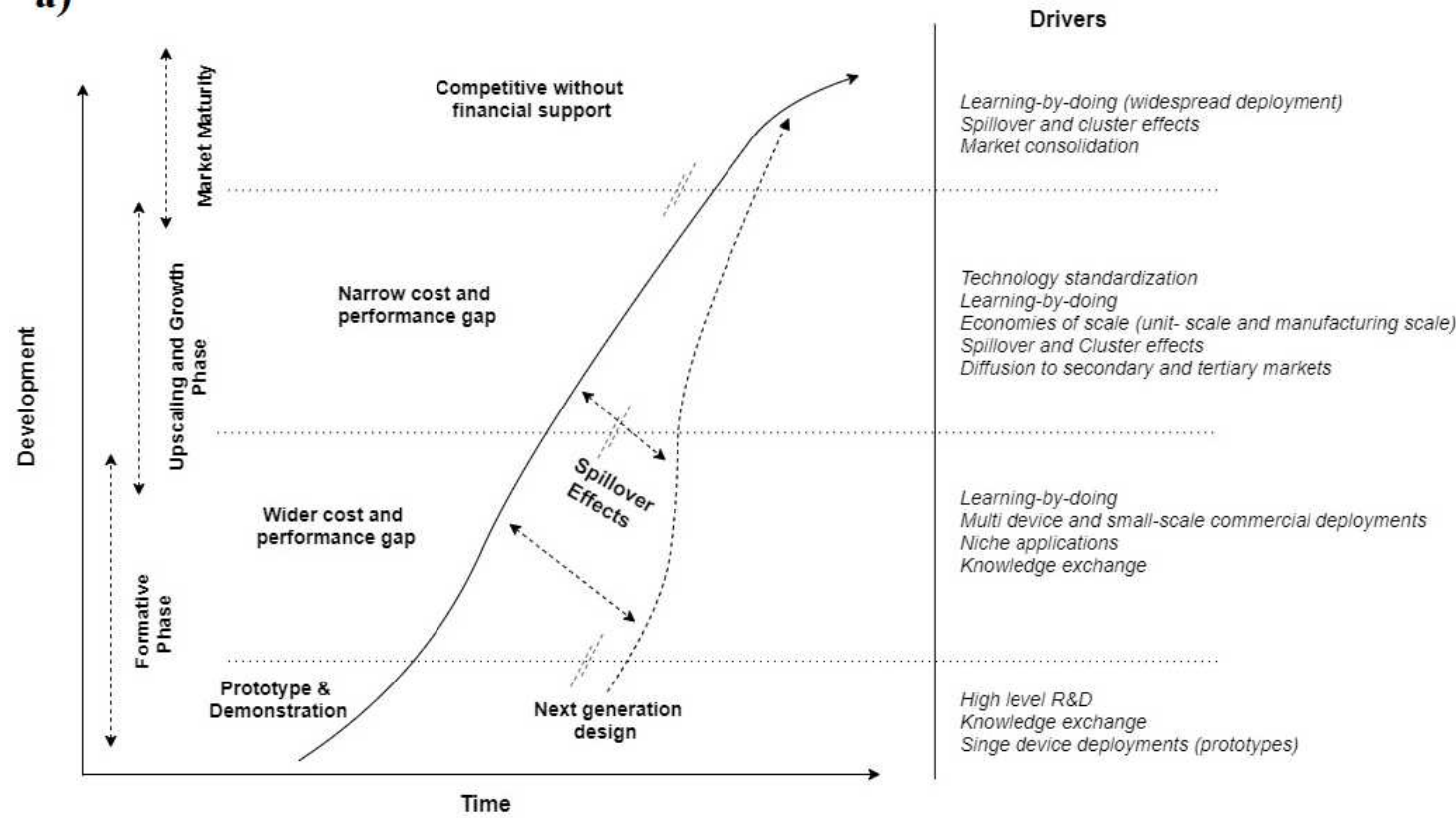

b)

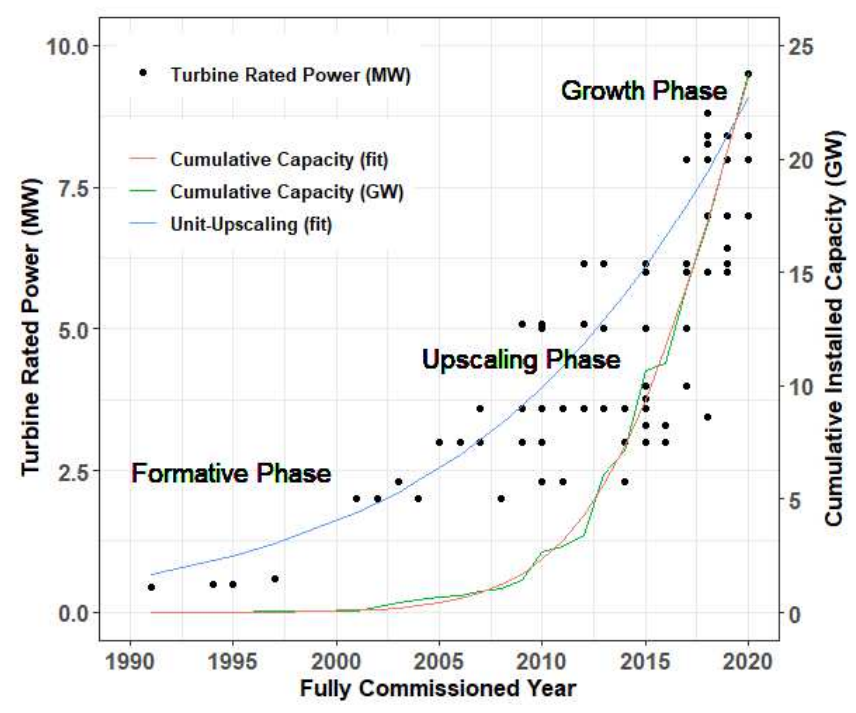




\section{Appendix D: Offshore wind farm characteristics assumed for CAPEX estimation}

The characteristics are referred from the available data and literature $[2,16]$.

\begin{tabular}{|l|c|c|}
\hline \multicolumn{1}{|c|}{ Characteristics } & FBOW & $\begin{array}{c}\text { FLOW } \\
\text { (first large-scale commercial } \\
\text { project) }\end{array}$ \\
\hline $\begin{array}{l}\text { Fully commissioned year } \\
\text { (Expected) }\end{array}$ & $2023-2024$ & $2027-2030$ \\
\hline Farm size (MW) & 1020 & $300[17]$ \\
\hline $\begin{array}{l}\text { Turbine Nameplate Capacity } \\
\text { (MW) }\end{array}$ & 12 & 12 \\
\hline Water Depth (m) & 40 & 100 \\
\hline $\begin{array}{l}\text { Distance to construction port } \\
\text { (km) }\end{array}$ & 90 & 40 \\
\hline Foundation type & Monopile (Steel) & 220 \\
\hline Rotor Diameter (m) & 220 & 135 \\
\hline Hub height (m) & 135 & 66 \\
\hline Inter-array cable voltage (kV) & 66 & 3 \\
\hline $\begin{array}{l}\text { No of mooring lines \& anchor } \\
\text { points per wind turbine (\#) }\end{array}$ & - & Semi-Sub (Steel) \\
\hline
\end{tabular}




\section{Appendix E: Cost assumptions made in this study to estimate CAPEX}

All the cost assumptions mentioned below are assumed to be in 2015 real terms.

\begin{tabular}{|c|c|c|c|c|}
\hline \multirow[b]{2}{*}{$\begin{array}{c}\text { Cost } \\
\text { Components }\end{array}$} & \multicolumn{2}{|c|}{$\begin{array}{l}\text { Fixed-Bottom Offshore Wind (FBOW) } \\
\text { (Assumptions outlined here can be found in Santhakumar et al.[14] ) }\end{array}$} & \multicolumn{2}{|c|}{ Floating Offshore Wind (FLOW) } \\
\hline & Assumptions & Comments & Assumptions & Comments and source \\
\hline $\begin{array}{l}\text { Development } \\
\text { (DEVEX) }\end{array}$ & $80 \mathrm{k} € / \mathrm{MW}$ & $\begin{array}{l}\text { Assumption referred from a } \\
\text { report on UK's FBOW } \\
\text { offshore wind developments } \\
{[18]}\end{array}$ & $156 \mathrm{k} € / \mathrm{MW}$ & $\begin{array}{l}\text { For projects in the early } \\
\text { development stage, the } \\
\text { development cost is higher due } \\
\text { to the high proportion of fixed } \\
\text { costs involved. With wind farm } \\
\text { size expected to scale up in the } \\
\text { future, as the technology } \\
\text { evolves, the development cost } \\
\text { will decline in specific } \\
\text { terms[19,20]. }\end{array}$ \\
\hline $\begin{array}{l}\text { Turbine } \\
\text { Supply }\end{array}$ & $1.35 \mathrm{M} € / \mathrm{MW}$ & $\begin{array}{l}\text { Offshore wind turbine prices } \\
\text { are influenced by market } \\
\text { concentration, commodity } \\
\text { prices, rated power of the } \\
\text { turbine, scale of purchase, }\end{array}$ & $1.5 \mathrm{M} € / \mathrm{MW}$ & $\begin{array}{l}\text { Wind turbines for floating wind } \\
\text { include adjustments to } \\
\text { compensate floater motions at } \\
\text { sea (tower and control } \\
\text { software). FLOW turbine price }\end{array}$ \\
\hline
\end{tabular}




\begin{tabular}{|c|c|c|c|c|}
\hline & & $\begin{array}{l}\text { and supply contract terms } \\
\text { [14]. Parametric relations } \\
\text { used in literature to estimate } \\
\text { turbine price neglects the } \\
\text { factors stated above (derived } \\
\text { from mature onshore wind } \\
\text { turbine industry)[21,22]. }\end{array}$ & & $\begin{array}{l}\text { is inflated from the FBOW } \\
\text { turbine assumption to account } \\
\text { for these modifications and } \\
\text { reduced scale of purchase } \\
\text { (smaller project sizes in the near } \\
\text { term) [23]. }\end{array}$ \\
\hline $\begin{array}{l}\text { Foundation } \\
\text { Supply }\end{array}$ & 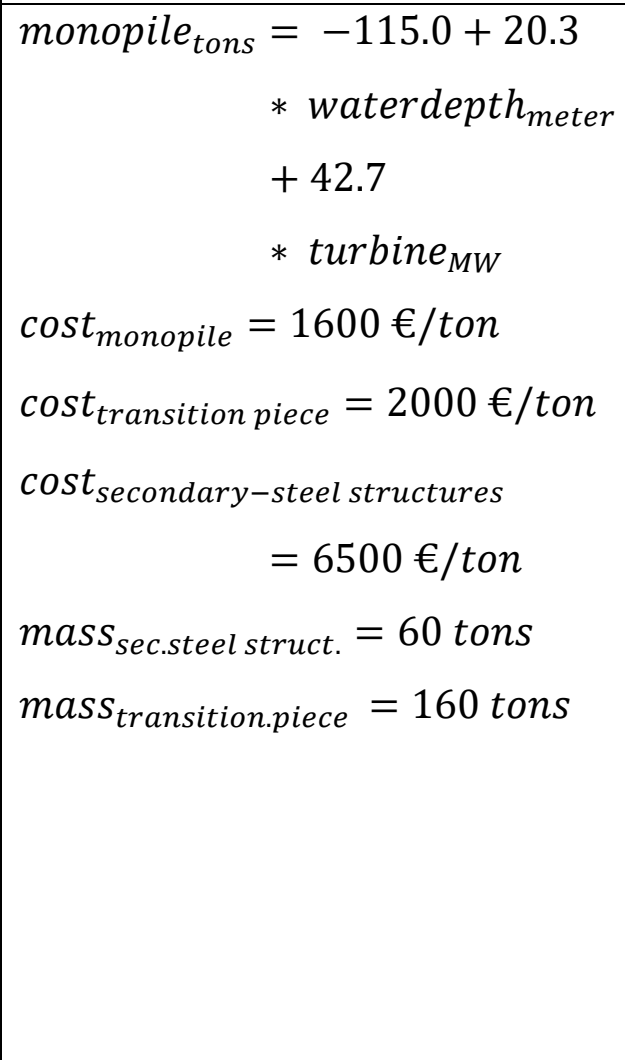 & $\begin{array}{l}\text { Foundation supply cost is } \\
\text { estimated as shown below, } \\
\text { cost }_{\text {foundation }} \\
=\text { cost }_{\text {monopile }} \\
+ \text { cost }_{\text {transition.piece }} \\
+ \text { cost }_{\text {sec.steel struct. }} \\
\text { The cost of monopile, } \\
\text { transition piece, and } \\
\text { secondary steel structures is } \\
\text { calculated by multiplying the } \\
\text { component mass (tons) with } \\
\text { supply cost ( } € / \text { ton). }\end{array}$ & 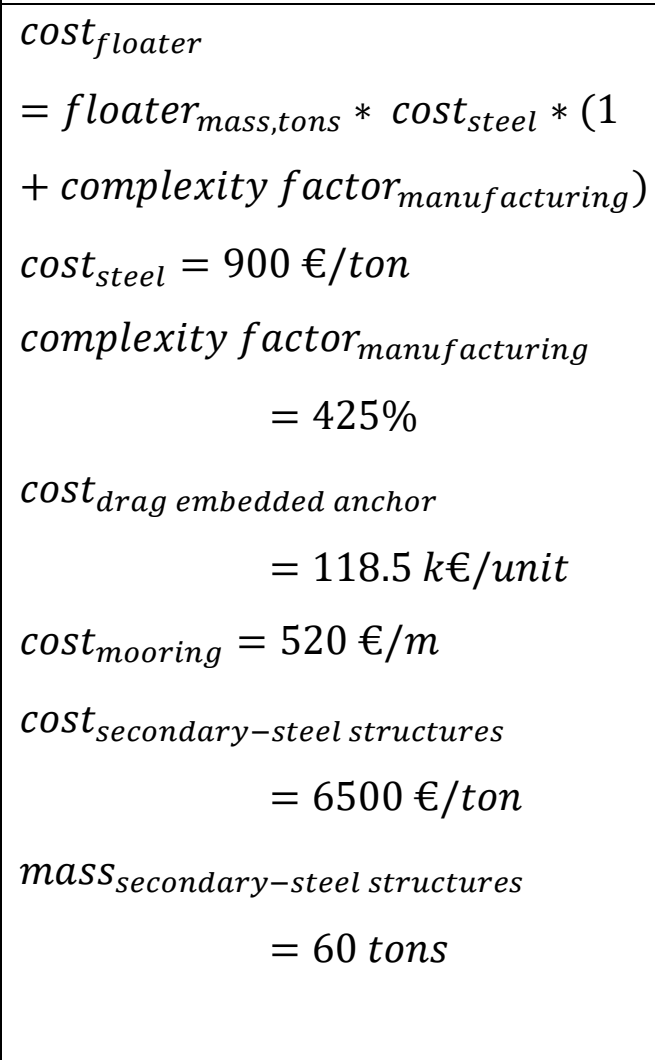 & 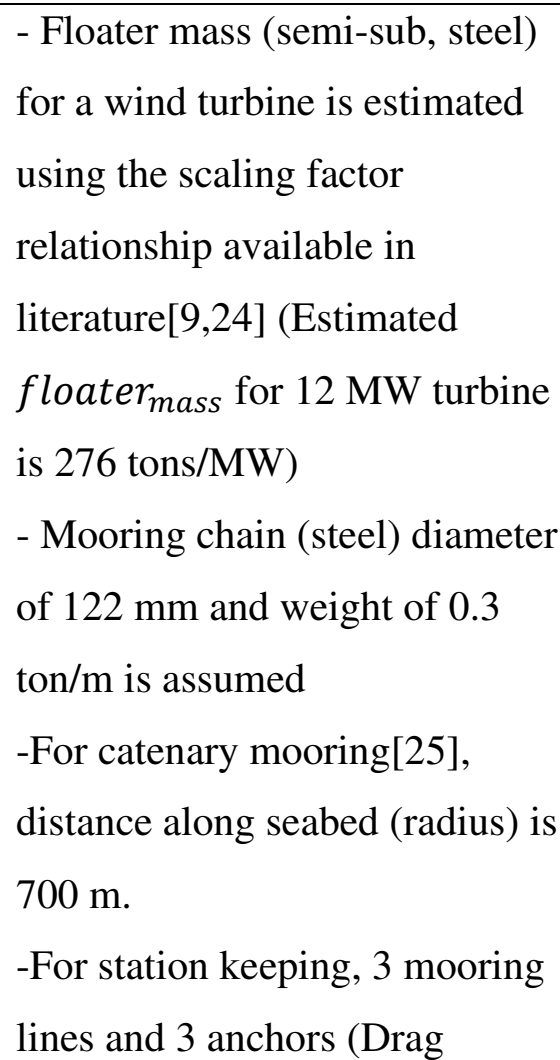 \\
\hline
\end{tabular}




\begin{tabular}{|c|c|c|c|c|}
\hline & & & $\begin{array}{l}\text { Mooring length } \text { unit }= \\
\text { (water depth }+ \\
\text { distance along seabed) } * 1.4 \text {. } \\
\text { The } 40 \% \text { extra length is assumed } \\
\text { required to form a catenary shape in } \\
\text { the mooring system. }\end{array}$ & $\begin{array}{l}\text { embedded anchor) per wind } \\
\text { turbine is assumed }\end{array}$ \\
\hline $\begin{array}{l}\text { Electrical } \\
\text { Infra. } \\
\text { (Excluding } \\
\text { grid } \\
\text { connection) }\end{array}$ & $\begin{array}{l}\text { Row spacing }=5 \\
\quad * \text { rotor diameter } \\
\text { String spacing }=9 * \\
\text { rotor diameter } \\
\text { Inter - array cable voltage } \\
=66 \mathrm{kV} \text { (in } 2 \text { sizes }) \\
\text { Cost }_{66 \mathrm{kV}, 630 \mathrm{~mm} 2}=425 € / \mathrm{m} \\
\text { Cost }_{66 \mathrm{kV}, 240 \mathrm{~mm} 2}=200 € / \mathrm{m} \\
\text { cost }_{\text {elec.infra. }}=\text { cost }_{\text {cable }} \\
\quad * \text { length }_{\text {cable }}\end{array}$ & $\begin{array}{l}\text { - For simplification, the wind } \\
\text { farm is modelled as a } \\
\text { rectangular grid } \\
\text { - Only static cables are } \\
\text { assumed for fixed-bottom } \\
\text { offshore wind } \\
\text { - The inter-array cable section } \\
\text { closest to the substation } \\
\text { system collects the total } \\
\text { power produced by the wind } \\
\text { turbines connected to them, } \\
\text { requiring a higher current } \\
\text { carrying capacity. Generally, } \\
\text { two cable sizes are used in } \\
\text { the wind farm to reduce } \\
\text { costs[26,27]. }\end{array}$ & $\begin{array}{l}\text { Row spacing }=7 \\
\quad * \text { rotor diameter } \\
\text { String spacing }=9 * \\
\text { rotor diameter } \\
\text { Inter - array cable voltage } \\
\quad=66 \mathrm{kV} \text { (in } 2 \text { sizes }) \\
\text { Cost }_{\text {dynamic cable }} \\
\quad=\text { Cost }_{\text {static cable }} \\
* 1.4 \\
\text { cost }_{\text {elec.infra. }}=\text { cost }_{\text {cable }} \\
* \text { length }_{\text {cable }}\end{array}$ & $\begin{array}{l}\text { Dynamic cables are used from } \\
\text { the floater to the seabed } \\
\text { connection point, and then, the } \\
\text { static cables are assumed along } \\
\text { the seabed[28]. } \\
\text { - Dynamic cables for FLOW are } \\
\text { assumed } 40 \% \text { more expensive } \\
\text { than the static cables (In } \\
\text { literature, more conservative } \\
\text { estimates can be found. i.e., } 66 \\
\text { kV dynamic cables will be } 60- \\
90 \% \text { expensive than the static } \\
\text { cables[28]) }\end{array}$ \\
\hline
\end{tabular}




\begin{tabular}{|c|c|c|c|c|}
\hline $\begin{array}{l}\text { Installation } \\
\text { Expenditure }\end{array}$ & $\begin{array}{l}L R_{\text {foundation,installation }}=7.92 \% \\
(11.97 \%, \text { if only monopiles are } \\
\text { considered) } \\
L R_{\text {turbine, installation }}=-3.24 \% \\
\text { (if corrected for turbine rated } \\
\text { capacity, LR increases to } 10.37 \%) \\
\text { For LR estimation procedure, please } \\
\text { refer to [14] } \\
\text { The LR assumptions result in no. of } \\
\text { days for the turbine, } \\
\text { Days per foundation = 3.03 days } \\
\text { Days per turbine }=4.25 \text { days }\end{array}$ & 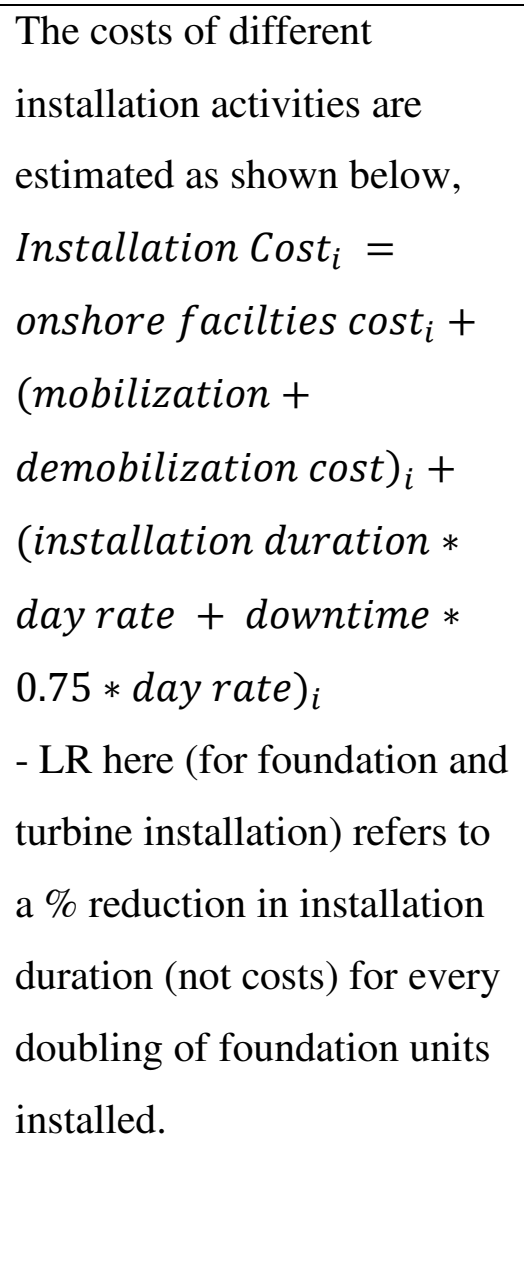 & $\begin{array}{l}\text { No of AHTS vessel }=1 \\
\text { No of tug boats }=2\end{array}$ & $\begin{array}{l}\text { - Day rates, mobilization, and } \\
\text { demobilization costs of } \\
\text { installation vessels are assumed } \\
\text { from a past study [29] (1€= } \\
0.83 £ \text { is assumed) } \\
\text { - The methodology described by } \\
\text { Bjerkseter and Ågotnes[30] for } \\
\text { installation of wind turbine and } \\
\text { floater (semi-sub steel floater) is } \\
\text { followed here, with altered } \\
\text { operational window assumption } \\
\text { for offshore activities (50\%) and } \\
\text { onshore activities (75\%). } \\
\text { - The cost estimation methods } \\
\text { for other installation activities, } \\
\text { including seabed preparation, } \\
\text { inter-array cable, are referred } \\
\text { from Santhakumar et al.[14] }\end{array}$ \\
\hline $\begin{array}{l}\text { Other } \\
\text { CAPEX }\end{array}$ & $\begin{array}{l}\text { insurance }_{\text {construction }} \\
\qquad=45000 € / M W \\
\text { Project Management: } 5 \% \text { of } \\
\text { (turbine supply cost }+ \text { foundation }\end{array}$ & $\begin{array}{l}\text { Other CAPEX } \\
=\text { insurance }_{\text {construction }} \\
+ \text { project management } \\
+ \text { contingency }\end{array}$ & $\begin{array}{l}\text { insurance }_{\text {construction }} \\
\qquad=48000 € / M W \\
\text { Project Management: same as } \\
\text { fixed-bottom }\end{array}$ & $\begin{array}{l}\text { Inflated assumption of } \\
\text { construction insurance and } \\
\text { contingency reflects the } \\
\text { limited track record of the } \\
\text { technology in the market } \\
\text { [31]. }\end{array}$ \\
\hline
\end{tabular}




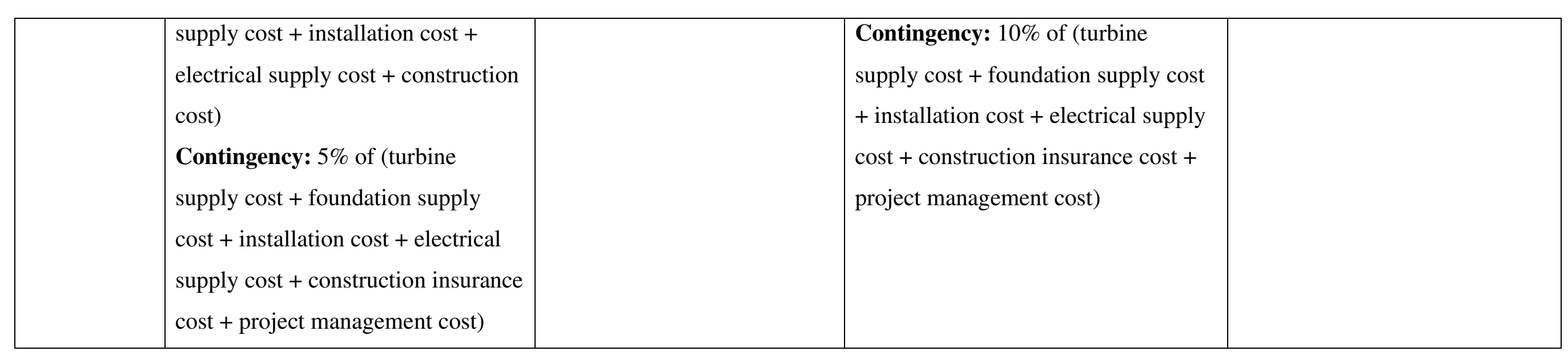




\section{Appendix F: Fixed-bottom offshore wind LR estimation}

\begin{tabular}{|c|c|}
\hline Markets focused & Denmark, Netherlands, Belgium, Germany, United Kingdom \\
\hline Data & $\begin{array}{l}\text { Period: } 1990 \text { - } 2020 \\
\text { Data Collection Method \& Sources: For UK, the annual accounts of the } \\
\text { registered companies (i.e., offshore wind SPV's) from Companies } \\
\text { House[32] are used to estimate the UK wind farm's CAPEX. For other } \\
\text { countries, the CAPEX estimates of wind farms are taken from past } \\
\text { literature. Refer to Santhakumar et al. [14] for a detailed description of the } \\
\text { data collection approach. } \\
\text { Data Availability: https://doi.org/10.5281/zenodo.4302588 }\end{array}$ \\
\hline $\begin{array}{l}\text { Boundary of } \\
\text { analysis }\end{array}$ & $\begin{array}{l}\text { The investment cost of transmission asset is deducted from the wind farm } \\
\text { total CAPEX to align with the cost breakup followed in this study (see } \\
\text { Methods section in the main article). }\end{array}$ \\
\hline $\begin{array}{l}\text { Experience } \\
\text { curve model }\end{array}$ & $\begin{array}{l}\text { We apply the single-factor experience curve model (SFEC) to quantify the } \\
\text { overall progress of FBOW in an aggregated manner (and not separate site- } \\
\text { characteristics effects using multi-factor experience curve models). For } \\
\text { such reasons, low } \mathrm{R}^{2} \text { were found in the SFEC model. After that, the } \\
\text { observed LR is applied to project future CAPEX costs. } \\
\text { Response Variable in experience curve model: Wind farm CAPEX, excl. } \\
\text { grid connection cost (M€ } M^{-1} \text { ) } \\
\text { Explanatory Variable in experience curve model: Cumulative installed } \\
\text { capacity (MW) }\end{array}$ \\
\hline Data uncertainty & $\begin{array}{l}\text { - Ideally, the experience curve relation should be derived using the } \\
\text { technology's cost and its cumulative output. Due to the data } \\
\text { unavailability issues, the market price is often used as a proxy for } \\
\text { technology cost to estimate LR's. Nevertheless, it is to be noted that the } \\
\text { market price is influenced by many internal (-firm) and external (- } \\
\text { market) factors, which can introduce bias in LR estimation. Without } \\
\text { data on the relation between technology price and cost, it is difficult to } \\
\text { isolate this bias. Here, } 30 \text { years of FBOW technology data is used to } \\
\text { estimate the LR, and the uncertainties, including the market effects } \\
\text { mentioned above, are accounted for by calculating a 95\% confidence } \\
\text { interval for LR based on standard error. Further, the future CAPEX } \\
\text { costs are projected from the CAPEX estimated through bottom-up } \\
\text { engineering cost modelling (reflecting near-term deployment } \\
\text { characteristics), and the LR-based projections are not extrapolated }\end{array}$ \\
\hline
\end{tabular}




\begin{tabular}{|c|c|}
\hline & $\begin{array}{l}\text { backwards to fit the future and past developments together (as in market } \\
\text { shake-out phase, LR's can be distorted by market effects }[13,33]) \text {. } \\
\text { - Data after } 2.5 \mathrm{GW} \text { of cumulative installed capacity is used to derive LR. } \\
\text { This threshold assumption is used to neglect the influence of early cost } \\
\text { overruns, commonly observed for large-scale energy technologies and } \\
\text { process systems [14,34]. }\end{array}$ \\
\hline $\begin{array}{l}\text { Model fit \& LR } \\
\text { observed }\end{array}$ & $\begin{array}{l}n_{\text {observations }}=65, R^{2}=0.06, p-\text { value }=0.04, \sigma=0.045 \\
\mathrm{LR}=6.22 \% \\
95 \% \text { confidence interval based on standard error is calculated to illustrate } \\
\text { LR uncertainty, } \mathrm{LR}=6.22 \pm 6 \% \text {. }\end{array}$ \\
\hline $\begin{array}{l}\text { The potential } \\
\text { impact of site } \\
\text { characteristics } \\
\text { on future } \\
\text { CAPEX costs }\end{array}$ & $\begin{array}{l}\text { The potential impact of not considering multi-factor experience curve } \\
\text { model outputs (which separates the influences of site characteristics from } \\
\text { overall developments) in our cost outlook is discussed below, } \\
\text { - As indicated earlier (the boundary of the analysis, see Methods), the } \\
\text { transmission cost is excluded from the CAPEX. This exclusion limits } \\
\text { the influence of distance to shore effect on future CAPEX costs } \\
\text { (although installation in farther challenging sites can introduce } \\
\text { difficulties in installation, past study shows no considerable impacts } \\
\text { were observed in installation durations because of distance to shore } \\
\text { factor [35]). } \\
\text { The water depth variations influence the fixed-bottom offshore wind } \\
\text { foundation designs (monopiles, jackets) and their material needs. } \\
\text { Nevertheless, the deployment of higher-rated turbines (10+ MW } \\
\text { expected for future projects) results in negligible deviations in wind } \\
\text { farm CAPEX on a per MW basis, as shown by Santhakumar et al.[14]. }\end{array}$ \\
\hline
\end{tabular}




\section{Appendix G: Assumptions for discount rate estimation}

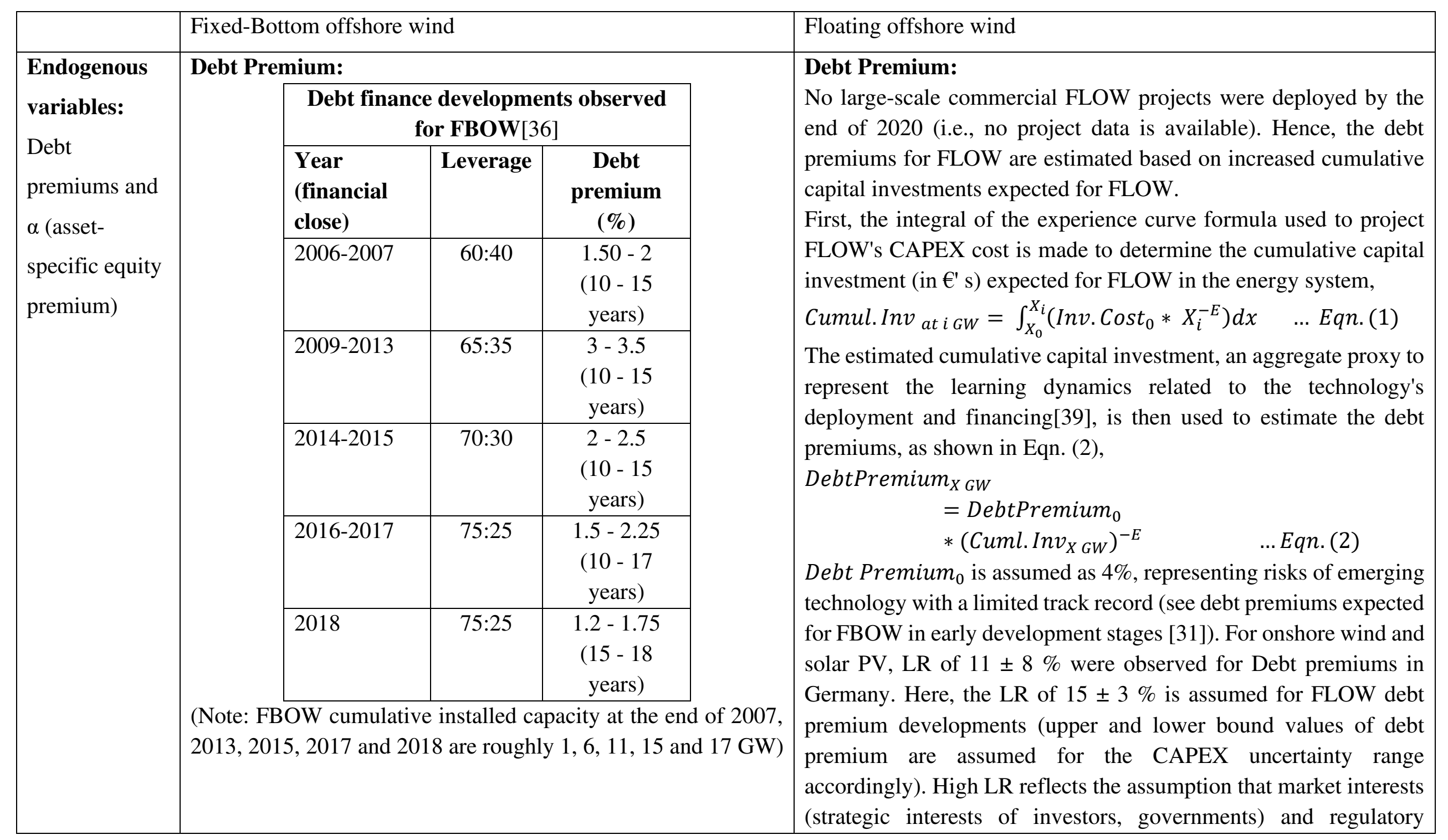




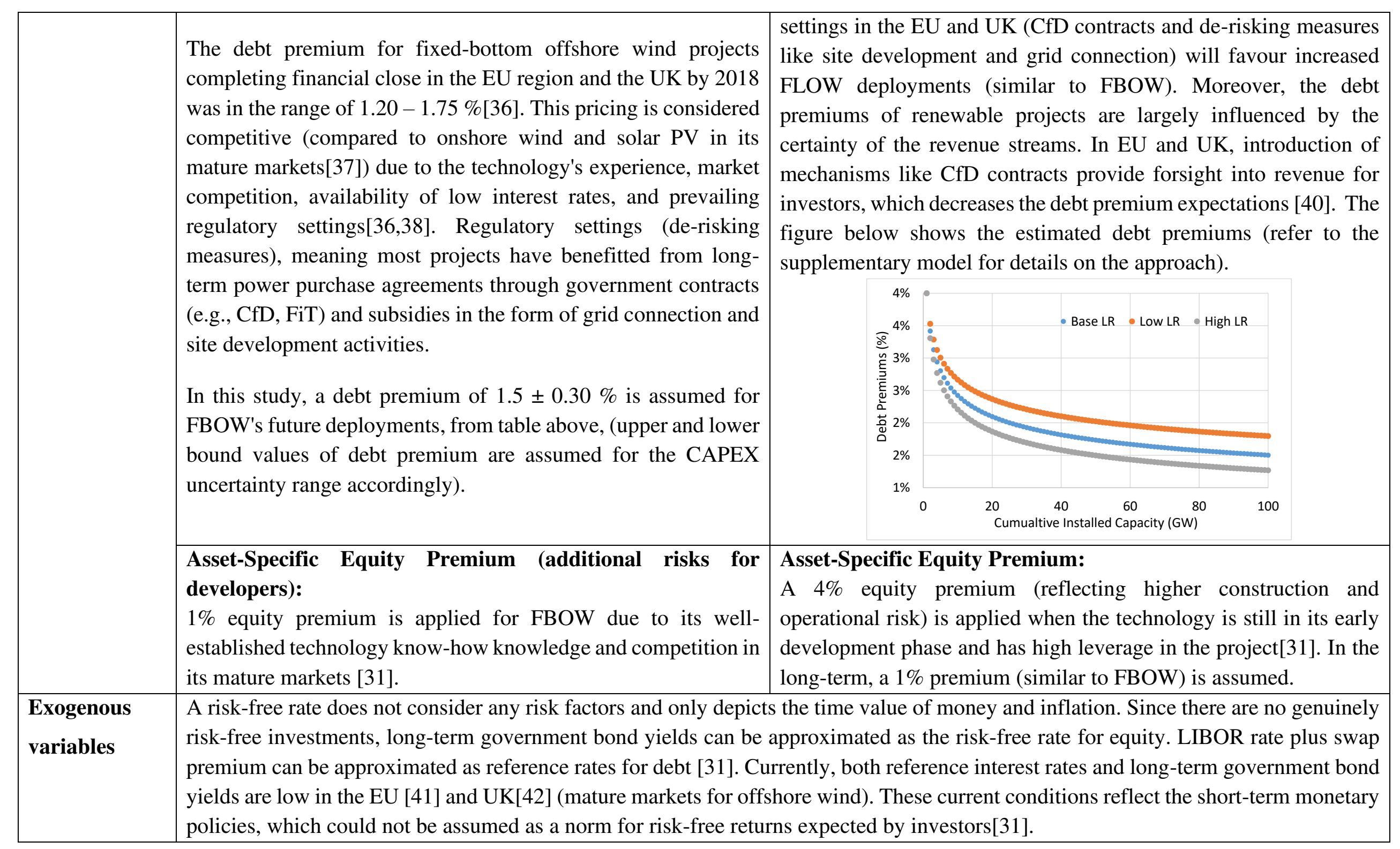




\begin{tabular}{|c|c|c|c|}
\hline $\begin{array}{l}\text { (reference/risk- } \\
\text { free rates and } \\
\text { EMRP) }\end{array}$ & \multicolumn{3}{|c|}{$\begin{array}{l}\text { Moreover, the long-term technology cost developments are estimated based on increased cumulative capacity (not based on time). } \\
\text { Hence, the discount rate formula's exogenous variables are kept constant, reflecting the long-term average returns expected by the } \\
\text { investors. The assumptions are[31], } \\
\text { Reference rate for cost of debt }=3.5 \%, \text { Risk - free rate for cost of equity }=4.5 \%, \\
\text { Estimated Market Risk Premium }(E M R P)=6 \% \text {, Inflation (implied) }=2 \%\end{array}$} \\
\hline \multirow[t]{7}{*}{$\begin{array}{l}\text { Debt share } \\
\text { assumptions } \\
(\delta, \text { in } \%)\end{array}$} & $\begin{array}{l}\text { Cumulative } \\
\text { installed } \\
\text { capacity }\end{array}$ & Debt share & \\
\hline & At $1 \mathrm{GW}$ & $0 \%$ & \\
\hline & At $2,3 \mathrm{GW}$ & $40 \%$ & \\
\hline & At $4,5 \mathrm{GW}$ & $50 \%$ & \\
\hline & At $6,7 \mathrm{GW}$ & $60 \%$ & \\
\hline & At $8,9 \mathrm{GW}$ & $70 \%$ & \\
\hline & From $10 \mathrm{GW}$ & $75 \%$ & \\
\hline $\begin{array}{l}\text { Uncertainties } \\
\text { in the } \\
\text { discount rate }\end{array}$ & \multicolumn{3}{|c|}{$\begin{array}{l}\text { In estimating the discount rate, two assumptions were made. 1) Exogenous elements in the discount rate are constant 2) Market interests } \\
\text { and regulatory settings in the EU and UK will favour increased FLOW deployments (similar to FBOW). When these assumptions } \\
\text { change, i.e., exogenous factors (base interest rates, inflation) changes or offshore wind market becomes uncertain on policies (no long- } \\
\text { term market visibility for the technology, no/limited subsidy support for emerging technologies, presence of merchant risks), the } \\
\text { discount rate can change. To showcase the influence of varying discount rates, we estimated FLOW LCoE at a } 0 \% \text { discount rate } \\
\text { (representing actual LCoE when there are no financing expenditures) and } 1 \text { to } 9 \% \text { discount rates. The difference of the LCoE at a } \\
\text { discount rate (say, for example, } 5 \% \text { discount rate) from the base LCoE (0\% discount rate) is regarded as financing expenditures for } \\
\text { FLOW. When the technology is emerging, limited market support or uncertain market settings can increase the returns expected by } \\
\text { the developers, thereby increasing the final LCoE of the technology in the system. }\end{array}$} \\
\hline
\end{tabular}




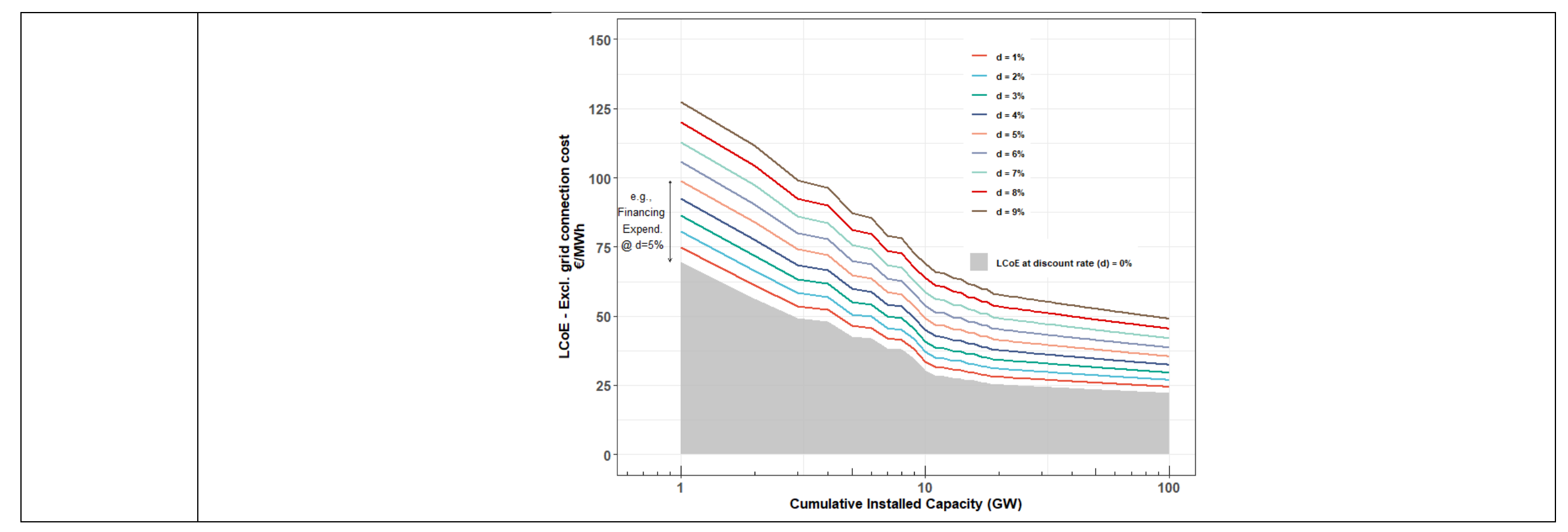




\section{Appendix H: Expected Capacity Factor Developments}

\begin{tabular}{|c|c|}
\hline & ns \\
\hline $\begin{array}{l}\text { Estimating } \\
\text { wind farm }\end{array}$ & 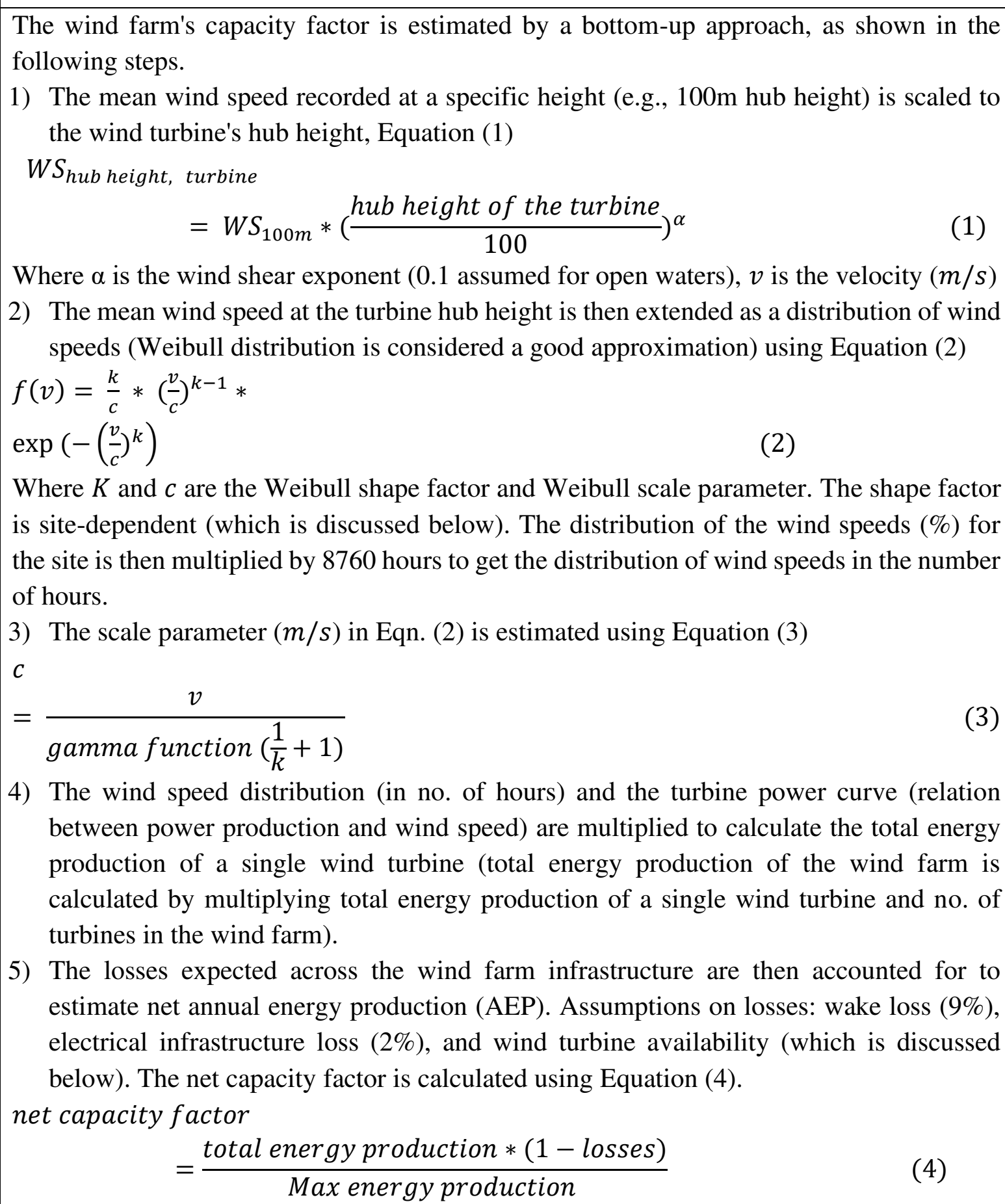 \\
\hline & $\begin{array}{l}\text { Power curves of offshore wind turbines are often not publicly available compared to onshore } \\
\text { wind turbines. Theoretical models are available in peer-reviewed literature[43], from which } \\
\text { extrapolations can be made. Here, two power curves, one representing current deployments }\end{array}$ \\
\hline
\end{tabular}




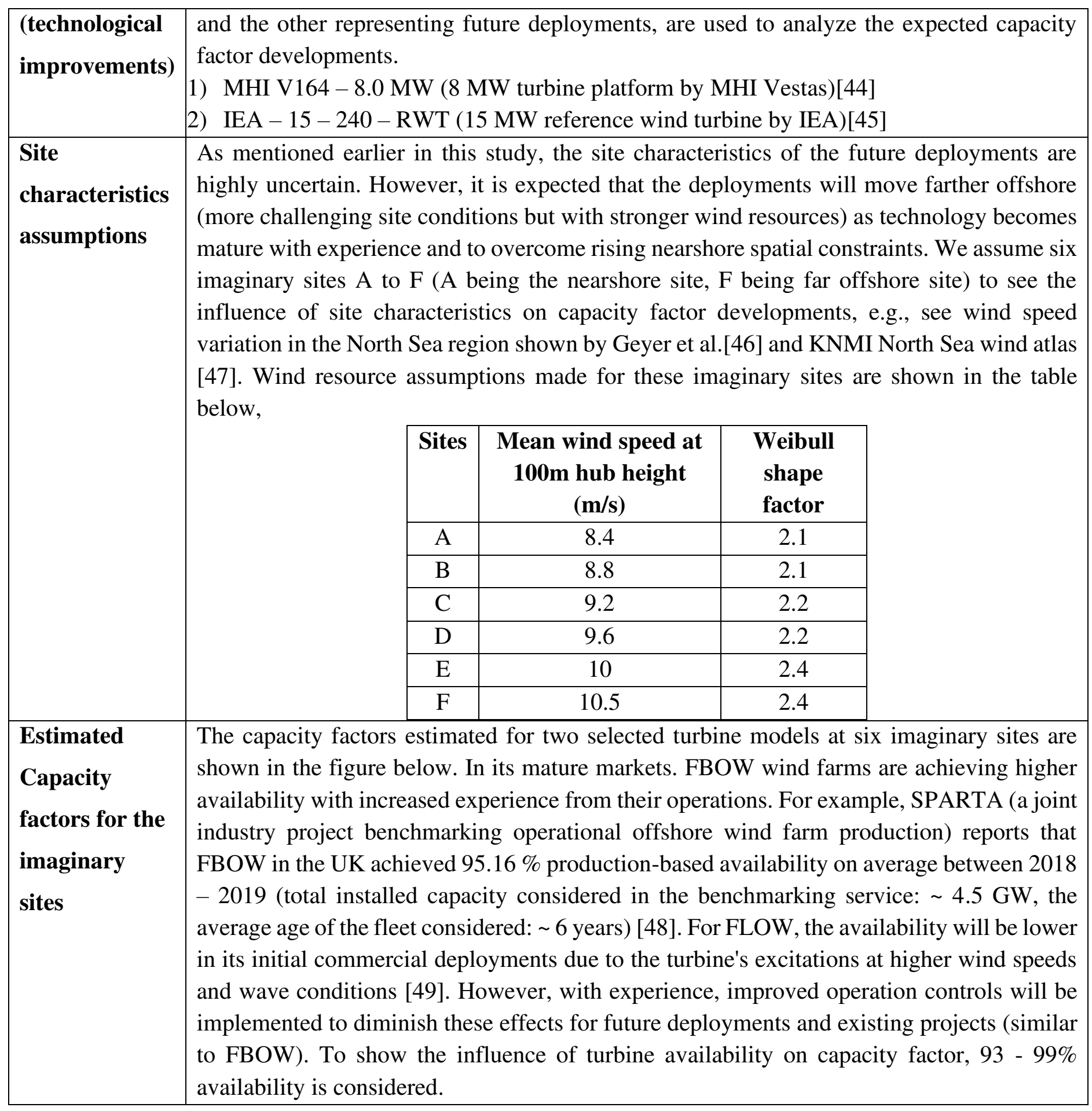




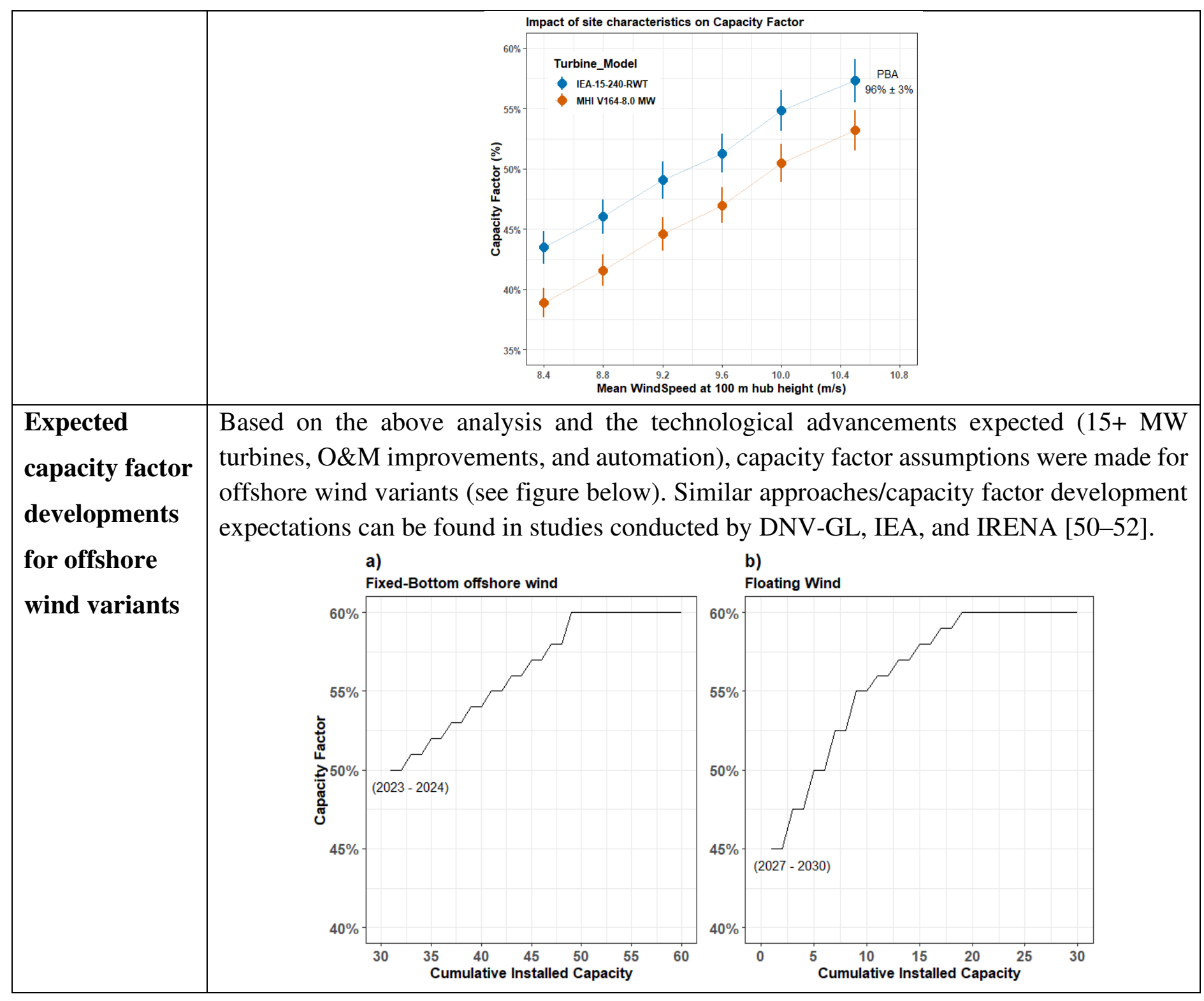




\section{Appendix I: OPEX Assumptions for offshore wind variants}

(OPEX Scope in this study: O\&M costs onshore and offshore plus O\&M insurance). All values are expressed in 2015 real values.

\begin{tabular}{|c|c|c|c|}
\hline & Fixed-Bottom offshore wind & \multicolumn{2}{|c|}{ Floating offshore wind } \\
\hline $\begin{array}{l}\text { Estimates } \\
\text { available in } \\
\text { the } \\
\text { literature }\end{array}$ & $\begin{array}{l}\text { - } \text { Ørsted states } 100 \mathrm{k} € \text { per MW per year for } 3-4 \mathrm{MW}, 67 \mathrm{k} € \text { per MW } \\
\text { per year for } 6-8 \mathrm{MW} \text { turbines (Scope: owner's costs, logistics \& } \\
\text { operation in onshore and offshore)[14,53,54] } \\
\text { - } 86 \mathrm{k} € \text { per MW per year[55] (average OPEX for wind farms owned } \\
\text { by Ørsted at 2016. Scope for this estimate is not clear from the } \\
\text { reference. Hence, it is assumed all-in OPEX estimate) } \\
\text { - } 53 \mathrm{k} € \text { per MW per year[55] (wind farms commissioning in } 2020 \text {. } \\
\text { Scope for this estimate is not clear from the reference. Hence, it is } \\
\text { assumed all-in OPEX estimate) } \\
\text { - } 41 \mathrm{k} € \text { per MW per year[18] (1500 MW wind farm size, } 15 \mathrm{MW} \\
\text { turbine, } 60 \mathrm{~km} \text { from O\&M port, Scope: O\&M costs and insurance) } \\
\text { - IEA says global average O\&M costs for FBOW stood at } 75 \mathrm{k} € \text { per } \\
\text { MW per year in } 2018 \text { and decline towards } 50 \mathrm{k} € \text { per MW in } 2030 \text { and } \\
41.5 \mathrm{k} € \text { per MW per year in } 2040 \text { (1USD = } 0.83 \text { EUR is } \\
\text { assumed)[51]. }\end{array}$ & \multicolumn{2}{|c|}{$\begin{array}{l}\text { - } 132 \mathrm{k} € \text { per MW per year [56] (500 MW wind farm size, } 5 \\
\text { MW turbine) } \\
\text { ORE Catapult reports OPEX of } 89.2 \mathrm{k} € \text { per MW per year } \\
\text { for } 300 \mathrm{MW} \text { wind farm (12 MW turbine), and } 81.9 \mathrm{k} € \text { per } \\
\text { MW per year for } 500 \mathrm{MW} \text { wind farm (15 MW turbine) } \\
{[24] .1 €=0.83 £ \text { is assumed for conversion. These OPEX }} \\
\text { estimates include O\&M operations onshore and offshore } \\
\text { and other OPEX costs (insurance, seabed rent and potential } \\
\text { transmission charges). The scope of OPEX defined in this } \\
\text { study does not include seabed rent and transmission } \\
\text { charges. Therefore, we assumed } 12 \mathrm{k} € \text { per MW per year as } \\
\text { O\&M insurance cost to align these OPEX estimate to the } \\
\text { scope defined in this study [31]. }\end{array}$} \\
\hline \multirow{6}{*}{$\begin{array}{l}\text { Assumptions } \\
\text { applied in } \\
\text { this study } \\
\text { (Assumptions } \\
\text { are based on } \\
\text { OPEX }\end{array}$} & \multirow{6}{*}{$\begin{array}{l}\text { - } 55 \mathrm{k} € \text { per MW per year is assumed for deployments at } 31 \mathrm{GW} \\
\text { cumulative installed capacity (expected to deploy 10-12 MW rated } \\
\text { turbines, 2023-2024). OPEX is decreased to } 50 \mathrm{k} € \text { per MW at } 32 \text { and } \\
33 \mathrm{GW} \text { cumulative installed capacity, and then to } 45 \mathrm{k} € \text { per MW at } \\
34,35 \text {, and } 36 \mathrm{GW} \text { cumulative installed capacity } \\
\text { - From } 37 \mathrm{GW} \text { cumulative installed capacity level, } 40 \mathrm{k} € \text { per MW is } \\
\text { assumed as OPEX (15+ MW turbines are expected to be deployed at } \\
\text { this stage) }\end{array}$} & Cumulative capacity & inith pei \\
\hline & & $\begin{array}{l}\text { At } 1,2 \text { GW (12 MW } \\
\text { turbines expected, 2027- } \\
\text { 2030) }\end{array}$ & 75 \\
\hline & & At $3,4 \mathrm{GW}$ & 65 \\
\hline & & At $5,6 \mathrm{GW}$ & 55 \\
\hline & & At $7,8 \mathrm{GW}$ & 50 \\
\hline & & At $9,10 \mathrm{GW}$ & 45 \\
\hline
\end{tabular}




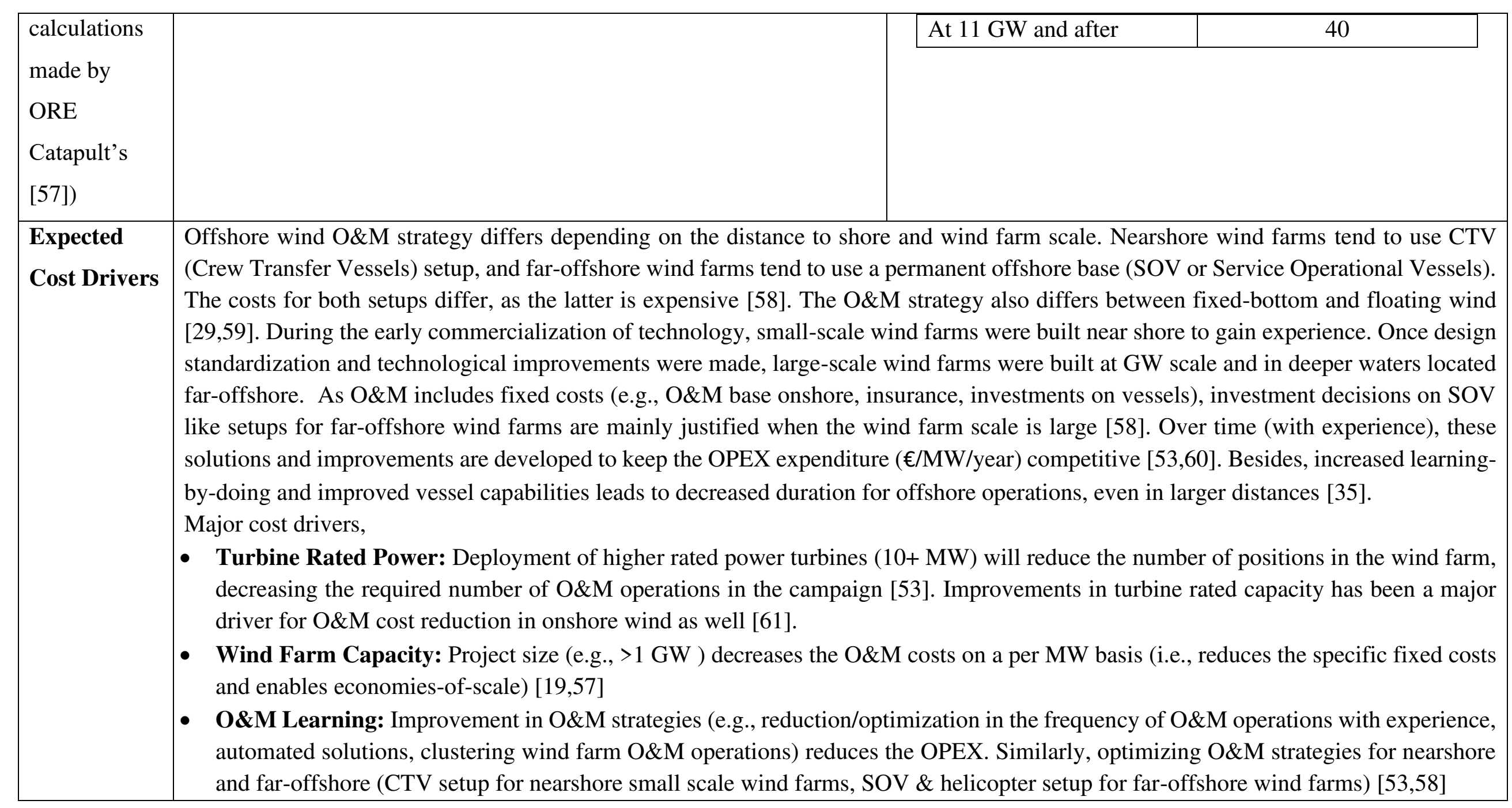




\section{Appendix J: Grid connection Characteristics}

\begin{tabular}{|l|c|}
\hline \multicolumn{1}{|c|}{ Characteristics } & Assumption \\
\hline Technology & HVAC \\
\hline Foundation Type & Semi-Submersible (Steel) ${ }^{1}$ \\
\hline Water Depth & $100 \mathrm{~m}$ \\
\hline Number of mooring lines & $5 \mathrm{~km}$ \\
\hline Onshore cable distance & 4 \\
\hline Number of tug boats needed for installation & 1 \\
\hline $\begin{array}{l}\text { Number of anchor handling vessel (AHT) needed for } \\
\text { installation }\end{array}$ & $220 \mathrm{kV}$ \\
\hline Export Cable Specification & 25 to $100 \mathrm{~km}$ \\
\hline Distance to shore range & $40 \%$ to $60 \%$ \\
\hline $\begin{array}{l}\text { Capacity factor range } \\
\text { (also referred to as utilization factor of transmission assets) }\end{array}$ & \\
\hline
\end{tabular}

${ }^{1}$ A semi-submersible floating substation was considered here to limit the influences of water depth variation. If the jacket foundations were to be considered (typical for FBOW), the water depth would strongly influence the foundation design; for example, in deeper waters, platform design complexity and material needs increase, thereby increasing the LCoT. 


\section{Appendix K: Deployment Scenarios for FBOW and FLOW}

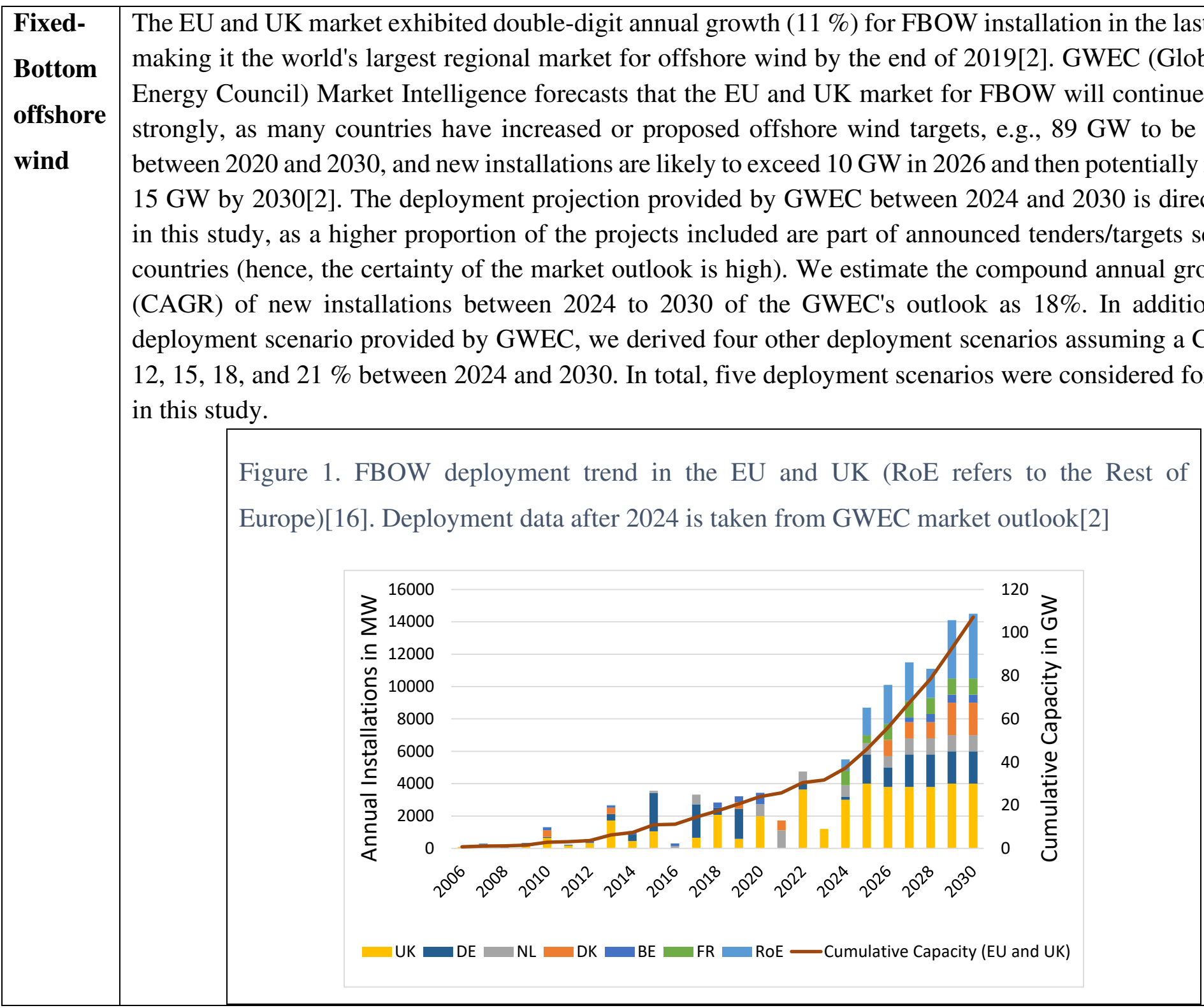




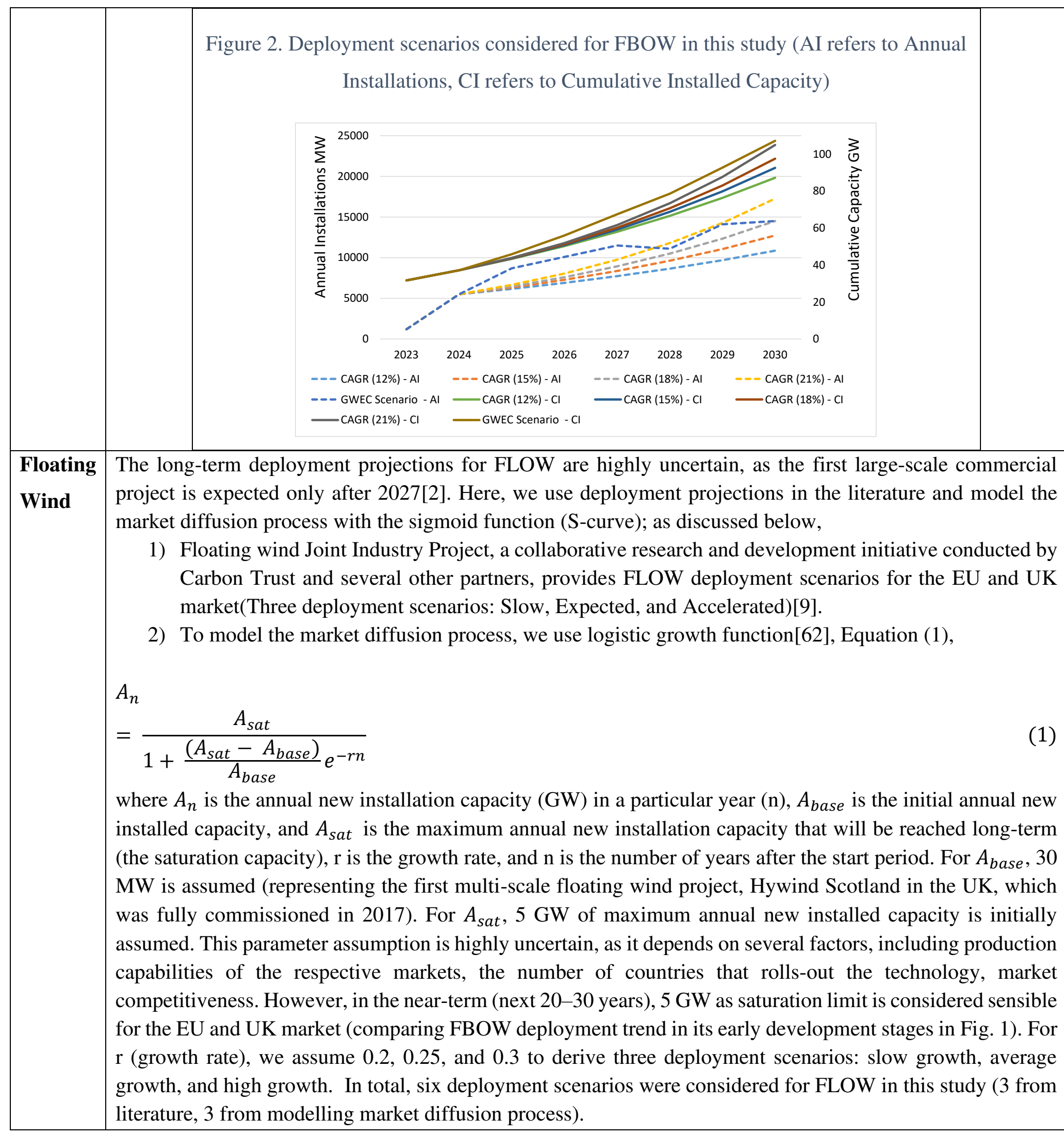




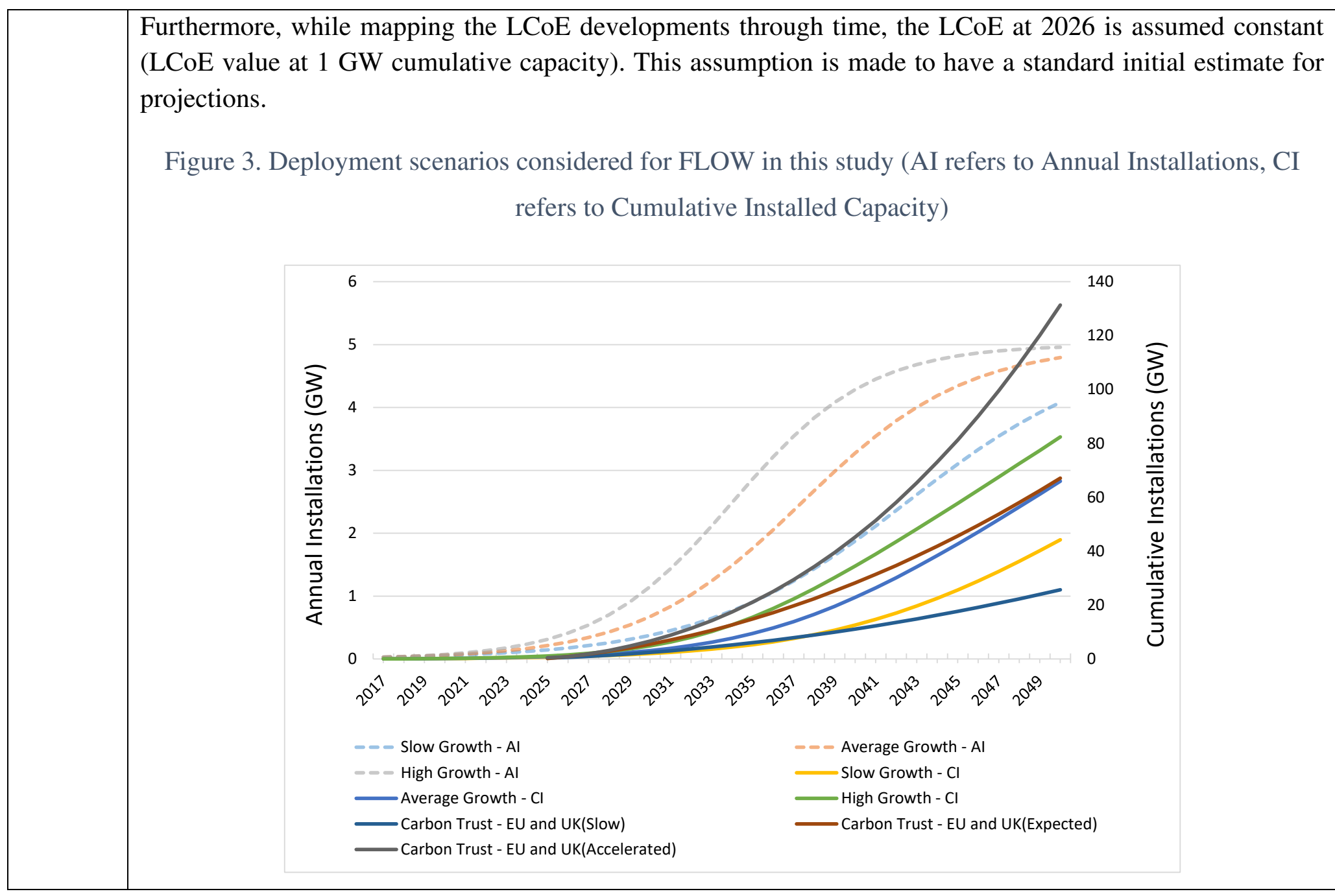




\section{Appendix L: LCoE forecast comparisons}
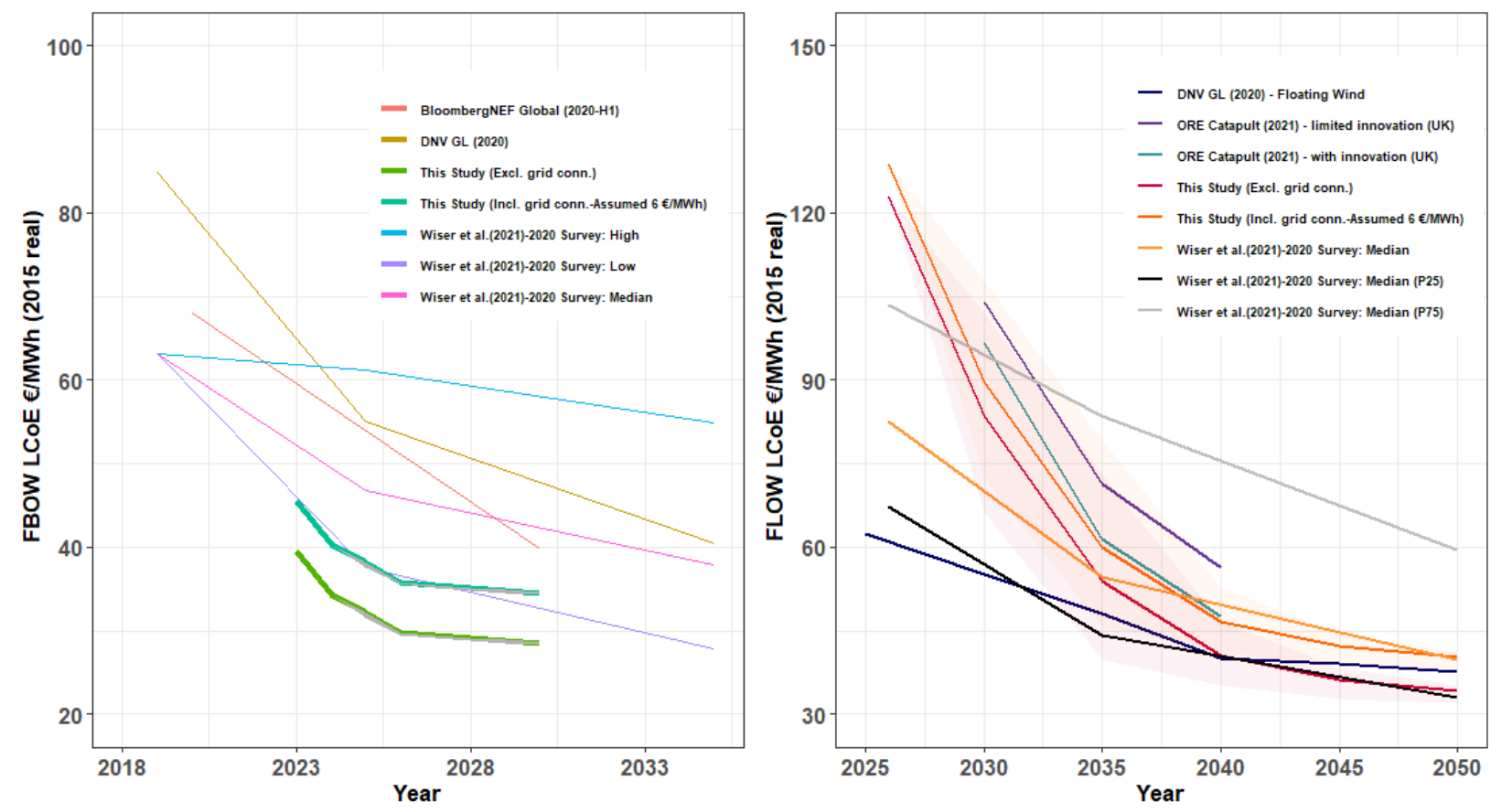

Here, the LCoE forecasts made in this study are compared with forecasts available in literature. All cost information from the literature are converted into 2015 real EUR values to enable likefor-like comparison. From the comparision (figure above), it can be seen that FBOW cost development in the literature were commonly underestimated or observed to be conservative (except Wiser et al. 2020 survey: low case [63]). For FLOW, on the other hand, the initial costs illustrating the near-term developments towards 2030 are observed to have been optimistic. In long-term, the FLOW costs estimated in this study are in line with values from literature. It is to be reminded that grid connection cost of $6 € / \mathrm{MWh}$ is assumed to enable comparison with estimates from the literature (as this study analyzes grid connection cost separately). Any changes in the grid connection cost due to site characteristics will influence the final LCoE, and the comparisons made above.

Lastly, in this study the assumptions leading to the forecasts have been made available for further analysis. As deployment progresses, the empirical observation has to be analyzed with such forecasts to understand the differences, e.g., structural changes in the market or step-change developments through radical innovations [64]. Such insights can have profound impacts in informed policy-decisions for emerging technologies. 


\section{References (Supplementary Material)}

[1] WindEurope. European Offshore Wind Farms Map Public. WindEurope 2021. https://windeurope.org/data-and-analysis/product/european-offshore-wind-farms-mappublic/ (accessed March 18, 2021).

[2] GWEC. Global Offshore Wind: Annual Market Report 2020. 2020.

[3] Wind Europe. Taiwan and the US to benefit from European offshore expertise. Wind Eur 2017.

[4] Ørsted A/S. Ørsted offshore wind farms 2021. https://orsted.com/en/our-business/offshorewind/our-offshore-wind-farms (accessed March 24, 2021).

[5] Radowitz B. RWE eyes 'sizeable positions' in East Asian and US offshore wind markets. Recharge 2020.

[6] The European Marine Observation and Data Network. Bathymetry Viewing and Download Service (EMODnet). EMODnet 2021. https://portal.emodnet-bathymetry.eu/\# (accessed March 19, 2021).

[7] Gusatu LF, Yamu C, Zuidema C, Faaij A. A spatial analysis of the potentials for offshore wind farm locations in the North Sea region: Challenges and opportunities. ISPRS Int J Geo-Information 2020;9:96. https://doi.org/10.3390/ijgi9020096.

[8] Matthew Hannon, Eva Topham, James Dixon, David Mcmillan, Maurizio Collu. Offshore wind, ready to float? Global and UK trends in the floating offshore wind market. n.d. https://doi.org/10.17868/69501.

[9] Spearman DK, Strivens S, Matha D, Cosack N, Macleay A, Regelink J, et al. Floating Wind Joint Industry Project - Phase 2 summary report. 2020.

[10] EOLFI. EOLFI - Developing floating wind power projects (NORWEP presentation). 2019.

[11] IEA. Technology Innovation to Accelerate Energy Transitions. 2019. https://doi.org/10.1787/ed67526d-en.

[12] Grübler A, Nakićenović N, Victor DG. Dynamics of energy technologies and global change. 
Energy Policy 1999;27:247-80. https://doi.org/10.1016/S0301-4215(98)00067-6.

[13] Santhakumar S, Meerman H, Faaij A. Improving the analytical framework for quantifying technological progress in energy technologies. Renew Sustain Energy Rev 2021;145:111084. https://doi.org/10.1016/j.rser.2021.111084.

[14] Santhakumar S, Smart G, Noonan M, Meerman H, Faaij A. Technological progress observed for fixed-bottom offshore wind in the European markets (Under Review). Technol Forecast Soc Change 2021.

[15] Vestas. Vestas V236-15.0 $\mathrm{MW}^{\mathrm{TM}}$ at a glance 2021. https://www.vestas.com/en/products/offshore-platforms/v236_15_mw (accessed April 20, 2021).

[16] Santhakumar S. Techno-economic details of fixed-bottom offshore wind projects deployed in the European markets. Zenodo 2020. https://doi.org/10.5281/zenodo.4302588.

[17] The Crown Estate. The Crown Estate to create new floating wind leasing opportunity in the Celtic Sea. The Crown Estate 2021. https://www.thecrownestate.co.uk/en-gb/media-andinsights/news/the-crown-estate-to-create-new-floating-wind-leasing-opportunity-in-theceltic-sea/ (accessed March 25, 2021).

[18] Noonan M. Delivering 40GW - Accelerating the UK's Transition to Net Zero. ORE Catapult 2020. https://ore.catapult.org.uk/blog/delivering-40gw-accelerating-the-ukstransition-to-net-zero/ (accessed February 9, 2021).

[19] Freeman K. Floating Offshore. 2017.

[20] Valpy B, Freeman K, Roberts A. Future renewable energy costs: offshore wind (Update 2016). 2014.

[21] Shafiee M, Brennan F, Espinosa IA. A parametric whole life cost model for offshore wind farms. Int J Life Cycle Assess 2016;21:961-75. https://doi.org/10.1007/s11367-016-1075$\mathrm{z}$.

[22] ODE limited. Study of the costs of offshore wind generation: A Report to the Renewables Advisory Board \& DTI. 2007. 
[23] Windplus Consortium. The WindFloat Project. Presentation at European leadership in renewables-funding innovation. Brussels: 2017.

[24] ORE Catapult. Supply Chain Report - Benefits of floating offshore wind to wales and the south west. 2020.

[25] Ikhennicheu M, Lynch M, Doole S, Borisade F, Matha D, Dominguez JL, et al. Corewind D2.1 - Review of the state of the art of mooring and anchoring designs, technical challenges and identification of relevant DLCs. 2020.

[26] Endegnanew A, Svedsen H, Torres-Olguin R, Faiella L. Design procedure for in array electric design. EERA DTOC Rep 2013.

[27] Maness M, Maples B, Smith A. NREL Offshore Balance-of- System Model 2017.

[28] Ikhennicheu M, Lynch M, Doole S, Borisade F, Wendt F, Schwarzkopf M-A, et al. Corewind D3.1 - Review of the state of the art of dynamic cable system design. 2020.

[29] Offshore Wind Innovation Hub. Floating wind: Cost modelling of major repair strategies. 2020.

[30] Bjerkseter C, Ågotnes A. Levelised costs of energy for offshore floating wind turbine concepts. Norwegian University of Life Sciences, 2013.

[31] PwC. Offshore wind cost reduction pathways study - Finance work stream. 2012.

[32] GOV.UK. Companies House 2020. https://beta.companieshouse.gov.uk/ (accessed June 29, 2020).

[33] IEA/OECD. Experience Curves for Energy Technology Policy. International Energy Agency; 2000. https://doi.org/10.1787/9789264182165-en.

[34] Rubin ES, Yeh S, Antes M, Berkenpas M, Davison J. Use of experience curves to estimate the future cost of power plants with CO2capture. Int J Greenh Gas Control 2007;1:188-97. https://doi.org/10.1016/S1750-5836(07)00016-3.

[35] Lacal-Arántegui R, Yusta JM, Domínguez-Navarro JA. Offshore wind installation: Analysing the evidence behind improvements in installation time. Renew Sustain Energy Rev 2018;92:133-45. https://doi.org/10.1016/j.rser.2018.04.044. 
[36] Green Giraffe. Recent trends in offshore wind finance. 2019.

[37] MAKE Consulting A/S. Renewable Energy Ownership Strategies (Sector Report). 2017.

[38] Wind Europe. Financing and investment trends: The European Wind Industry in 20182019.

[39] Egli F, Steffen B, Schmidt TS. A dynamic analysis of financing conditions for renewable energy technologies. Nat Energy 2018;3:1084-92. https://doi.org/10.1038/s41560-0180277-y.

[40] Dukan M, Kitzing L, Brückmann R, Jimeno M, Wigand F, Kielichowska I, et al. Effect of auctions on financing conditions for renewable energy: A mapping of auction designs and their effects on financing. 2019.

[41] FRED. Organization for Economic Co-operation and Development, Long-Term Government Bond Yields: 10-year: Main (Including Benchmark) for the Euro Area [IRLTLT01EZM156N]. Fed Reserv Bank St Louis n.d.

[42] FRED. Organization for Economic Co-operation and Development, Long-Term Government Bond Yields: 10-year: Main (Including Benchmark) for the United Kingdom [IRLTLT01GBM156N]. Fed Reserv Bank St Louis n.d.

[43] Saint-Drenan YM, Besseau R, Jansen M, Staffell I, Troccoli A, Dubus L, et al. A parametric model for wind turbine power curves incorporating environmental conditions. Renew Energy 2020;157:754-68. https://doi.org/10.1016/j.renene.2020.04.123.

[44] Staffell I. Wind Turbine Power Curves (Working Paper). 2012.

[45] Gaertner E, Rinker J, Sethuraman L, Zahle F, Anderson B, Barter GE, et al. IEA Wind TCP Task 37: Definition of the IEA 15-Megawatt Offshore Reference Wind Turbine. 2020.

[46] Geyer B, Weisse R, Bisling P, Winterfeldt J. Climatology of North Sea wind energy derived from a model hindcast for 1958-2012. J Wind Eng Ind Aerodyn 2015;147:18-29. https://doi.org/10.1016/j.jweia.2015.09.005.

[47] the Royal Netherlands Meteorological Institute (KNMI). KNMI North Sea Wind atlas 2021. https://www.knmiprojects.nl/projects/knw-atlas (accessed March 25, 2021).

[48] ORE Catapult. SPARTA (System Performance, Availability and Reliability Trend 
Analysis) - Portfolio Review 2018-19 2020. https://www.sparta-offshore.com/SpartaHome.

[49] Barter GE, Robertson A, Musial W. A systems engineering vision for floating offshore wind cost optimization. Renew Energy Focus 2020;34:1-16. https://doi.org/10.1016/j.ref.2020.03.002.

[50] DNV GL. Potential to improve Load Factor of offshore wind farms in the UK to 2035. 2019.

[51] IEA. Offshore Wind Outlook 2019 - World Energy Outlook Special Report. 2019.

[52] IRENA. FUTURE OF WIND: Deployment, investment, technology, grid integration and socio-economic aspects. 2019.

[53] Ørsted A/S. Ørsted Capital Markets Day 2018 (Presentation). 2018.

[54] IRENA. Renewable Power Generation Costs in 2019. 2019.

[55] Danish Energy Agency. Technology Data for Energy Plants for Electricity and District heating generation (Last update - June 2019) 2016.

[56] Myhr A, Bjerkseter C, Ågotnes A, Nygaard TA. Levelised cost of energy for offshore floating wind turbines in a lifecycle perspective. Renew Energy 2014;66:714-28. https://doi.org/10.1016/j.renene.2014.01.017.

[57] ORE Catapult. Floating offshore wind: Cost reduction pathways to subsidy free. 2021.

[58] Ashish D, Asgarpour M. Reference O\&M Concepts for Near and Far Offshore Wind Farms. Ecn-E--16-055 2016:49.

[59] Offshore Wind Innovation Hub. Operations \& Maintenance: Cost Drivers (Industry Insights Series). 2019.

[60] IREA. Renewable Power Generation Costs in 2020. 2020.

[61] Steffen B, Beuse M, Tautorat P, Schmidt TS. Experience Curves for Operations and Maintenance Costs of Renewable Energy Technologies. Joule 2020;4:359-75. https://doi.org/10.1016/j.joule.2019.11.012.

[62] Schmidt O, Hawkes A, Gambhir A, Staffell I. The future cost of electrical energy storage based on experience rates. Nat Energy 2017;2:17110. 
https://doi.org/10.1038/nenergy.2017.110.

[63] Wiser R, Rand J, Seel J, Beiter P, Baker E, Lantz E, et al. Expert elicitation survey predicts $37 \%$ to $49 \%$ declines in wind energy costs by 2050. Nat Energy 2021;6:555-65. https://doi.org/10.1038/s41560-021-00810-z.

[64] Meng J, Way R, Verdolini E, Diaz Anadon L. Comparing expert elicitation and modelbased probabilistic technology cost forecasts for the energy transition. Proc Natl Acad Sci 2021;118:e1917165118. https://doi.org/10.1073/pnas.1917165118. 